Portland State University

PDXScholar

\title{
Residential Mobility and Revitalization in Portland Between 1970 and 1980: A Study of the Urban Structural Impacts on Neighborhood Revitalization
}

Sheka Gassimou Kamara

Portland State University

Follow this and additional works at: https://pdxscholar.library.pdx.edu/open_access_etds

Part of the Social Policy Commons, Urban Studies Commons, and the Urban Studies and Planning Commons

Let us know how access to this document benefits you.

\section{Recommended Citation}

Kamara, Sheka Gassimou, "Residential Mobility and Revitalization in Portland Between 1970 and 1980: A Study of the Urban Structural Impacts on Neighborhood Revitalization" (1992). Dissertations and Theses. Paper 1341.

https://doi.org/10.15760/etd.1340

This Dissertation is brought to you for free and open access. It has been accepted for inclusion in Dissertations and Theses by an authorized administrator of PDXScholar. Please contact us if we can make this document more accessible: pdxscholar@pdx.edu. 


\section{RESIDENTIAL MOBILITY AND REVITALIZATION IN PORTLAND BETWEEN 1970 AND 1980: A STUDY OF THE URBAN STRUCTURAL IMPACTS ON NEIGHBORHOOD REVITALIZATION}

by

SHEKA GASSIMOU KAMARA

A dissertation submitted in partial fulfillment of the requirements for the degree of

DOCTOR OF PHILOSOPHY

in

URBAN STUDIES

Portland State University

1992 
TO THE OFFICE OF GRADUATE STUDIES:

The members of the Committee approve the dissertation of Sheka Gassimou Kamara presented Nofjember 12, 1991.

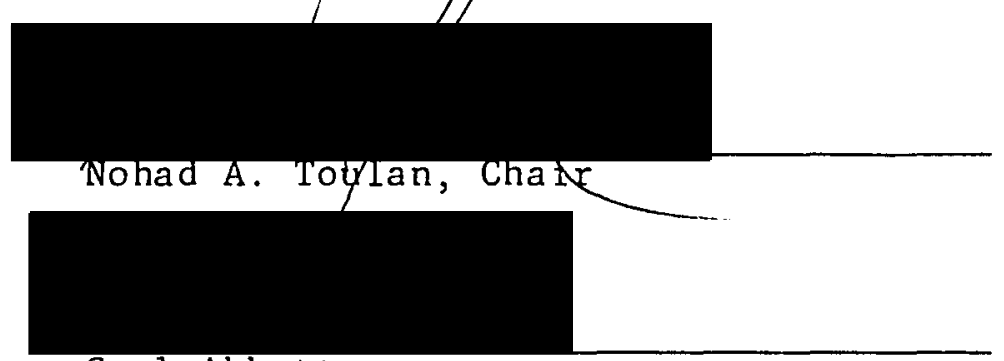

Carl Abbott

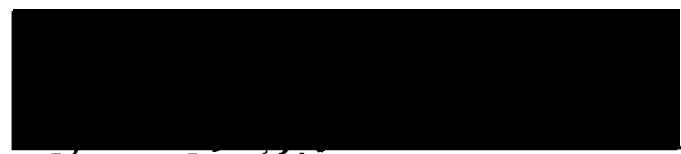

Jámes Stráthman
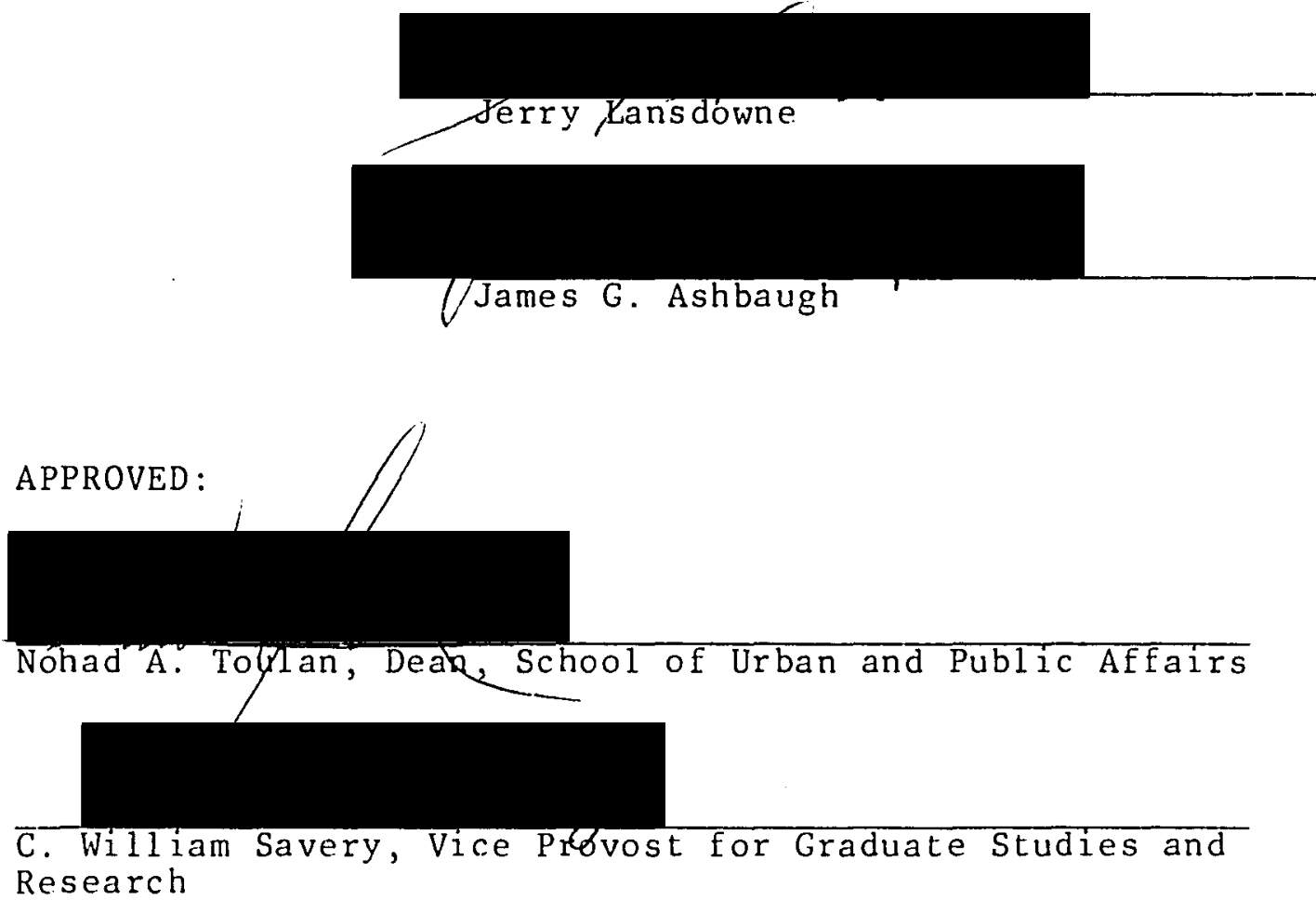
AN ABSTRACT OF THE DISSERTATION OF Sheka Gassimou Kamara for the Doctor of Philosophy in Urban Studies presented November 12,1991 .

Title: Residential Mobility and Revitalization in Portland Between 1970 and 1980: A Study of the Urban Structural Impacts on Neighborhood Revitalization.

APPROVED BY THE MEMBERS OF THE DISSERTATION COMMITTEE:

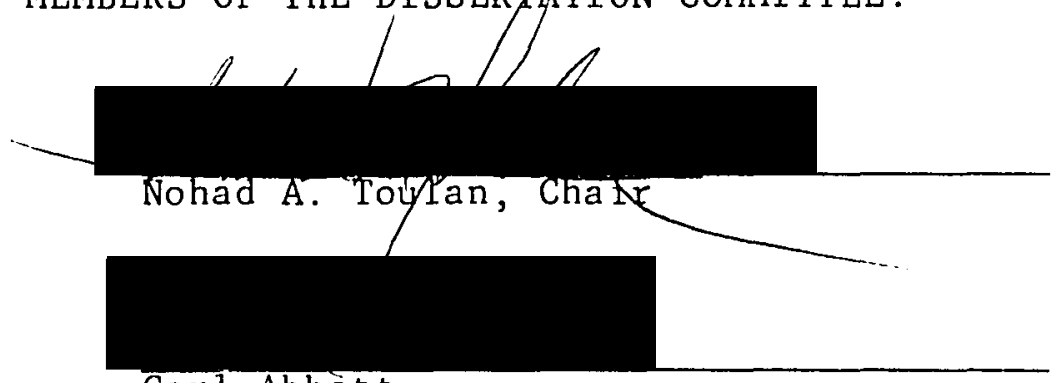

Carl Abbott

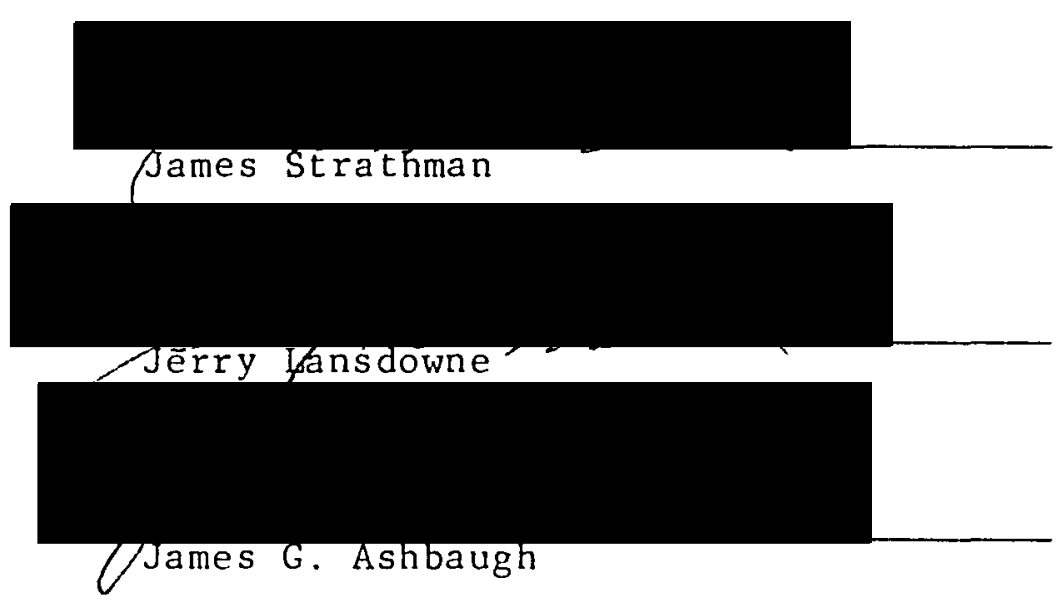

Evidence of physical decline due in part to the rapid encroachment of commercial and industrial activity into some 
of Portland's residential areas in the mid-1960s and efforts to combat the forces of time and change through neighborhood revitalization provide the basis for this study. Additionally, some of the characteristics often employed in explaining the phenomenon in cities are manifested in the city of Portland. For example, Portland is endowed with a distinctive and well established downtown area that provides opportunities for the establishment of businesses as well as white-collar job opportunities. By the standards of the U.S. Bureau of the Census, Portland has a relatively large population and several older neighborhoods. The city provides its residents the feel for inner-city living, such as its beautiful waterfront scenery, its high-rise and park block apartments, its cultural facilities and unique transit mal1. These criteria underscore the selection of Portland as the geographical area of this research.

The purpose of this research itself is to assess the urban structural changes that occurred in Portland between 1970 and 1980. The research used a sample of inner-city neighborhoods from the city to explain these structural changes over time. Additionally, two samples of neighborhoods (Northeast and Southeast) within the city were selected as the basis for comparing the structural changes.

The data developed from the 1970 and 1980 census of population and housing characteristics comprised the change in the median household income ratio, the change in the home 
value ratio, and the change in the median rent ratio designated as dependent variables. Nine independent variables representing the pre-existing conditions in the city at the start of the decade were selected from locational, demographic, and housing factors,

The research hypotheses were tested by regressing the three dependent variables against the nine independent variables resulting in three regression models for each sample. The a priori expectations as reflected by the signs of the coefficients show mixed support for the hypotheses in each sample in predicted direction, and in level of significance.

In the city sample the neighborhood housing quality factor was observed to have a strong positive causal relationship with neighborhood revitalization. The outcome confirmed the contention that a significant and systematic reverse revival trend occurred in Portland at the start of the 1970 decade. This finding contradicts the conventional invasion-succession theory associated with Burgess (1925).

Similar reverse revival trends were observed in the Northeast and Southeast samples. But unlike the city sample the race factor had a strong positive causal relationship with revitalization. The outcome may be a reflection of the rental squeeze in terms of housing affordability faced by black renters in both subareas because their incomes could not keep pace with housing costs. Consequently their demand 
for rental housing may have grown faster than the supply of the rental housing stock in a segregated rental market.

The chow tests show significant structural differences between the two submodels, but the impact of the race factor as reflected by the measures of relative variability was greater in Northeast Portland than in Southeast Portland.

In 1 ight of the research findings, this study concludes that Portland may undoubtedly be the only city in the nation that experienced a significant and systematic revival trend between 1970 and 1980. However, this trend did not extend to the predominantly black areas of the city as reflected by the strong negative outcome of the race factor. In addition, the functional significance of the systematic revival trend in Portland may not be substantial when compared to larger and older cities like St. Louis and New Orleans that received media attention for a similar trend. 


\section{DEDICATION}

I dedicate this work in memory of my late uncle who laid the foundation for my continuing education.

This work is also dedicated to my children Sheka (Jr.), Sidikie, Zainab, and Sultan to serve as an inspiration for the realization of their respective educational goals in the near future.

(Quisque faber, fortunae suae est.) 


\section{ACKNOWLEDGEMENTS}

A number of people deserve special acknowledgement because, without them, this study would not have been completed.

I would like to express my profound gratitude to the Chairman of my dissertation committee, Dr. Nohad Toulan, for his advice, encouragement, and constructive comments and criticisms throughout the dissertation process. Profound gratitude is extended to Dr. James Strathman for his constructive comments and suggestions. I am also thankful to all the other members of my dissertation committee, Dr. Carl Abbott, Dr. Jerry Lansdowne, and Dr. Jim Ashbough, whose suggestions and comments helped towards the completion of this dissertation.

Grateful acknowledgement is also extended to Dr. Hassan B. Sisay, professor of history and coordinator of the Ethnic and Women's Studies Program at California State University, Chico, California, for giving me the opportunity to travel to the United States to pursue graduate studies.

In addition, I deeply express my sincere thanks and appreciation to my wife, Mariama for her forbearance and encouragement throughout the dissertation process. Without 
her unstinting social support and hard work this study would not have been completed.

Finally, I wish to extend sincere thanks to Miss Jennifer Mckay for typing the manuscript. 
TABLE OF CONTENTS

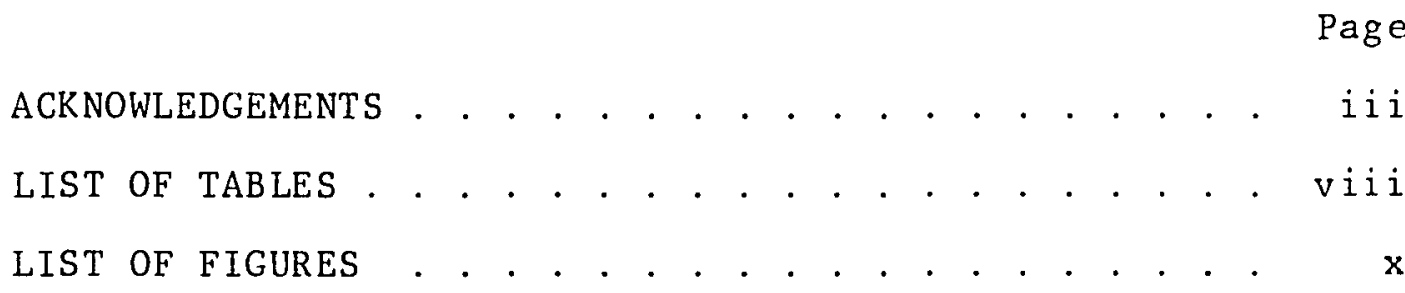

CHAPTER

I INTRODUCTION . . . . . . . . . . . . . . . . 1

Federal Government Efforts . . . . . 5

Federal Housing Administration . . 6

Urban Renewa 1 Program..... . 10

Housing Programs of the 1960s.. . 13

Housing Programs in the 1970s... 16

Housing Programs in the

Reagan Years . . . . . . . . . 19

Housing Programs in the

Bush Years . . . . . . . . . . 22

State Government Efforts . . . . . . 28

Efforts in the State of Oregon . 32

State Efforts in the 1980s . . . . 35

Local Government Efforts . . . . . 39

The Scope of the Study . . . . . . . . 46

Format of the Study . . . . . . . . . . 54

I I PORTLAND: A CASE STUDY OF

REVITALIZATION EFFORTS . . . . . . . . . . . 56

The PDC and Revitalization . . . . . 57

Neighborhood Associations and

Revitalization . . . . . . . . 62 
Neighborhood Associations and the Model Cities Program . . . . . . 64 The HCD Program and Neighborhood Redevelopment... . . . . . . 66

The Study Area . . . . . . . . . . . 74

III HISTORICAL BACKGROUND AND LITERATURE

REVIEW . . . . . . . . . . . . . . . . . . . 78

Ecological Approach to Neighborhood Revitalization... . . 83

Changing Age Structure and Neighborhood Revitalization. . . . 95

IV METHODOLOGY . . . . . . . . . . . . . . . . 102

Hypotheses . . . . . . . . . . . 104

Hypothes is 1 . . . . . . . . . . 104

Hypothes is 2 . . . . . . . . . . . 105

Hypothes is 3 . . . . . . . . . . . 107

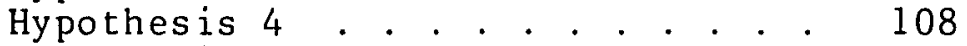

Hypothes is 5 . . . . . . . . . . . . . 109

Hypothes is 6 . . . . . . . . . . . 110

Hypothes is 7 . . . . . . . . . . . 111

Hypothes is 8 . . . . . . . . . . . . 112

Hypothes is 9 . . . . . . . . . . . . 113

Data and Methods . . . . . . . . . 113

Dependent Variables . . . . . . . . 115

Median Household Income . . . . . 115

Median Home Value. . . . . . . . . 116

Median Rent . . . . . . . . . . . 117

Independent Variables . . . . . . . . 118

Locational Factor . . . . . . . 118

Demographic Factors . . . . . . . 119

Housing Factors. . . . . . . . . . 121

Regression Models . . . . . . . . . . 122

$\mathrm{V}$ ANALYSIS AND RESEARCH FINDINGS . . . . . . . 126

Section One: Results of the
Ratio Method .............. 127 
Neighborhood Revitalization Trends of the Income Index... . . . . 128

Neighborhood Revitalization Trends of the Home Value Index . . . . . 129

Neighborhood Revitalization Trends of the Rent Index... . . . . 130

Section Two: Analysis of the

Regression Models for the City

Sample . . . . . . . . . . . 131

Descriptive Measures . . . . . . 134

Section Three: Analysis of the

Regression Models for the Two

Samples. . . . . . . . . . . . . 147

Regression Results of the Income Index in Northeast Portland. . . 147

Regression Results of the Home Value Index in Northeast Portland . . . . . . . . . . . 150

Regression Results of the Rent Index in Northeast Portland... 153

Regression Results of the Income Index in Southeast Portland . . . 156

Regression Results of the Home Value Index in Southeast Portland............. . 158

Regression Results of the Rent Index in Southeast Portland. . . 161

Results of the Pooled Models . . . . . 163 SUMMARY AND CONCLUSIONS . . . . . . . . . . 172

Part One: General Conclusions . . . . 172

Part Two: Specifics from the Research . . . . . . . . . . . . . . 179

Significance of the Research . . . 180 Theoretical Implications . . . . . 183 Policy Implications . . . . . . . 185 Suggestions for Future Research. . 189 


\section{LIST OF TABLES}

TABLE

PAGE

I Correlation Matrix with Means and Standard Deviations for the Study Area . . . . 135

II Regression Results for the Change in the

Median Household Income Index for the

Inner-City Neighborhoods of Portland

1970 and 1980 . . . . . . . . . . . 138

II Regression Results for the Change in the

Median Home Value Index for the

Inner-City Neighborhoods of Portland

1970 and 1980 . . . . . . . . . . . . 142

IV Regression Results for the Change in the

Rent Index for the Inner-City

Neighborhoods of Portland

1970 and 1980 . . . . . . . . . . . 145

V Regression Results for the Change in the

Income Index for N.E. Portland

1970 and 1980 . . . . . . . . . . 148

VI Regression Results for the Change in the

Home Value Index for N.E. Portland

1970 and 1980 . . . . . . . . . 
VII Regression Results for the Change in the Rent Index for N.E. Portland 1970 and 1980 . . . . . . . . . . 154

VIII Regression Results for the Change in the Income Index for S.E. Portland 1970 and 1980 . . . . . . . . . .

IX Regression Results for the Change in the

Home Value Index for S.E. Portland

1970 and 1980 . . . . . . . . . . 159

$X$ Regression Results for the Change in the

Rent Index in S.E. Portland

1970 and 1980 . . . . . . . . . . . . 162

XI Chow Test Results of the Differences

Between the Regression Coefficients

of the Two Submodels... . . . . . 166

XII Coefficients of Variation (Measures of

Relative Variability) for the

Two Submodels . . . . . . . . . . 168 


\section{LIST OF FIGURES}

FIGURE

PAGE

1. Study Area: Inner-City Neighborhoods

of Portland. . . . . . . . . . . . 75

2. Neighborhood Change Trends for the Income

Index : 1970-1980 . . . . . . . . . . 128

3. Neighborhood Change Trends for the Home

Value Index: 1970-1980 . . . . . . . . 129

4. Neighborhood Change Trends for the Rent

Index: 1970-1980 . . . . . . . . . . 130 


\section{CHAPTER I}

\section{INTRODUCTION}

The purpose of this research is to assess why some inner-city neighborhoods undergo certain structural changes over a certain period of time while others do not, as well as to determine the factors predicting such structural changes.

The research used a sample of inner-city neighborhoods from the city of Portland to estimate existing conditions in the 1970-1980 decade that have enhanced the process of neighborhood revitalization. Additionally, the study selected two inner-city neighborhoods (Northeast and Southeast) as a basis for comparing the structural changes that occurred during the decade.

In this research the unit of analysis is the census tract defined as a small geographic unit or neighborhood with a population within the range of 2,500-8,000 (Lee, 1985).

Inner-city neighborhood decline, especially in some older American cities, became a matter of great concern to policy-makers as well as to planners. This concern led to some major policy decisions in terms of what needed to be done in order to combat the forces of time and change in the 
inner-city neighborhoods in central cities affected. The solution to this problem, as some decision makers came to realize, depends upon neighborhood revitalization, a concept which has always been surrounded with controversy because of its negative side effects.

Neighborhood revitalization cannot be divorced from housing policy decisions, which in turn can be seen within the context of community development policy whereby a geographical or political entity strives to improve the quality of its physical environment as well as its social and economic life (Hays, 1985).

Efforts to combat the forces of time and change received a wake-up call from a series of congressional legislatures with a commitment to provide "a decent home and a healthy living environment for every American family." Thus this introductory chapter provides elaborate but by no means exhaustive housing policy decisions undertaken by officials at various levels of government in order to provide the reader with a historical sequence of these congressional decisions that have influenced neighborhood revitalization activity in many American cities such as Portland.

Initial neighborhood revival programs directed mainly towards residential housing activity in the inner-city areas of the older cities in the 1950s intensified in the 1960 s (Sumka, 1979). 
By the 1970 s housing activity undertaken to revitalize the core areas of the cities so as to attract the middleand upper-income residents who were believed to have fled into the suburbs was given a wide range of terms. Some of the terms used to describe housing activity aimed at attracting middle- and upper-income residents included revitalization, gentrification, incumbent upgrading, private market residential rehabilitation and investment, and "backto-the-city-movement" (Laska and Spain, 1979).

The term "revitalization" used in this study is implicit with the notion of residential housing activity as it relates to the socioeconomic characteristics of the residents as well as the characteristics of the housing units.

Since the post-World War II era the problem that presented the greatest challenge to urban policy-makers has been the social, economic and physical decline of many inner-city neighborhoods in American cities. Sumka (1979) suggested some reasons that may have contributed to the decline during this period. First, large numbers of middleand upper-income residents selected to reside in the suburbs because such areas offered low cost of land for the construction of fashionable homes, as well as reasonable mortgage terms offered by the Federal Housing Administration and Veterans Administration for newly constructed homes. Second, transportation development in the United States, culminating in the construction of freeways through and 
around cities under the National Defense Highway Act of 1954, enhanced intra-metropolitan commuting. Third, restrictive zoning and building codes, and to a certain extent outright discrimination, limited suburban migration to special and more homogeneous groups of people. These factors did not only exacerbate the political rift between central cities and their suburbs, but also widened the fiscal gap between them through the loss of the cities' tax clientele to the suburbs (Sumka, 1979).

Faced with the problem of urban blight, policy-makers decided to counter disinvestment and the flight to the suburbs by initiating programs to revitalize the declining urban neighborhoods. But by and large, urban housing programs have revolved around the debate over the shape and direction of community growth and development. The issues in this debate are whether the government should be involved and how the involvement of the public should be structured and carried out (Hays, 1985).

It is amid this debate that federal, state, and local government officials acknowledged that their combined efforts and even those of the private sector are deemed necessary to initiate inner-city reinvestments in the area of housing. The initiatives undertaken by the three levels of government, working in conjunction with the private sector in some instances, are considered pertinent in providing a historical background to the problem of neighborhood 
decline in some American cities, as well as how these efforts are relevant to the issue of neighborhood revitalization. Such efforts are now discussed in a chronological sequence.

FEDERAL GOVERNMENT EFFORTS

The Great Depression marked a turning point for housing policy in the United States. There was a widespread loss of jobs and incomes that led to an unprecedented rate of foreclosures and tenant evictions. This in turn led to a downward trend in economic growth because of the decline in housing construction resulting in high unemployment rates in the building industry. Both policy-makers and planners reached the consensus that a constructive and positive action was required to wrestle with the crisis that engulfed the country. The need to do something enabled the federal government to embark on housing activity programs for the improvement of the physical environment, which programs under normal circumstances would have been met with some resistance. The Federal Housing Administration and the public housing program were an offshoot of federal government interventions to stave off rapid neighborhood decline ( Hays, 1985 ). 
Federal Housing Administration

The National Housing Act of 1934 was one of the most important pieces of congressional housing legislation in the history of the United States. The Act represented the response of the Roosevelt Administration and Congress to the structural as well as the institutional deficiencies in the housing market with reference to the mortgage market. The Act created the Federal Housing Administration (FHA) to provide government insurance for mortgages offered by private lenders in order to encourage private investment in housing by offering affordable loan terms for borrowers (Jacobs et al., 1986). For example, by introducing longterm, low downpayments, fully amortized mortgage payments to replace the short-term, high downpayments (balloon payments), the FHA enhanced the effective demand by increasing the numbers of residents who could afford to buy a home (Weicher, 1980).

It should be noted, however, that the mortgage insurance loans offered by the FHA never addressed the problems faced by those who could not afford to buy homes. The FHA in one way or the other was considered a very conservative program because of its parochialism in its dealings with the public. From its inception onwards the FHA gradually became identified with the industry it purported to serve. FHAinsured mortgage loans were handled by private financial institutions whose underwriting practices clearly reflected 
FHA lending practices. In essence, FHA policies of discrimination against minority black residents and against innercity neighborhoods in central cities became a reflection of private business practices which made the FHA unpopular (Hays, 1985).

As housing activity assumed the peacetime posture, in 1947 the National Housing Agency was replaced by the Housing and Home Finance Agency (HHFA), which remained the major federal housing agency until the U.S. Department of Housing and Urban Development (HUD) was created in 1965. The agencies that constituted the HHFA included the Home Loan Bank Board (HLBB), the FHA, and the Public Housing Administration (PHA). The HLBB was later renamed as the Federal Home Loan Bank Board (FHLBB) and became an independent agency in 1955 (Jacobs et a1., 1986).

These agencies were established to coordinate the nation's housing finance and construction system to alleviate the burden on homeowners of high mortgage payments which have led to a high rate of mortgage foreclosures. But instead, the agencies progressively reinforced the discriminatory lending practices of the private financial institutions which have led to both a disinvestment from and a reinvestment in other neighborhoods within the same city. The salient idea behind the policies of these federal agencies was to enhance the profit motive of the private housing 
market sector and that of the entire business community (Hartman, 1983).

The disinvestment, on one hand, was done through the undercutting of maintenance expenditure, redlining, tax delinquency, abandonment, and in some cases, by withdrawing or withholding public services and thereby exacerbating the problem of neighborhood decline and decay in certain areas. On the other hand, real estate owners and lenders reinvest capital and credit in the speculative purchase as well as the refinancing of housing units in rising and stable neighborhoods through blockbusting. That is, they buy the housing units at cheap rates and sell them at high costs, while at the same time mortgage lenders convert their old mortgage loans into more profitable investment in the neighborhood. Those residents who can no longer afford the expensive rents or make their mortgage payments are either gentrified or are faced with home foreclosures (Mercuse, $1981)$.

The passing of the Housing Act of 1949, which reaffirmed the commitment of the federal government to provide a "decent home and a suitable living environment for every American family," can be described as the beginning of the modern era of federal housing and development programs (Jacobs et a1., 1986).

A very important aspect of this Act was the creation of the urban renewal program (to be discussed in the 
appropriate section of this discussion). In the next three decades that program changed the face of several American cities but created more controversy than any other piece of congressional legislation in the history of the federal housing and community development program (HUD, 1974).

The early 1950s saw the first major FHA housing scandals. For example, the Section 608 Multifamily Program established for war veterans' housing needs was extremely sympathetic to some builders as regards the terms of its mortgage loans (HUD, 1974). The FHA was also criticized for its practices of blockbusting, discrimination in the sale and rental of housing, and redlining. These practices have not only desegregated the neighborhoods but have created a vicious circle of poverty in neighborhoods that have predominantly minority residents. Such neighborhoods are likely to experience a rapid decline, thus providing a justification for neighborhood revitalization (HUD, 1977).

The criticism of the FHA and several other urban redevelopment programs led to the establishment of the President's Advisory Committee on government housing policies and programs in 1953. The committee's report recommended, among other things, federal aid to communities to combat the spread of slums, FHA financing for the construction of new housing units and the rehabilitation of rundown units in older neighborhoods, the restructuring of the FHA home mortgage program to meet the needs of low-income families, the 
provision of housing assistance for minority family groups, enhancing the continuation of the public housing program, and establishment of a private secondary market facility (Jacobs et al., 1986).

The report of the President's Advisory Committee resulted in the passage of the Housing Act of 1954. The Act was established to retain the basic structure of the housing and develop programs for the next 20 years and to modify and expand such programs to meet the needs of the post-war era in housing. The Act restructured the FHA mortgage insurance programs and established specific measures to prevent FHA program mismanagement. It also amended the 1949 urban renewal program.

\section{Urban Renewal Program}

The urban renewal program began in 1949 as the Urban Redevelopment Program but was later changed to Urban Renewal by the Housing Act of 1954. In addition to support for slum clearance and redevelopment, the program required communities to be provided with federal assistance to prevent the rapid spread of slums and blight through neighborhood revitalization. For a state or local government entity to receive continued federal assistance, it had to provide a workable program for eliminating and preventing the spread of slums and blight in central city neighborhoods. 
The urban renewal program was initiated to deal with such housing-related problems as the high cost of housing production, which can be reduced through eminent domain by local government agencies; the deterioration of housing, particularly of lower priced stock; the decline of public services and facilities; the abandonment of sound units; and an insufficient stock of public and private housing by encouraging new construction and rehabilitation (Wexler et al., 1975).

The Act also addressed the difficulty of initiating housing construction on a site that has been cleared. In order to qualify under the program, a redevelopment site had to either be predominantly residential before clearance or be redeveloped for entirely residential purposes after clearance. Included in the Act of 1954 was a new mortgage insurance--the Section 220 Program--to generate housing credit and production in renewal neighborhoods. This program was criticized because it produced housing for highincome families and not for those displaced from the neighborhood. It was not the kind of program intended for lowincome or displaced families, but rather provided housing needed in the community|and housing that added to the city's tax base (Weicher, 1980).

The program was beset by a controversy centered around its methods and objectives, and it was slow in accomplishing its objectives for a number of reasons. First, it is a 
federally sponsored program that requires dealing with an intricate process of red tape. Second, even though the federal government pays the cost of clearing the area in which a planned renewal project is to be located, it is not easy to find a developer to buy such land. Third, there is the racial problem. Blighted areas are more often than not inhabited by blacks. It is believed that socio-political problems involved in relocating blacks are sometimes considered quite formidable and obstruct the renewal process (Wilson, 1963). The fourth reason is the growing resentment of neighborhoods to clearance and urban renewal.

Advocates of the program, especially liberals, regarded the process of urban renewal as a major redevelopment effort. By the same token, they began to express doubts about the program, especially in cases of massive clearance by bulldozers like the total elimination of the Italian West End Neighborhood of Boston (Wilson, 1963). Numerous charges, such as the one by the black community that slum clearance was just another name for "Negro Clearance," were brought to bear upon liberals (Wilson, 1963). The program was later suspended during the Nixon years.

In the remaining years of the 1950 s the housing and development programs in the country were expanded to serve a considerable number of special interest groups. For example, the Housing Act of 1959 gave a major boost to housing for the elderly by creating section 231 to provide FHA 
mortgage insurance for rental housing units for the elderly, and Section 202 provided 3\% loans for housing developed by private nonprofit organizations (HUD, 1977).

Housing Programs of the 1960s

The federal government involvement in housing and community development saw a rapid increase in the 1960s. During the Kennedy years Congress passed the Housing Act of 1961. The new Act restructured the urban renewal program by increasing the share of program costs for the federal government for smaller cities and expanded the FHA Section 221 program to include all low- and moderate-income residents. The 1961 Act also established the first subsidy program for public housing officials that did not cover operating costs with rent payments (Hays, 1985).

The Johnson years witnessed the creation in 1964 of the Section 312 housing rehabilitation lpan program, which provided a $3 \%$ financing for the rehabilitation of housing units in urban renewal areas and the expansion of the rural housing programs; the establishment of HUD in 1965; and the passage of the landmark housing bill in 1968 .

The Housing Act of 1965 established।HUD in order to address the problem of rapid urbanization and increasing importance of housing and community development programs. The new Act transferred the functions of the HHFA, the FHA, and the PHA to HUD. The Act stipulated that one of the 
assistant HUD secretaries was to be designated the Federal Housing Commissioner, but his duties and powers were to be determined by the Secretary of HUD (HUD, 1974). In essence, the housing needs of lower income households addressed through a variety of direct federal spending programs were all brought under one agency: HUD (U.S. Office of Research and Development, 1988). The Federal National Mortgage Association (FNMA), which was originally a corporate entity, was also transferred to HUD.

The Housing Act of 1965 enacted two additional programs--the supplemental program and the Section 23 program--to provide housing for families eligible for regular public housing by utilizing privately owned housing. Under the Supplemental program the federal government provided a portion of the rent of low-income groups in privately owned housing built with FHA mortgage insurance assistance. Under the Section 23 program local housing authorities are authorized to lease privately owned housing units and make them available to low-income groups eligible for regular public housing (HUD, 1974).

The following year saw the passage of the Demonstration Cities and Metropolitan Development Act of 1966. This Act created the "Model Cities" program through which federal grants as well as technical assistance were made available to city demonstration agencies. This would enable such agencies to plan, develop and conduct comprehensive 
demonstration programs to restore or rebuild entire sections or neighborhoods within their communities, increase their housing supply for low- and moderate-income groups, and provide education and social services vital to the health and welfare of the people (HUD, 1974).

The most important congressional housing legislation during the 1960s was the Housing and Urban Development Act of 1968. The Act modified and expanded several housing programs. For example, in order to create new homeownership and rental programs, the Act relied on interest-subsidy payments. With regard to mortgage finance and providing more housing units for the poor, the Act created the Government National Mortgage Association (GNMA) to supplement the functions of the FNMA. The Act also added Section 235, which offered a federal subsidy of mortgage payments to moderate-income households who wished to purchase their own dwelling units (Hays, 1985).

Under the Act of 1968 Congress set a 10-year time frame for the construction and rehabilitation of 26 million housing units, 6 million of which were for low- and moderate-income groups (HUD, 1974). Programs to make this production schedule tenable as well as conferring special benefits such as deeper subsidy assistance for homeownership and rental housing on low-income residents of rural areas and declining inner-city neighborhoods and on low-income families were enacted (HUD, 1974). 
But by the same token the late 1960 s also saw several of these programs experiencing financial problems as a result of poor management and tenant vandalism. Although Congress funded more housing units, they were, however, reluctant to address the problem of operating subsidies. When housing authorities decided to address this issue by increasing tenants' rents, a civil unrest culminating in rent strikes broke out in some cities such as Newark and St. Louis. Congress in 1969 responded to the situation by instituting the Brooke Amendment, which required a tenant to pay no more than $25 \%$ of his income in public housing rent (Mandelker, 1973).

\section{Housing Programs in the 1970s}

The decade began with the passage in 1970 of the Emergency Home Finance Act, which authorized the FNMA to buy conventional mortgages. The Act also created the Federal Home Loan Mortgage Corporation (FHLMC). By 1972 the federal government had provided housing assistance to an additional 1.6 million low- and moderate-income residents. Additionally, high-risk mortgages on more than 150,000 inner-city neighborhood housing units were underwritten by the federal government (Weicher, 1980).

However, when one considers the high proportion of housing consumers--renters as well as owners--that spent higher proportions of their incomes to stave off mortgage 
foreclosures or evictions, one would conclude that these actions were tokenistic. For example, it is estimated that in 1972 more than $53 \%$ of all renters that comprised a little over one-third of the households nationwide spent $25 \%$ or more of their income on housing; a little over one-third (34\%) spent $35 \%$ or more. Comparatively, in 1970 only twofifths of the renter households spent $25 \%$ or more of their income on housing, and only one-fourth spent $35 \%$ or more (U.S. Bureau of the Census, 1982). At the same time, the displacement of residents from their homes and neighborhoods was also occurring at an ever increasing rate (U.S. Bureau of the Census, 1982).

The decade also showed a considerable reduction in other housing indices centered around inadequate sanitary facilities, overcrowdedness, conversion of apartments to condominiums, high costs, structural dilapidation, lack of equity, and abandonment of housing units in some inner-city neighborhoods of central cities put a squeeze on housing consumers. These factors highlighted two major problems that have been strongly criticized. They are the continuous gap between the living conditions of the nation's rich and poor residents and the nation's ability to provide decent and affordable housing for its people (Hays, 1985).

As a result of this criticism, in January 1973 the Nixon Administration imposed a moratorium on all subsidized housing programs. The Administration later set up the 
National Housing Policy Review (NHPR) to evaluate the programs and make recommendations (Weicher, 1980).

The recommendations of the NHPR brought about the enactment of the 1974 Housing and Community Development Act (HCDA). The Act consolidated all previous programs. It also created the Community Development Block Grant (CDBG) program, the Comprehensive Planning Assistance, and the Urban Homesteading programs administered by state and local governments, and changed the revised section 23 programs to Section 8 (Weicher, 1980).

Under the Section 8 program the federal government provided the tenant with a subsidy that could be used to negotiate his or her own housing with the landlord. In essence the Section 8 program was both an income transfer and a housing subsidy (Weicher, 1980). By the end of 1977 about 165,000 housing units had been built, while 227,000 units were under construction. HUD approved 90,000 housing units for the fiscal year 1980 and 115,000 in 1981 (Weicher, $1980)$.

The federal government housing programs have had their own share of problems. Many of the programs were expensive and wasteful because they failed to satisfy the needs of the clientele and had problems with poor project management, location, and changing characteristics of the tenants (Weicher, 1980). These problems were further exacerbated by massive budget cuts during the Reagan Administration. 
Housing Programs in the

Reagan Years

The Reagan Administration's national economic recovery program of the 1980 s terminated assistance for subsidized housing and either rescinded or cut back funding for other programs like CDBGs, Comprehensive Planning Assistance, Urban Development Action Grants (UDAGs), and Urban Homesteading. These moves, so to speak, turned back the clock on 50 years of federal government response to the problems of rapid urbanization, inadequate housing and community development (Achtenberg, 1989). The Administration literally either slowed revitalization efforts or expedited the decline of neighborhoods through its program of budget cuts.

The budget for HUD's subsidized housing program dropped from $\$ 30.1$ billion in fiscal 1981 to $\$ 8.7$ billion in fiscal 1983, $\$ 9.9$ billion in 1984 , and $\$ 10.8$ billion in 1985 (Appelbaum, 1990).

The Administration's economic recovery plan was based on the belief that a market economy that is completely free of federal government housing policies and regulations would provide better housing than the federal housing and neighborhood redevelopment programs of the past decades (Achtenberg, 1989). In light of this belief, the Economic Recovery Act of 1981 was passed and provided tax incentives to encourage the private sector to make housing investments. 
The Act enabled owners of subsidized housing property to write off project costs much faster than they would under similar depreciation methods used in the 1970s. For example, a 15year rather than a 19-year time period was considered the age at which subsidized housing should start undergoing repairs. An industry estimate showed that $80 \%$ of the subsidized housing that was 15 years old in 1987 had repair costs that averaged $\$ 3,000$ per unit. The capital improvement costs for about $50 \%$ of the subsidized housing stock were estimated at $\$ 606$ million against $\$ 75$ million proven reserves (Achtenberg, 1989).

It should be pointed out that the new policy of substituting private investment for public housing in order to accomplish the Administration's housing objectives never went through the regular Congressional rule-making procedure. Instead, the decision was the outcome of a number of administrative directives geared towards the disposition, foreclosure and ownership transfer of subsidized projects. These policies were not only opposed by the different community groups affected, but also resulted in the loss of a viable portion of affordable housing units, especially for those who cannot compete in the housing market and are dependent entirely on subsidized housing (Achtenberg, 1989).

In order to ameliorate the housing problem and other discriminatory practices in the housing industry, in 1988 the Fair Housing Law of 1968 was amended. The new act 
became known as the Fair Housing Amendment Act of 1988. The new Act forbids "blockbusting" for profit, i.e., persuading owners to sell or rent their housing units by telling them that minority groups are moving into the neighborhood; discriminating by advertising that housing is available only to a certain group of persons; denying that housing is available for inspection, sale or rent when in fact it is available; and refusing to sell or rent or deal or even negotiate with a person on account of race, sex or national origin (Bureau of National Affairs, 1989).

In the Reagan years problems of mismanagement or programs operating with diminished funds were not uncommon. Members of Congress criticized former HUD Secretary Samuel R. Pierce, Jr. for not taking decisive action to wrestle with the troubled Section 8 program despite repeated warnings by the Office of the Inspector General (OIG) about widespread problems and abuses in the program (Bureau of National Affairs, 1989).

The Section 8 program became the subject of a wideranging OIG audit as well as House and Senate hearings. It also exemplifies a program in which cutbacks in funding by the Reagan Administration created an environment in which developers were required to hire well-connected--frequently Republican--individuals to lobby HUD for a proportion of the diminished funds for housing projects (Bureau of National Affairs, 1989). 
The legislators also charged that top HUD officials bypassed public housing authorities and oftentimes made moderate rehabilitation awards that were intended for specific projects that came to the attention of headquarters (Bureau of National Affairs, 1989). As a matter of fact, public housing authorities are supposed to be awarded units and then select the projects in order to receive the moderate rehabilitation assistance.

Members of Congress also charged that, according to an OIG investigation, fees paid to consultants--ranging from $\$ 500$ to $\$ 1,500$ per unit--were eventually passed on to the taxpayer and resulted in the availability of fewer housing units for the poor (Bureau of National Affairs, 1989).

In retrospect the Reagan Administration did not just literally destroy 50 years of federal government involvement in providing housing assistance to low- and moderateincome families vis-a-vis reducing the chances of neighborhood revitalization, but left a legacy that should be structurally transformed by the succeeding administration.

Housing Programs in the Bush Years

In compliance with the federal government policy of providing public housing and rent supplements--the two programs that have been directed toward $10 \mathrm{w}$-income residents-Congress recently passed the Affordable Housing Act of 1990. The new Act reaffirmed the national housing goal of 
providing a "decent, safe, sanitary, and affordable living environment for all Americans."

Despite this reassurance, Congress found that the supply of affordable rental housing was in decline, a large proportion of tax incentives for the production of affordable rental housing has been removed by the Tax Reform Act of 1986, and over the past decade the living conditions of Americans have deteriorated due to cutbacks in federal assistance to $10 w^{-}$and moderate-income families. Congress concluded that a community-based housing partnership program to increase the supply of rental housing for low-income families should be encouraged, and homeownership opportunities for low-income groups must also be encouraged (Turpel and Uba, 1990).

As corollaries to the Fair Housing Act of 1988 the Americans with Disabilities Act and the Community Reinvestment Act of 1990 were passed. The Americans with Disabilities Act ensured that housing was readily accessible to the disabled. Such housing has to meet specific architectural standards in construction and renovation. The Community Reinvestment Act is intended to encourage banks and other lending institutions to give out credits to their local community groups in 1 ow- and moderate-income neighborhoods for revitalization (Turpe 1 and Uba, 1990).

A more recent development in housing under the Bush Administration is the affordable housing program. The 
conferees modified the proposal that required each Federal Home Loan Bank to establish an affordable housing program, a fund that would offer subsidized cash advances to member institutions to make below-market loans for eligible housing projects. Activities in this new deal include the purchase of homes by 1 ow - and moderate-income households ( $80 \%$ or less of area median income) and the purchase, construction or rehabilitation of rental projects. At least $20 \%$ of the units in a rental project would have to be occupied by and affordable to every 1 ow-income household ( $50 \%$ of area median income) for mortgage term or the remainder useful life of the property (Bureau of National Affairs, 1989).

The Federal Housing Finance Board (FHFB), the new agency entrusted to oversee the Federal Home Loan Banks as the successor to the abolished Federal Home Loan Bank Board, issues regulations for implementing the new affordable housing program requirements (Bureau of National Affairs, $1989)$.

However, public housing programs under the Bush Administration have also had their own share of economic as well as management problems. A report by the General Accounting Office (GAO) to the Senate Banking Committee showed that the FHA mutual mortgage insurance experienced a \$452 million loss in fiscal 1988 as a result of the decline in premium collections and an increase in claims payments (Bureau of National Affairs, 1989). 
By and large, federal policies, especially those of the federal mortgage institutions such as the FHFB, affecting housing and neighborhoods have been described as part of a government strategy to reinforce the profits of the private sector as well as that of the entire business community in the housing industry (Hartman, 1983). As a result, the underlying promotion of corporate profits has forced some residents to leave their homes for various reasons that include gentrification, which is a form of neighborhood change.

Invariably, the housing crisis nationwide has been worse and continues to be worse for some, especially lowincome and minority residents, than for others. For example, in the early 1980 s it is estimated that $72 \%$ of all households nationwide that earned less than $\$ 10,000$ per year paid $25 \%$ or more of their earnings for housing alone, while only $3 \%$ of those that earned $\$ 50,000$ or more per year paid this much on housing (U.S. Bureau of the Census, 1981). This unequal distribution of wealth has continued throughout the 1980s and even beyond and has exacerbated the gentrification of inner-city neighborhoods which were considered unsuitable in the 1950 s and 1960 s and the problem of homelessness which is an outcome of housing insecurity and unavailability.

In response to the economic and management problems with the FHA, the Secretary of HUD, Jack Kemp, announced 
sweeping changes to the FHA. The package, called the "FHA for the "90s" initiative, has five basic reform components. They include shoring up accounting practices, determining the actual soundness of the $\mathrm{FHA}$, requiring management accountability for program activity, preventing fraud, identifying lenders with serious default and claim problems, and creating a task force to oversee the initiative (Bureau of National Affairs, 1989).

Unlike the previous regime the current administration continues to gradually repair the destruction of housing programs done by its predecessor. A testimony to this personal assessment is shown in the Senate Spending Bill approved by the House on July 20, 1989. The House bill provides $\$ 9.1$ billion for assisted housing, including $\$ 1.1$ billion for the renewal of Section 8 contracts that expired in fiscal 1990 and early 1991. The bill also provides $\$ 3$ billion for the CDBG program and more than $\$ 370$ million for homeless programs (Bureau of National Affairs, 1989).

In conclusion, the evolution of the federal housing programs since their inception has not had much success in making the national goal of providing every American with a decent home and living environment tenable, especially for the poor. The success can rather be measured in terms of creating an awareness of the growing problem of neighborhood decline and creating the need for neighborhood revitalization, tokenistic improvement in housing quality and 
homeownership, and directing the bulk of federal spending in housing to upper middle-class homeowners in the form of tax incentives and mortgage interest. It is estimated that the latter policy in 1984 cost the Treasury $\$ 49.4$ billion, an amount that surpassed the money spent on HUD-assisted housing programs since the inception of the public housing program in the 1930s (Sumka, 1990).

Therefore, the federal housing programs since the Great Depression can be described to have economic and political underpinnings. On the economic side the federal housing policies either by theory or by design served the interests of the private market sector in order to "stabilize" and "reinforce" the existing social and economic status quo. In the process they enhanced neighborhood change in terms of forcing residents, especially low-income and minority households, from their inner-city homes and neighborhoods which at some point in time were considered unsuitable by those now displacing low-income and other minority in the innercity neighborhoods. On the political side they used patronage by providing 1 imited housing concessions in order to stave off any disruption of the social and economic status quo by dissatisfied social groups and effect the integration of such social groups within the mainstream of the American society (Hartman, 1983).

With the current administration being charged by Democrats of misplaced priorities, i.e., not focusing more 
on its domestic policies rather than on its success in the Persian Gulf War, the success of existing and future housing programs or community redevelopment programs is suspect.

The discussion continues with state and local government involvement in the federal housing programs.

\section{STATE GOVERNMENT EFFORTS}

In response to the federal government housing programs of the late 1960s, the states established their own agencies to enhance the planning and the construction of housing. By 1960 New York was the only state with a finance agency. But by the late 1960s 11 states had established their own agencies to finance the construction and rehabilitation of housing. Between 1970 and 1972 , 14 additional states had established their own agencies (HUD, 1974).

The primary objective of state finance institutions has been the provision of financial assistance for the construction of housing for $1 \mathrm{ow}^{-}$as well as moderate-income groups. Usually the agencies work concertedly with private developers that do the actual construction or rehabilitation work, while the finance institutions select and acquire the site and determine the size and number of housing units in a given project. They also determine the scope and extent of communty facilities and establish equal opportunity standards, employment and the marketing of the housing units ( HUD, 1974). 
Aside from providing financial assistance, state finance agencies were also given a wide range of authority. As of 1973 all but six of the states' finance agencies were authorized to survey and assess housing deficiencies statewide and develop programs to rectify these deficiencies. Among the states that had established finance agencies in 1973, 13 agencies directly administered federal housing subsidies; another 18 were authorized to acquire land by purchase or eminent domain; and 9 states had the authority to act as public housing authorities, while a few were allowed to construct or rehabilitate housing on their own directly (HUD, 1974).

Between 1969 and 1973 state agencies directed the construction of 90,587 housing units, and 65,994 units of this total were subsidized under Section 236 of the Housing Act of 1968. Additionally, several state financial institutions were given the authority to raise funds for housing construction or rehabilitation by issuing tax-exempt bonds. Through this process, as of 1974, 11 state agencies raised approximately $\$ 4.7$ billion from bonds. The bonds were then sold to private investors through private underwriters (HUD, $1974)$.

State housing finance agencies have focused on the development of multi-family rental housing units to the exclusion of homeownership development. About $72 \%$ of the dwelling structures developed are high rise. Rather than 
investing some of the funds on the rehabilitation of old housing units, most of the housing development activity has been centered on the construction of new housing units. Nearly all these new housing units have been built in urban and suburban areas to cater to the housing interests of the affluent residents. Therefore, the housing activities of the state agencies have always been strongly criticized because of their redlining underpinnings which have resulted in the dislocation of many families in several inner-city neighborhoods to which such housing activities are targeted.

The redlining controversy resulted in the passage of regulatory measures to combat this discriminatory practice that has polarized many urban communities and neighborhoods in some states. The action has been through mortgage disclosure and reviews of the financial institutions' lending practices undertaken in such states as California, New York, Illinois, New Jersey, Michigan, Wisconsin and Pennsylvania (HUD, 1977).

For example, in California state-chartered savings and loan associations were required in 1964 to submit a wide range of information on institutional lending practices to the California Savings and Loan Commissioner. The state also established a Board of Inquiry that handled complaints about the denial of mortgage loans (HUD, 1977). Similarly, in Illinois a Financial Disclosure Act passed in 1975 requiring all banks, savings and loans, mortgage bankers, 
and insurance companies to disclose mortgage loan information (HUD, 1977).

Another reflection of increased state involvement in the area of housing has been the creation of community affairs offices. These community departments are charged with state-wide planning, regional planning, local planning and urban renewal programs. But by and large the functions of these departments have been limited to providing information, research, technical assistance, and planning to local groups or communities (HUD, 1974).

Until 1974 control for land use was the responsibility of local governments in the form of zoning power delegated by the states. Since then some states have assumed control over land use rather than delegating such control to local governments.

The land use planning programs adopted by the states nationwide are required by Congressional acts to be comprehensive. That is, reflecting various planning elements such as housing, transportation, economic growth and development, open space, and environmental protection and conservation, to name but a few. Such comprehensive plans must be prepared within the framework of key federal regulations such as the National Environmental Policy Act of 1959, the Clean Air Act Amendments of 1970, and the Water Pollution Control Act of 1972 as well as other state regulations. 
Since all planning goals of the states have an element of housing, it is appropriate at this juncture to provide a section on the aregon state planning system relative to the efforts undertaken by the state toward the housing element.

Efforts in the State

of Oregon

In the state of Oregon concerns over uncontrolled urban growth, environmental quality, the conservation and improvement of the existing communities, and the cost of public services in the late 1960 s and early 1970 s intensified the adoption of the comprehensive planning process mandated by Congressional acts for all states (Rohse, 1987). In 1969 the State Legislature established 10 planning standards for the state, and it required all local government entities in Oregon to adopt comprehensive plans. These were considered very ambitious planning moves. However, the execution of the legislature's plans was stalled by two problems. First, the state failed to appropriate the funds that would enhance the making of these comprehensive plans at the local government level; second, the state failed to establish an agency that would execute the 10 statewide planning standards (Rohse, 1987).

In 1973 the State Legislature addressed those problems by passing the now reputable senate Bill 100. The bill created the Land Conservation and Development Commission ( $L C D C$ ), mandated to provide planning goals and objectives 
that can be used by state agencies, cities, counties, and other special districts in the entire state of Oregon (Rohse, 1987). Among the statewide planning goals is the provision of housing in the land use plan. Such a plan, among other things, should include an inventory of standard as well as substandard housing units that can be rehabilitated and then made available in the housing market at affordable price tags and rent levels for Oregon residents, especially for those in the low-income and minority groups (Turpel and Uba, 1990).

The new bill also established the Department of Land Conservation and Development (DLCD) as the agency responsible for administering the statewide planning standards, and appropriated the necessary funds to enhance the making of the comprehensive plans to be adopted by the local government entities of the state (Rohse, 1987).

Other departments stemming from the new bill include the Department of Economic Development, Department of Energy, Department of State Lands, Department of Veteran Administration, and the Oregon Housing Agency, to mention but a few. All these agencies in one way or another administer housing programs. However, the bulk of the state housing programs are administered by the Oregon Housing Authority (OHA) which include rental housing, homeownership, technical assistance program, and the state homeless program (Turpel and Uba, 1990). 
As regards the rental program the OHA offers permanent mortgage loans to developers for the construction of new housing units. It is also responsible for the acquisition and rehabilitation of rental housing for elderly and disabled Oregon residents. Additional1y, OHA administers federal as well as state income tax credits to developers who construct, rehabilitate or acquire low-income housing units and to lending institutions that give non-profit agencies reduced interest rate loans and later pass on the savings benefit to low-income tenants by reducing their rents (Turpe1 and Uba, 1990).

The OHA homeownership program provides loans and tax credits to home buyers in the state. The financing of loan money is done through the sale of bonds. The agency has a mortgage credit certificate program through which it provides federal tax credits for below-median-income state residents who have obtained loans from private lenders to purchase or rehabilitate their homes (Turpel and Uba, 1990). The OHA provides technical assistance in the areas of housing information and economic data, planning, loans and grants to individual residents, public as well as private investors, and educational services. The OHA also administers the federal Community Development Corporation Program that assists non-profit entities in the construction, rehabilitation, and management of low- and moderate-income housing (Turpel and Uba, 1990). 
But nationwide, states' efforts to enhance the national housing goal of providing a decent home and a healthy 1 iving environment for their residents, as the reader may find out in the next discussion, were forestalled in the 1980 s by the Reagan plan. Funding for some programs was drastically reduced to the extent that some programs were terminated and others modified or restructured in compliance with the budget estimates of his administration.

State Efforts in the 1980 s

Before the l980s state governments always relied on federal government grants to enhance their housing and urban development programs. But when Ronald Reagan took office in 1980 , sectors of the economy that relied heavily upon federal assistance, state housing programs inclusive, became stalled for lack of funds due to the president's plan of budget cuts. The plan was based on the assumption that a reduction in federal spending would encourage private investors to step in and replace federal programs, especially housing programs that were designed to benefit the poor, with their own programs (Peterson and Lewis, 1986).

The Reagan plan, contained in a 1982 National Urban Policy Report, placed emphasis on the concept of "selfreliance" for state and local governments to expedite housing-related developments. No wonder that the Reagan Administration proposed the enterprise zone concept for 
states based on the assumption that, by removing all federal regulatory measures as well as reducing taxes, private inner-city reinvestment would be enhanced (Peterson and Lewis, 1986). The enterprise zones are described as follows :

These are sprawling areas of urban blight such as visual ugliness, crime, and declining property values, that threaten to spread decay to adjacent areas. And as the home of concentrated numbers of the nation's minorities, recent immigrants, lowincome elderly, public assistance recipients, and other economically distressed groups, they symbolize mény problems of poverty and disadvantage. (Bendick and Rasmussen, 1986, p. 97)

But the states responded to the enterprise zone policy in a different way. They incorporated the support of the public sector rather than getting rid of it as well as tax reductions directed to specific areas to enhance their operation (Peterson and Lewis, 1986).

In 1 ight of this, 21 states nationwide passed their own zone laws in anticipation of having their zones designated as both a federal and state zone with all the benefits that go with it. But unfortunately, most state zones operated through incentives provided either by the state itself or the local government. Fifteen of the 21 states that passed enterprise zone laws as early as 1984 have varied programs. But a common theme that runs through these programs is that the programs themselves are basically tax incentive efforts (Bendick and Rasmussen, 1986). In short, state enterprise zones are nothing more than areas of consolidated public 
activity in land use planning and inner-city revitalization (Bendick and Rasmussen, 1986).

The state of Connecticut, although not typical, is an example of a successful enterprise zone program in terms of urban revitalization. The success of the Connecticut program can be attributed to a number of factors. First, it utilized public support as a prerequisite for attracting private investment rather than avoiding such public expenditure. Second, emphasis was placed on attracting inmigrant businesses rather than depending on indigenous firms. Third, tax reductions are offered as a means of competing against neighboring areas rather than as a means geared to reducing tax burdens believed to stall work and private investment. Fourth, government regulatory measures are used to provide and allocate areas for the program (Bendick and Rasmussen, 1986).

The Connecticut enterprise zone package included the following: an $80 \%$ reduction in local property taxes for newly constructed or renovated manufacturing facilities; $\$ 1$ million made available to small firms in the form of venture capital loans; a cash offer of $\$ 1,000$ to manufacturers for each new job opening created in the zone of operation; and a $50 \%$ state corporate tax reduction for a period of 10 years for firms or businesses that employ $30 \%$ of the residents in the zone of operation (Bendick and Rasmussen, 1986). 
The enterprise zone approach, as conceived by the Reagan Administration, does not offer an alternative that will replace the conventional approach to urban revitalization. However, if the concept is integrated with public support and the conventional approach, as was the case in the state of Connecticut, future enterprise zone programs in states will be achieved with much greater success.

In summary, a wide range of housing programs have been developed by the states nationwide in response to the 1949 federal government's call of providing every American with a decent home and a healthy living environment and in response to their own social, economic, and political pressures from within. But by and large the housing policies of the states in the post-World War II era purported to enhance neighborhood decline through the concerted efforts of state and private investment in housing did not fully achieve their objective. This is because most of these programs in some of the states have more or less favored the affluent through direct and indirect housing assistance, while at the same time direct housing assistance to the poor has, at best, been modest.

What we have in some of the states' cities today can be described as a rerun of the earlier urban renewal programs which resulted in the displacement or dislocation by the affluent of low-income and minority residents from their 
neighborhoods that, at some stage in time, had been redlined.

In the section below the activities of local government entities, such as municipalities and counties, to revitalize declining neighborhoods, in some cases through the enterprise zone approach, are discussed.

\section{Local Government Efforts}

Local governments have not only been recipients of grants to enhance economic development but have, in some instances, employed the enterprise zone concept to encourage investment in housing within their cities. Local government efforts as implied in this research mean community development activities, subsumed under housing programs, carried out by cities, counties, and other local entities. These activities are considered relevant to this research not only because they created a sense of awareness among planners and policy-makers about the growing problem of inner-city neighborhood decline. They are also relevant because housing programs employed to combat the forces of time and change through neighborhood revitalization have resulted in the displacement of one group of residents by another.

Between 1979 and 1980 about 2,000 municipalities and counties nationwide used CDBGs to enhance the revitalization of property for low- and moderate-income property owners and renters. Additionally, they negotiated about $\$ 400 \mathrm{mill}$ ion 
in supplemental private sector participation in the rehabilitation process. Local governments also played a significant role in revitalizing 20,000 units through the Section 8 moderate and substantial rehabilitation program of HUD (Ehrmann and Ford, 1981).

Invariably, before a project for low-rent public housing is started, the local housing authority has to select the site subject to the approval of HUD. Oftentimes sites recommended by the local housing authority must be approved by the local city council or other body. Due to the increasing neighborhood opposition to public housing, the selection process has been to locate the public housing project in the inner-city neighborhoods that are characterized by high concentrations of minority groups and inadequate public services, jobs and commercial opportunities (HUD, 1974).

By the l980s the activities of local governments were stymied by the Reagan Administration's cutbacks in housing assistance programs, creating a shortage of rental housing that affects low-income tenants. The shortage led to the displacement and eviction of low-income minority residents who were unable to pay their rents. The displacement in the 1980 s is reflected in a relatively high proportion of homeless persons and an increased rate of gentrification (Angotti, 1986). 
Local governments were thus compelled to solicit the involvement of the private sector to enhance their community development programs. No wonder that the controversial enterprise zone concept embraced by President Reagan was also supported by local governments. The concept involves taking big chunks of land or entire city neighborhoods in areas that are depressed and designating them for special development. Businesses that locate within these enterprise zones receive huge tax break exemptions from the capital gains tax, investment tax credits, and credits for employing residents within these zones (Guskind, 1990).

An example of the enterprise zone concept is provided by the North/Northeast Portland Enterprise Zone Project. The City of Portland, it should be remembered, is the largest metropolitan area in the state of Oregon located along the Pacific Seaboard. The city has an estimated population of over 385,000 inhabitants (U.S. Bureau of the Census, 1980) and is located near the mouth of the Columbia River. In order to enhance administrative and economic development the city is divided into five major districts which include the North, Northeast, Northwest, Southeast, and Southwest neighborhoods. The agency responsible for revitalizing the city's core and declining neighborhoods is the Portland Development Commission (PDC), created in 1958 by the Oregon State Legislature. 
The North/Northeast Portland Enterprise Zone Project, as mentioned earlier, was designated in 1986, and it is one of 30 project areas in the state of Oregon. The project provides property tax breaks and local incentives for new investment by businesses that locate within the boundaries of the zone. The program also requires qualified businesses to lure residents within the enterprise zone (PDC, 1990). The economic development staff of the PDC is responsible for implementing the enterprise zone program. According to an annual status report Nabisco, Blue Bell and Mutterperl invested $\$ 27.2$ million in fiscal 1989 and 1990. The staff of the PDC continues to monitor the activities of these companies to ensure that they comply with precertification plans as well as hiring requirements (PDC, 1990). The staff of the PDC works concertedly with representatives from the State of Oregon and different interest groups to ensure the input of the City and the reviewing of enterprise zone legislation proposed by the federal government. This enterprise zone program is an ongoing project (PDC, 1990).

Earlier renewal efforts undertaken by the PDC were not confined only to the revitalization of the South Auditorium Neighborhood in Southwest Portland that involved the demolition of 400 structures and razing 54 entire blocks. The Albina Neighborhood Improvement Program in North Portland that cost $\$ 2.3$ million was indicative of the City's commitment to neighborhood revitalization (PDC, 1978). Other 
activities of the $\mathrm{PDC}$ over the years include reclaiming vacant housing units through homesteading, helping low- and moderate-income homeowners in Portland to make improvements to their property according to the City's building and energy requirements through the single-family housing program, and by working with special social service groups that the PDC helps to locate in order to finance and develop housing units for residents with special needs (PDC, 1989).

Community development activities employed by local government bodies to effect inner-city neighborhood change have seemingly been impressive. But at the same time, their impact on the issue of neighborhood change is suspect because housing policies made by these local government bodies have tended to favor the affluent by providing them with direct and indirect housing assistance at the expense of the poor. Such activity has resulted in the dislocation of residents from their homes and communities. The group of residents most vulnerable are the low-income and minority tenants. Many factors have contributed to the squeeze on tenants and these include increasing housing and rental costs, the decrease in the supply of rental housing due to insufficient construction levels, and the abandonment of some housing units in some neighborhoods of central cities. Also vulnerable are homeowners who are increasingly faced with mortgage foreclosures and possible eviction. 
In summary, the rationale for discussing federal, state, and local government efforts directed toward housing is to provide a historical background to the issue of neighborhood change in terms of what has been done and what still needs to be done to combat the forces of time and change.

Indeed, there is no doubt that the more than half a century of government involvement in housing made some improvement in housing. But it should be pointed out that housing policies were not just made from an act of good faith alone on the part of policy-makers to provide a home and a decent living environment for every American, but such policies had an underlying motive, that is, the enhancement of profit opportunities for the private sector in the housing industry on one hand, and the entire business community on the other. The pursuit of these two objectives has resulted to two opposing movements--the gentrification of certain inner-city neighborhoods and the suburbanization of some of the nation's cities--in the 1980s (Adams, 1987).

Those in support of the gentrification phenomenon attribute the process to economic, demographic, physical, and the trickle down of middle-class households into the inner-city neighborhoods once considered in the 1950 s and 1960 s as unsuitable. Supporters also believe that as the proportion of the affluent increases in the gentrified neighborhoods community growth and development is sustained (Adams, 1987). 
Supporters of the suburbanization process argue that if the affluent residents did not have any neighborhood to return to in the 1950 s and 1960 s, there is less optimism that after more than a quarter of a century later they will return (Adams, 1987 ).

Although this argument may sound credible, there is every reason to believe that as long as housing policies at the three levels of government continue to favor high rates of new construction for the affluent, gentrification into inner-city neighborhoods closer to the Central Business District (CBD) will continue.

For many years the housing policy debate has centered around two issues. First, how much politically motivated subsidy should be provided for middle- and upper-income households, considering the fact that as the affluent move up to better housing, used household will trickle down to the poor? Second, how much subsidy should be provided directly for the poor households in the form of rent subsidies, household allowances or vouchers, low-interest loans to enhance homeownership, and publicly built and operated housing units? The success of the second issue faces an uncertain future for a number of reasons. These include the growing number of people below the poverty level, the stagnation of middle-class incomes, and a housing finance system that continues to be influenced by housing market forces. 
In light of this political and economic environment and in light of the fact that politicians often used housing as a medium for dispensing political patronage, the housing needs of the affluent will continue to receive the utmost political urgency rather than the housing needs of the poor residents, unless there is a coordinated understanding among the various actors on what the specifics of reinvestment should be.

THE SCOPE OF THE STUDY

The choice of the city of Portland as the geographical area of this study was prompted by a number of factors. First and foremost, several empirical studies that have attempted to establish a contextual framework of neighborhood revitalization contend that the phenomenon is most likely to occur in cities with the following characteristics: a city with a relatively large population; a city with a relatively distinctive and extensive downtown area offering white-collar employment opportunities as well as having the potential for business establishment; and a city having several older neighborhoods (Black, 1975; Lipton, 1977; Clay, 1979) or stop-over neighborhoods (Abbott, 1983). these characteristics are manifested in the city of Portland. Therefore, by these criteria Portland was considered an appropriate choice for undertaking this research. 
Portland has been described as a young city because at the turn of the century its population was only 90,426 . Because of this slow population growth the city was able to escape the problem of rapid industrialization and urbanization reminiscent of the large cities such as Philadelphia, Boston, and Pittsburgh along the Atlantic Seaboard (Portland City Planning Commission [PCPC], 1965). But by the mid1960 s the city's population had grown to over 200,000, and by 1980 the estimated population of Portland was over 385,000 inhabitants which was considered a relatively large population. Accounting for this large population growth are the city's excellent location for Pacific Rim trade, as well as the diversification of its economy from just an entirely wood products and agricultural base. The diversification brought about a rapid incursion of commercial and industrial activity into what were once regarded as pleasant residential areas (PCPC, 1965).

With the passage of time residential areas that did not experience commercial as well as industrial encroachment started to show visible signs of decline. For example, housing units that were once considered to be strong and sound were beginning to fall apart. Maintenance and repair work on some housing units were not only overdue but were further deferred because the physical conditions of the neighborhood became so bad that they no longer justified a significant level of capital investment (PCPC, 1965). By 
1980 over $57 \%$ of the city's housing stock was estimated to be more than 40 years old. The age of these housing units, and especially because they are wooden structures, justifies a continuing commitment to maintenance and repairs ( $P C P C$, $1965)$.

The city of Portland may not be a typical. example of a city experiencing rapid neighborhood decline. However, evidence of decline, as explained above, provides another reason for selecting the city of Portland as the geographical area for assessing neighborhood revitalization over time.

Other reasons that prompted the selection of the city of Portland as site for this research are as follows. Portland's impressive downtown endowed with a transit mall, max light rail, lighted office buildings, high-rise apartments, a beautiful waterfront scenery, and park block apartments provide some residents a feel for inner-city living. Concern among some Portland residents over historic preservation, especially the preservation of older and architecturally appealing buildings, was one of the reasons that caused some residents to lobby for and establish their own neighborhood organizations in order to influence the planning process vis-a-vis the preservation of historic places within their neighborhoods (Abbott, 1983).

The variables used in this research included the calcu1 ated ratio differences for the periods 1970 and 1980 for 
the changes in median household income, home value, and rent designated as measures of neighborhood change. These were regressed against nine other structural characteristics derived from locational, demographic, and housing factors. Both the dependent as well as the independent variables are described in the methodology chapter of this research.

Therefore, the objective of this study is to explain why some of these neighborhoods in the city of Portland are assumed to have changed between 1970 and 1980 while others have not. More specifically, the objective is to measure the extent of this assumed change over time by employing a series of multiple linear regression methods. In order to make this objective tenable, a number of parameters such as household income, home value, and contract rent usually associated with the filtering concept will be selected and designated as the dependent variables. It is against these filtering parameters that a carefully selected number of variables from locational, demographic, and housing characteristics designated as independent variables will be regressed to assess the urban structural impacts of neighborhood revitalization in the city of Portland between 1970 and 1980 .

Basically, this study should be viewed as just another extension of the much debated filtering concept.

A study similar to the present study was earlier done by Mba (1983). He used a principal component statistical 
technique to develop an index to measure and monitor changes in status of residential housing and market conditions in the entire Portland Standard Metropolitan Statistical Area (SMSA) in 1960 and 1970 , using census tract housing data of the Portland SMSA.

Mba (1983) found that three factors (home value, household income per capita and housing quality) had high factor loadings on the first component, but the same factors loaded low on the second component. While other factors, such as percent of all owner-occupied housing units and all occupied housing units, had high loadings on the second component, their loadings on the first component were extremely low. He concluded that the high factor loadings on the first component in home value, household income, and housing quality reflected "a demand-side component of change" and hence a reflection of housing filtering. The high factor loadings on the second component in such factors as the percent of all occupied and owner-occupied housing units in the SMSA "depicted a supply-side component of change," and hence a reflection of neighborhood stability.

In Mba's analysis of the census tracts, the computed component scores resulting from the principal component analysis for each census tract in the SMSA became the measure of change.

For example, census tracts with high positive composite scores indicated a decline in residential housing 
status. Such tracts were located in the inner-city areas of Portland and Vancouver, corresponding to the older built-up areas in the Portland SMSA. The area exemplified by this trend was the Albina area, which had experienced a transition in socioeconomic and racial status with a high percent of low-income households, thus signaling downward filtering and succession. Similarly, census tracts with high positive composite scores indicated a rise in residential housing status. Such tracts were located in the suburbs of the Portland SMSA. These were areas that were experiencing new construction and also serving as residences for middle- and higher-income people, thus reflecting upward filtering. Finally, census tracts with small and insignificant composite scores indicated a stable residential housing status. These tracts were located in the older suburbs and some inner-city areas of the Portland SMSA. Such areas had not experienced any filtering and had a mix of older and new housing units occupied by some lower-middle income and blue collar residents (Mba, 1983).

Mba found that the changes in the relative residential housing status, regressed on five selected factors of all the census tracts in the entire Portland SMSA in 1960 and 1970 , revealed that median household income per capita, new construction, and year-round vacancies substantiated the hypothesis. The other factors, such as housing stock, defined as the percentage of all occupied housing units, as 
well as the percentage of all owner-occupied housing units, were found to be unrelated to the relative residential housing status in the Portland SMSA. Therefore, Mba was quick to say that "a study specifically addressed to these variables may shed further light on the findings" (Mba, 1983, P. 125).

Furthermore, the selection of five "key housing market variables" at the expense of pertinent socioeconomic factors to describe the status of residential housing in the Portland SMSA appears to undercut the following statement:

economic characteristics of households who occupy
the housing units, as well as the quality of the
units, must be part of the assessment. (Mba,
1983, p. 121)

The paucity of the variables used in his investigation, especially as they reflect the socioeconomic characteristics of the residents, is acknowledged in the following statement:

to investigate the relationships of the changes
in urban subarea residential housing status to
other characteristics. . Such as sex, occupa-
tion, education and age. (Mba, 1983, p. 128)
In light of these issues, the present study draws from an amalgam of factors selected from locational, socioeconomic and housing characteristics to address the research problem. In order to accomplish this objective, a series of statistical techniques was employed to calculate the changes and to test the research hypotheses. First, a ratio method 
developed by Fisher and Winnick (1951) and later tested by Toulan (1960) in a study of the filtering process in Philadelphia was used to calculate the ratio differences that represented measures of neighborhood change in the sample during the decade. But rather than replicating a study that monitored housing market conditions in the entire Portland SMSA (Mba, 1983), this research estimated conditions that have influenced revitalization in the inner-city neighborhoods of Portland. Second, two phases of regression analysis were employed in this investigation. In phase one a simple regression analysis was used to assess the correlation between the independent and dependent variables. In the second phase a multivariate analysis was used to determine the degree to which the measures of neighborhood change are contingent upon the predictors. These procedures are discussed in the chapter on methodology.

The time frame, 1960 and 1970, selected in Mba's study may have tended to exclude the major part of the revitalization trend since the bulk of the literature on this phenomenon started to appear in the 1970 s and 1980 s (London et al., 1986). But the selection of the time frame, 1970 and 1980, for the present study was based on events which occurred in the mid-1970s and 1980s. First, during these periods a considerable number of cities nationwide started experiencing private market reinvestments in the form of housing, commercial and cultural activities (Laska 
and Spain, 1980). Second, forces in the housing market made prices of suburban homes extremely expensive for first-home buyers and renters (Goetze et al., 1977; James, 1977).

\section{FORMAT OF THE STUDY}

The study takes the following format. In Chapter II state and local government initiatives on neighborhood revitalization--a case study of Portland--are discussed. The chapter focuses upon what has been done in Portland to wrestle with the problem of neighborhood decline since the 1949 federal government legislation. In Chapter III the pertinent literature on which the research is based is reviewed.

In Chapter IV the methodology of the research is discussed. The chapter describes the conceptual development of the research design in terms of theory and hypotheses formulation. It also describes the pertinent variables used in the research and the two statistical techniques employed for testing the formulated hypotheses resulting in a two-phased description of the techniques. In phase one the procedure employed to obtain the mean differences or ratio differences used as dependent variables is described. Phase two describes the regression methods used for testing the research hypotheses. The chapter ends with a statement on the sources of data for the investigation. In Chapter $V$ the results and findings of the regression method are presented 
and discussed. In Chapter VI the conclusions of the study are presented. 


\section{CHAPTER II}

\section{PORTLAND: A CASE STUDY OF REVITALIZATION EFFORTS}

Local politicians and planners in the city of Portland expressed great concern in the 1950 s over the visible evidence of decline in some of the city's neighborhoods. There was also concern over the rapid expansion of commercial and industrial activities amid what were once regarded as healthy residential neighborhoods. These concerns prompted the undertaking of positive steps to combat the forces of time and change through neighborhood revitalization (PCPC, 1965)

The first step toward this goal was the implementation of the Thurman/Vaughn Redevelopment Project in Northwest Portland in 1952. The project involved the conversion of a 40-block neighborhood into a residential and industrial complex and the demolition of 500 substandard housing units. But by and large, the project failed because there was no efficient planning agency at the time, and there was also no political support for the project (Abbott, 1983).

The failure of the Thurman/Vaughn Project provided the basis for the creation of a planning agency. In 1958 the PDC was formed. The new agency was given the task and 
responsibility by the Portland City Council to revitalize the city's core and the surrounding neighborhoods (PDC, 1978).

The role of the $\mathrm{PDC}$ in revitalizing the city of Portland, a task that is contingent upon cooperation with the City Council, city bureaus and departments, neighborhood organizations and participation of the private sector, is now discussed.

\section{THE PDC AND REVITALIZATION}

The city of Portland through the PDC became one of the first cities in the country to revitalize its blighted neighborhoods. The South Auditorium Neighborhood became the first urban renewal project undertaken by the PDC. The South Auditorium Neighborhood during the late 1950 s was comprised mostly of aging Italians and European Jews because most of the younger elements of these groups had left the neighborhood (Portland Bureau of Planning, 1977).

The project itself involved the massive clearance of a 54-block area in the city's downtown, the demolition of 445 structures, and the relocation of 336 families and 289 business enterprises (Portland Bureau of Planning, 1977). What was considered a blighted neighborhood was, by 1963 , transformed into the present Portland Center--a lively neighborhood of high-rise apartments, commercial activities, office buildings and public facilities flanked on the west 
side by Portland State University (PSU). The vast majority of the South Auditorium's open spaces, such as Forecourt Fountain, Pettygrove Park, Lovejoy Fountain and the Civic Auditorium, are a testimony of the city's architectural work (Portland Bureau of Planning, 1977).

The project has enhanced the city's economic viability. Before the project started, property owners in the area contributed about $\$ 143,000$ every year in property taxes to pay for services provided in the area by the City, but that was not enough. At the completion of the project, the taxes generated from the project repaid $\$ 5$ million in neighborhood revitalization bonds, at the same time adding $\$ 2.9$ million every year to the revenue of the community (PDC, 1978).

The revitalization of the South Auditorium Neighborhood was not the only early urban renewal project undertaken by the PDC. Other early renewal projects were the Albina Neighborhood Improvement Program, Portland State Urban Renewal Program and Emmanuel Hospital Urban Renewal Program (PDC, 1978).

The Albina Project was a $\$ 2.3$ million program that involved the rehabilitation of 556 housing units in the area, improvement of streets and street 1 ighting, and the planting of trees. In short, the program was a strong commitment by the City to preserve a deteriorated ethnic neighborhood in North Portland (PDC, 1978). 
The urban renewal project of PSU was started in 1965 to complement the South Auditorium Neighborhood. The program, completed since 1975 with the cooperation of the Oregon State Board of Higher Education, was undertaken to enhance the expansion of the university as well as to create a more unified campus within an urban environment. Funding for the program was provided in part by the federal government and in part by the State Board of Higher Education at a cost of $\$ 16.7$ million. The PDC was responsible for the acquisition of 1 and for the project, site improvement and relocation, and architectural design. The South Park Blocks that run through the campus were also redesigned as part of the PSU urban renewal project.

One of the primary objectives of the South Park Blocks Urban Renewal Plan, which became effective in 1985, was to increase middle-income rental housing supply in the southwest area of the downtown. The projects within the South Park Blocks Urban Renewal Plan include: University Park, which has 125 one- and two-bedroom units on the block bounded by Market and Clay Streets, Park Avenue and Broadway. The University Park Project was completed in 1987. The South Park Square, another aspect of the plan, has 191 studio, one- and two-bedroom units on a block bounded by Market and $\mathrm{Clay}$ Streets, Park and Tenth Avenues, and was completed in 1988. Gallery Park, with 31 one- and twobedroom units on a quarter block bounded by Clay and 
Columbia Streets, Park and Broadway, was completed in 1989. Finally, Park Place, which comprised of 23 studio and onebedroom units on an infill site along Park Avenue and located between Clay and Columbia Streets, was completed in 1991 (PDC, 1990).

The South Block Renewal Project was followed by the North Park Blocks Renovation Project. The purpose of this program was to renovate the blocks to a standard that is comparable to that of the South Park Blocks. It was hoped that by so doing private investment and redevelopment in the surrounding area as a whole would be encouraged. The role of PDC in the redevelopment of the park was to provide funds for as well as to coordinate the park blocks' renovation plan with assistance from the Bureau of Parks and Recreation (PDC, 1990).

Another urban renewal project was the Emmanuel Hospital Urban Renewal Program. The program, completed since the mid-1970s, involved the expansion of the hospital which was located in a neighborhood characterized by deteriorated housing and blight. The total funds for the program amounted to $\$ 6.7 \mathrm{million}$, and two-thirds of the funds were provided by HUD; the remaining one-third was comprised of hospital funds. The Housing Authority of Portland (HAP) also added 110 housing units for low-income elderly residents in the area (PDC, 1978). 
But by and large, in the early neighborhood revitalization programs the PDC neither solicited the participation in its activities by the ordinary citizens nor did it show any accountability for its action of massive slum clearance. A good number of citizens started perceiving the PDC as a threat to efficient planning. There was also much concern among ordinary citizens that the PDC's planning programs might result in the destruction of the inner-city neighborhoods. These concerns became even greater after the failure of the Vaughn Street Redevelopment Project caused by the lack of political support and the failure of the planners to make a strong comitment to revitalization (Abbott, 1983).

The concern of the citizens over the arbitrary planning decisions undertaken by the PDC, coupled with their disenchantment for not having a say in the planning process, came to a head when the administration of Mayor Goldschmidt began to target specific neighborhoods for revitalization. Three such areas were the Corbett, Terwilliger and Lair Hill neighborhoods .

Lair Hill and Corbett were once part of an extensive area that was part of the South Auditorium Renewal Program. The Lair Hill-Corbett neighborhood was initially the home of European immigrants and had a large proportion of nonresident property owners. But as the forces of time and change took their toll, the original residents began to move out and sell their property to non-residents. The housing 
stock deteriorated so much over time that revitalization became either impossible or, in some cases, more expensive (Corbett-Terwilliger-Lair Hill Planning Committee, 1977). Comparatively, Terwilliger was more stable than either Corbett or Lair Hill. The percentage of resident homeownership was much higher than in the other two neighborhoods. Above all, it experienced less traffic flow than Corbett (Corbett-Terwilliger-Lair Hill Planning Committee, 1977).

The PDC revitalization package involved the tearing down of 143 structures at the risk of displacing 20 businesses, 45 household members, and 95 single persons; the provision of a road corridor to reduce the congestion of traffic in the Corbett area; and the construction of subsidized housing for faculty and students from PSU and Oregon Health Sciences University (Abbott, 1983).

Once again the PDC failed to include citizen participation in the implementation of this program. The PDC action resulted in the formation of an advocacy group by various interest groups from the three neighborhoods to protest any future revitalization activity in their neighborhoods.

Neighborhood Associations and Revitalization

The residents of the Corbett-Terwilliger-Lair Hill neighborhoods finally got what they wanted when the John's Landing Development Program and the Macadam Avenue Improvement Program were proposed by the PDC in 1974. These 
programs were an alternative to the earlier Corbett-

Terwilliger-Lair Hill project. It involved the construction of new housing units, stores, office buildings and a road.

The residents of the three neighborhoods immediately formed the Hill Park Association--the first neighborhood association formed in the mid-1960s to protest the PDC revitalization plan (Corbett-Terwilliger-Lair Hill Planning Committee, 1974).

The action of these neighborhoods even went beyond protest. They formed a neighborhood council as well as a planning committee that prepared a plan with the help of professional planners. The plan presented to the PDC by the neighborhood planning committee demanded that Lair Hill remain a predominantly residential neighborhood. In 1977 the Portland City Council declared Lair Hill as one of the first historic preservation neighborhoods in the city of Portland (Abbott, 1983).

The creation of the federal Model Cities Program in 1966 enabled Portland neighborhoods to establish their own neighborhood associations which were advocacy groups that exerted pressure on the PDC on the type and nature of revitalization project to be undertaken. For example, when the Corbett-Terwilliger-Lair Hill residents in Southwest Portland formed their own neighborhood associations, the other neighborhood residents in the remaining four districts of the city did the same. Neighborhood revitalization in 
the city undertaken jointly by the PDC and the neighborhood organizations, with funds coming from the federal government and private investors, reflected the requirements of the Model Cities Program.

Neighborhood Associations and the Model Cities Program

In response to the Model Cities Program the various interest groups in Northeast Portland created the Northeast Community Development Corporation, an advocacy group that brought pressure to bear on the PDC to allow the group to participate in the area's revitalization activity. One such area that was targeted for redevelopment in accordance with the Model Cities Program was the Eliot Neighborhood, located south of Fremont Street and west of Martin Luther King, Jr. Boulevard (PCPC, 1969).

The Eliot Neighborhood was among five Northeast Portland neighborhoods that the PDC targeted in 1967 for its Neighborhood Development Program (NDP). Revitalization activity under the NDP included such activities as the rehabilitation of housing; the improvement and provision of streets, street lighting, sidewalks and curbs; and the promotion and expansion of schools, recreation facilities and parks (PDC, 1978).

The plan for the Eliot Neighborhood involved providing housing in the neighborhood. The plan has been on the planning agenda of the City since 1966. But by the early 
1970 s the Eliot Neighborhood revitalization program was suspended and replaced by the Emmanuel Hospital Urban Renewal Project. The Eliot Neighborhood project was resumed and completed by the HAP, which bought the site from the PDC (PDC, 1978).

In Southeast Portland various interest groups from the Brooklyn, Buckman, Sunnyside, Sellwood and Westmoreland neighborhoods created the Portland Action Committees Together (PACT) to enhance the redevelopment of their neighborhoods in accordance with the Model Cities Program. But by the time PACT was formed, HUD had already decided to limit the scope of its funding program. It was not until 1974 when several interest groups came back together to form the Inner Southeast Coalition, which drew a plan acceptable to the PDC, that redevelopment funds were disbursed by HUD (Abbott, 1983).

Another offshoot of the Model Cities Program of the 1960 s was the creation of the Northwest District Neighborhood Association. The group in 1969 opposed a PDC neighborhood redevelopment plan, requested by Good Samaritan Hospital and Consolidated Freightways, on the grounds that the urban redevelopment project did not have a comprehensive plan. Instead, committee members from the Northwest Neighborhood Association, working together with the staff of the Planning Bureau, prepared a comprehensive plan for the area that was adopted and approved in 1975 (Abbott, 1983). 
The passage of the federal HCDA in 1974 not only terminated the NDP vis-a-vis the Model Cities Program of the mid1960 s, but it also extended revitalization activities to several Portland neighborhoods through the Block Grant program (PDC, 1978).

The impact of the Housing and Community Development (HCD) program in some Portland neighborhoods is now discussed.

The HCD Program and Neighborhood Redevelopment

HCD Block Grant funding has been a valuable resource for neighborhood redevelopment programs undertaken by neighborhood groups as well as the PDC. For example, the PDC housing rehabilitation program received funding from HCD Block Grants, other federal grants and the private sector. Between 1975 and 1978 the PDC rehabilitated 3,500 homes and provided $\$ 14.5$ million in loans to property owners (PDC, 1975 ).

In North Portland the PDC has a neighborhood office in St. Johns that is readily accessible to the community. Between 1975 and 1978, 275 homes were rehabilitated at a low-interest loan cost of approximately $\$ 1.6$ million. A major comprehensive and commercial revitalization project was implemented by the PDC at an estimated cost of $\$ 2.5$ million. The project, completed in the 1980s, involved the creation of a new traffic system, the rehabilitation of 
the city hall and fire station, the construction of tennis courts, and the improvement of the community center (PDC, 1975).

Since the termination of the Model Cities Program, Northeast Portland over the years has seen considerable home rehabilitation activity and street and park improvement. One such community development program was the improvement of the Dawson Park at a cost of $\$ 118,000$. The project was jointly administered by the neighborhood itself and the PDC. Other community development programs sponsored by the PDC in the late 1970s include the following: providing street lighting in the neighborhoods of Irvington and Boise-Humboldt, improving the Lillis Albina Park, planting about 200 trees in the Eliot area, and constructing a street in the King-Vernon-Sabin neighborhoods (PDC, 1975).

A more recent and ongoing program in Northeast Portland is the federally funded Nehemiah Housing Opportunity Grant program for the improvement of housing. The program is part of a comprehensive plan to reclaim and revitalize declining neighborhoods in the city of Portland by providing opportunities for homeownership for low- and moderate-income families (PDC, 1990).

The Northeast Community Development Corporation (NECDC) was awarded $\$ 3.75 \mathrm{mill}$ ion in 1989 to reclaim and develop 250 low- and moderate-income single-family housing units. Private, public and other charitable organizations have already 
made a commitment to NECDC to reclaim vacant lots as well as vacant and abandoned housing units in dilapidated neighborhoods in Northeast Portland. The price tag for the homes derived from this program will be $\$ 45,000$. Home buyers will be allowed to make a down payment of $\$ 1,000$ and receive a first mortgage loan of $\$ 30,000$ through the OHA. The remaining $\$ 15,000$ will be provided from the Nehemiah funding. Monthly mortgage payments are estimated at \$350 (PDC, 1990).

Another recently completed $H C D$ program is the Northeast HCD Neighborhood Improvement Project. It was a three-year project administered under contract with the NECDC. The program involved acquiring and renovating single-family units in the Eliot, Boise, King, Sabin, Vernon, and Humboldt neighborhoods (PDC, 1990).

A PDC-sponsored and recently completed urban renewal program is the Oregon Convention Center in Northeast Port1and. In 1988 the PDC prepared a plan for the project in cooperation with the Bureau of Planning and the Portland Office of Transportation. The plan, adopted in 1989, called for a comprehensive area plan that addressed such issues as transportation, land use, economic development and urban design in order to make the area attractive to visitors of the Convention Center (PDC, 1990).

The HCD program has also benefited neighborhoods in Southeast Portland. At the inception of the program the PDC 
established a neighborhood office that administered home rehabilitation loans and improved several Southeast neighborhood parks. One such improvement involved Colonel Summers Park in the Buckman Neighborhood at a cost of $\$ 165,000$. A $\$ 200,000$ grant was used for the renovation of the Brooklyn, Oregon, Johnson Creek, Sellwood, Westmoreland, and Sewall parks in Southeast Portland. Other neighborhood improvement activities through the HCD program include $\$ 200,000$ for street construction, $\$ 40,000$ for the installation of traffic signals and $\$ 18,000$ for the planting of trees (PDC, 1978).

In Northwest Portland the improvement of HCD neighborhoods was combined with the housing and rehabilitation loan program. The PDC carried out the improvement of Couch, Macleay, and Wallace Park. The PDC also authorized the Thurman/Vaughn area project. Other participants in this project were the City of Portland, the State of Oregon, the Northwest District Association and the Northwest Industrial Neighborhood Association (PDC, 1975).

The plan had three objectives: (1) to stop the continuing residential and commercial decline in the area; (2) to carefully plan for and implement the redevelopment of the area; and (3) to maintain and increase the supply of housing in the area (PDC, 1975).

The feasibility study found that as much as $40 \%$ of the housing units in the area were built before 1910 and most of 
these units were poorly constructed and lacked maintenance and repairs. In addition, the area had a high proportion of low-income residents, high unemployment rates, and many single-person households (PDC, 1975). The program, adopted in 1977, was completed in the 1980s.

Since the inception of the HCD program in the early 1970s, the PDC has administered over 12,000 low-interest and deferred-payment loans. Since the 1980s, the PDC has inspired the rehabilitation of over 20,000 housing units that were badly in need of repairs (PDC, 1989).

The reclaiming of vacant homes through homesteading was also a preoccupation of the PDC. The homestead program gave the opportunity to those who could not afford a home to own one if they agreed to renovate it according to building code standards. Since 1980 the PDC has utilized federal funds to acquire over 130 vacant homes that they have made available to homesteaders. Low-interest loans provided through the PDC are used by the occupants to make their own repairs. In order to enhance the stability of the neighborhood, the homesteaders agree to stay in the renovated home for at least five years (PDC, 1989).

Aside from the neighborhood revitalization activities that have been discussed so far, downtown Portland also received the attention of planning officials. Before the adoption of the Downtown Plan in 1972 that called for maintaining the area as the major regional, employment, cultural 
and business center, the downtown area was declining. The pattern of decline was described by the vice president of the Portland Chamber of Commerce and developer of $01 \mathrm{~d}$ Galleria and 01d Town, and other commercial restoration projects, as follows:

As . . . suburban shopping centers thrived businesses became discouraged with the declining economic situation of downtown, and many closed shop. This downward trend continued and worsened when the development plan for the city instituted with the Clean Air Act Program and the parking lid was announced. Retailers who were both sharing risks the City was taking and trying to compete with suburbia and its shopping centers, thought that doomsday had finally come to down town.

The trend was for downtown businesses to get out of the area and move to newly developed suburban shopping malls where business was booming. (U.S. Department of Transportation, 1980, p. 48)

In order to wrestle with the problem described above, the City decided to implement the 1972 Downtown Plan as updated by council ordinance. The plan called for the City to assist in promoting retail, lodging, office, residential, and cultural opportunities in the CBD (Tri-County Metropolitan Transportation District, 1975). The City undertook to develop a Transit Mall in downtown Portland defined as

streets reserved for the use (public) transit vehicles and pedestrians: They are generally located at the intersection of several transit routes in downtown near heavy pedestrian activity, such as retail stores, restaurants, and office buildings, and may include shelters, benches, plants, and route and schedule information displays. (U.S. Department of Transportation, 1980, p. 48) 
The Mal1 was designed and constructed by the Tri-County Metropolitan Transportation District of Oregon. The cost of the project was estimated at $\$ 15$ million, with the federal government providing $80 \%$ of the money (Tri-County Metropolitan Transportation District, 1975). Work on the project began in 1975 and by 1977 the Mall was opened to travel by bus .

Besides the Transit Mall, which has become a "national showcase," other developments occurred in the downtown area in the 1970s and 1980s. These were in the areas of housing, retailing, office construction, hotels, parking structures, and cultural activities (such as the Performing ArtsCenter). The total cost of the Arts-Center was $\$ 25$ million, with the voters of Portland authorizing $\$ 19$ million in bonds and the private sector providing $\$ 6 \mathrm{million.} \mathrm{No}$ wonder Portland was described in the following words:

Often called the "City of Parks and Fountains," Portland's downtown has grown up in a setting of parks, fountains, outdoor sculptures and other artworks, and landscaped pedestrian ways. The famed Ira Keller Fountain, located adjacent to the Civic Auditorium, is a national landmark. Lovejoy Fountain, Pettygrove Park, O'Bryant Square, the Park Blocks and the newly constructed Waterfront Park all provide a place to lunch, sit in the sun, or simply take a quiet moment out from their busy workday lives. (PDC, 1981, p. 14)

An innovative program conceived by the PDC in the 1980s for the downtown area is the Downtown Housing Preservation Program (DHPP), meant to increase the supply of low-income housing in compliance with the Downtown Housing Policy. 
Four agencies--PDC, HAP, Central City Concern, and Portland Metropolitan Chamber of Commerce--joined together to sponsor the DHPP. The goal of the program is to develop 500 new housing units by 1991 for the homeless and people with special needs (PDC, 1990).

According to an agreement by the four sponsors of the program, the PDC finances and develops the projects, HAP provides federal rent subsidies for the operation of the building, Central City Concern owns and manages most of the buildings, and the Chamber of Commerce solicits funds to tenants for social services (PDC, 1990).

By 1990 two projects--the 96-unit Foster Apartments and the Henry Building, a vacant, historic office building renovated to accommodate 153 units for downtown service workers--were completed. Two other projects--the Athens Hotel, a 95-unit project, and the 62-unit Shoreline Hote1-are still under development (PDC, 1990).

In summary, the increased concern over the city's deteriorating neighborhoods among Portlanders suggests that the city is a dynamic system of political, social, and economic forces which, in one way or the other, are interrelated. Government as well as citizens became increasingly more sensitive to the interrelationships between physical development and social issues, between economic growth and changes to the environment, and between governmental decisions and the quality of life. The result of this 
awareness was the creation of PDC in 1958 to undertake the revitalization of the city's core and surrounding neighborhoods. In pursuing this goal, the PDC established policies to govern the future growth of the city and to effect neighborhood change. But neighborhood change has, in some instances, left its imprint on the city landscape by creating upscale neighborhoods, in some instances at the expense of the poor, and this has been the subject of debate among social researchers.

The study area believed to represent the inner-city neighborhoods within the city of Portland is briefly described below.

\section{THE STUDY AREA}

The study area as delimited (see Figure 1) is comprised of 117 census tracts representing the area considered as the inner-city neighborhoods of the city of Portland (Office of Planning and Development, 1981). According to this information there are five major districts or neighborhoods in the entire city itself. The census tracts representing the research area in this study were selected from the inner Northwest, Southeast, Southwest, and Northeast districts, respectively. The latter district includes census tracts representing some areas in North Portland considered pertinent to the study. The estimated population of the census tracts in the research area in 1970 was 409,656 . By 1980 


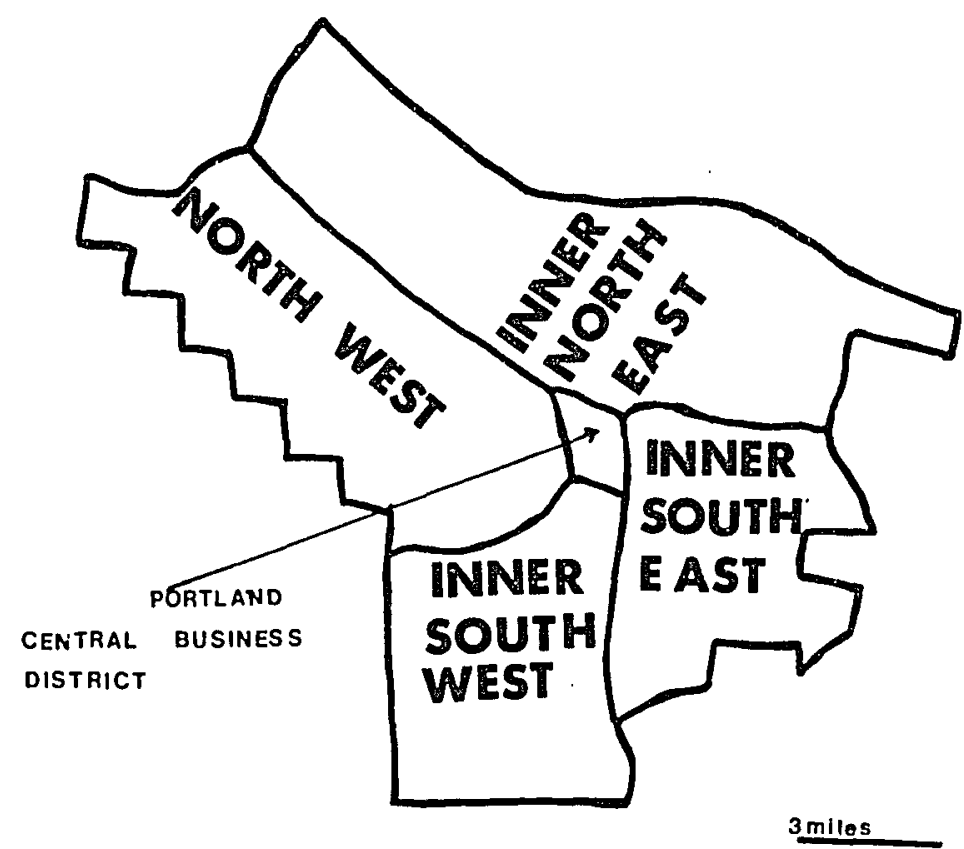

$\frac{\text { Figure 1. Study area: Inner-city neighborhoods }}{\text { of Portland. }}$

the estimated population of the same area had dropped to approximately 386,323 inhabitants (Office of Planning and Development, 1981).

The Northwest area, which includes Burnside and some parts of the Northwest industrial area, is located on the west side of the Willamette River and north of Burnside Avenue. The north end of the area is comprised of cheap hotels, "flop" houses, older businesses, taverns, and specialty shops (Office of Planning and Development, 1970). The area was identified as having a high proportion of minority groups, elderly, and poorly educated residents 
(Columbia Region Association of Governments [CRAG], 1978c, 1978d).

The inner Southeast is comprised of such neighborhoods as Brookyn, Buckman, Hosford-Abernethy, Kerns, Richmond, Sellwood-Moreland, and Sunnyside. The area is located south of the Banfield Freeway and east of the Willamette River and is characterized by older housing units. The area residents are predominantly blue-collar workers (CRAG, 1978a, 1978f).

The inner Southwest is located on the west side of the Willamette River and south of Burnside Avenue. Some of the neighborhoods include Healy Heights, Homestead, Lair Hill, Goose Hollow and Corbett-Terwilliger. The downtown, with only a limited number of single-family homes but many condominiums, is included in this area. The CorbettTerwilliger-Lair Hill area, located close to the downtown, is characterized by older housing units, lower income households and home values, more rental units, and a high percentage of minorities (CRAG, 1978b, 1978f).

The inner North Portland area lies west of Williams Avenue. Some of the neighborhoods include Arbor Lodge Overlook, Kenton, Portsmouth, and St. Johns. The area has the smallest proportion of residents with at least a year of college education as well as the highest proportion of residents with less than high school education. The area is also characterized by a higher proportion of black and elderly residents (CRAG, 1978b). 
The inner Northeast neighborhoods are located north of the Banfield Freeway and east of Williams Avenue. A large proportion of the city's black residents is concentrated in the Humboldt, Piedmont, Woodlawn, King-Vernon-Sabin, El iot and Boise neighborhoods. The area has a low ratio of owneroccupied and renter-occupied housing units.

The revitalization of declining neighborhoods as reflected in the activities of the PDC has long begun. But as its pace intensified in the 1970s and 1980 s nationwide, so has its literature burgeoned, which is now discussed. 
CHAPTER III

\section{HISTORICAL BACKGROUND AND LITERATURE REVIEW}

The invasion-succession concept of Burgess (1925) and his associates of the "Chicago School," often used to describe changes in the urban environment and shifts in population, has never escaped challenge. In retrospect, their theory did not include the reverse of the invasionsuccession process (Lee and Mergenhagen, 1984). The challenge to the "classical ecological" theory associated with Burgess has been either an expansion or modification of this ecological theory (Birch, 1971; Hoover and Vernon, 1959). The process by which older neighborhoods in the core areas of cities were gradually becoming sites for housing renovation activity and the resettlement of middle- and upperincome residents became known as neighborhood revitalization (Clay, 1979; Gale, 1980; Laska and Spain, 1979).

This phenomenon which began in the mid-1970s (London, 1980) became of interest not only to urban scholars but to other civic groups such as realtors, lenders, downtown businesspeople, and local government officials, who interpreted the trend as symbolizing the salvaging of the declining areas in the cores of metropolitan areas (Lee and Mergenhagen, 1984). Standing in the way of these advocates 
are the poor, the elderly, blacks and other groups concerned about the negative economic, political, and residential displacement consequences of the trend (Lee and Mergenhagen, 1984). By and large, the argument over the positive and negative effects of neighborhood revitalization has continued to the present time.

It is amidst this debate that an inexhaustive social science literature has emerged, the bulk of which is based upon the formulation of neighborhood change models (National Urban Coalition, 1978; Clay, 1979; Gale, 1980; London, 1980). These models employed different approaches to the subject. For example, while some empirical studies focus on the displacement issue or segregation caused by the trend, other studies focus on assessing the factors explaining its occurrence. Despite the different approaches, all seem to reach the consensus that revitalizing neighborhoods go through stages of change.

Hoover and Vernon (1959) and Birch (1971), associated with the stage theory, identified five stages of neighborhood change. The first stage is marked by the construction of single-family homes and low population densities. The second stage is marked by the construction of more singlefamily homes as population increases. The third stage is the period when the housing units begin to run down. The fourth is marked by the creation of slums as a result of intensified use of the housing units. The fifth and final 
stage is the period characterized by the replacement of rundown housing units with multi-family housing units. Spatial location theorists suggest that as high-status households move from the inner-city neighborhoods to reside in the suburbs to consume more space, low-income households move into the housing units left behind by the affluent. But the literature posits that this trend is either slowing down or reversing itself. That is to say, high-status residents are, to a certain extent, opting to reside in the inner-city neighborhoods that are undergoing revitalization (Smith, 1979). The households moving into such neighborhoods are young white singles and childless couples employed in professional and managerial jobs (Lee et al., 1985).

Revitalization theorists also strongly believe that the lifestyles of these young high-status residents have changed with time. According to Smith (1979), changes such as delayed marriages, high divorce rates, the desire to have smaller families, increasing numbers of single and married women in the job market, and the increasing numbers of working married couples have tended to influence young homebuyers and renters to opt for "a new dream defined in urban rather than suburban terms" (p. 71).

A justification for these changes in the lifestyles of incumbent inner-city residents was provided by Bell (1968), who asserted that households are characterized by "fami1ism," "careerism," and "consumerism." The household, on 
one hand, selecting to live in the inner city, was more career oriented as well as consumer oriented. On the other hand, the household living in the suburb was the familyoriented type who wanted to marry early and raise children. Bell (1968) concluded that the number of high-status residents in the inner city may be attributed to certain demographic changes.

According to the U.S. Bureau of the Census (1980) the population of the United States between 1970 and 1980 increased by $11 \%$, while the number of households increased by over $24 \%$ as a result of the continuing decline in the size of the average household and the high divorce rates. Since 1960 both single-person households and households comprised of unrelated individuals have also increased (U.S. Bureau of the Census, 1980). The increase in single-person households, combined with the decreasing birth rates, has resulted in the shrinking of the average American household and greater demand for smaller housing units (U.S. Bureau of the Census, 1980). Furthermore, the percent of working women over sixteen years old was $38 \%$ in 1960 , but by 1980 this figure increased to $52 \%$ (U.S. Bureau of the Census, 1980). Between 1970 and 1980 the proportion of young single-person households increased in the inner cities as well as in the work force (Sternlieb and Hughes, 1980). Neighborhood revitalization, or gentrification as it is also known, was made popular in the mid-1970s by the media 
as a result of private market reinvestment in housing in the declining urban cores of cities across the country (Laska and Spain, 1979; Lee et al., 1985). The popularity of the neighborhood revitalization trend aroused the interest of researchers and agencies to further investigate the phenomenon (Lee et a1., 1985). But by and large, the literature is considered by some observers to be deficient in evaluating the structural impacts generated by neighborhood revitalization due to the recent nature of the trend and the unavailability of data to assess changes in cities over time (Lee et al., 1985; Schill and Nathan, 1983).

Despite these problems a variety of approaches or explanations are used by researchers to investigate the gentrification phenomenon. For example, some researchers see in the process a respite to the end of the urban housing crisis. Others see it in light of the plight of the dislocated or displaced residents. While others see the gentrification process from an entirely economic perspective, some others still see it in light of changing demographic factors (London, 1984) .

The literature review further shows that five major approaches to the gentrification process can be distinguished. These include a sociocultural, political-economic, demographic-ecological, community networks, and the social movement approach. Since the variables often used by researchers tend to overlap with each other in some 
instances, therefore, no single approach can be said to be exclusively independent of the other (London, 1984).

With this as a backdrop, considered to provide a more focused theoretical framework for predicting neighborhood revitalization in the city of Portland, the relevant studies for this research are now reviewed. These studies, as the reader will find out, revolve around monitoring the factors causing neighborhood change, the areas or neighborhoods that are revitalizing, and the characteristics of the incumbent households as well as neighborhood or housing characteristics. In light of these approaches the studies in this review fall under two explanations reflectiang the needs and estimates of this research. The explanations now discussed below include an ecological approach and the changing age structure approach.

\section{ECOLOGICAL APPROACH TO NEIGHBORHOOD REVITALIZATION}

The bulk of the studies in this review fall under this approach, which includes such parameters as population characteristics, social organization, technology, and environmental conditions.

Black (1975) conducted a mail and telephone survey of 260 cities in the United States with a population of over 50,000 inhabitants. Evidence of "private market" renovation of housing was observed in the inner-city areas of half of those cities. Many cities since the 1970 s have also begun 
to experience some economic changes that may have contributed to neighborhood revitalization (Black, 1975). The most dramatic development in the service industries of some central cities occurred in the corporate and financial sectors, where corporate and bank officials have begun to appreciate inner-city business location because of the economic benefits and face-to-face contacts (Black, 1975). Between 1970 and 1978 office space accounted for $43 \%$ of the revitalizing areas in the core areas of twenty large American cities (Black, 1975).

Leven et al. (1976), in one of the most outstanding studies on St. Louis, asserted in an arbitrage model of neighborhood change and decline that black in-migration into a neighborhood signals a change in its housing occupancy. That is to say, lower-income residents were succeeding higher-income residents. Put in another way, household utility has a direct positive relationship on neighborhood income and negative effect on the proportion of the nonwhite population. The arbitrage model states:

As the boundary moves into the erstwhile rich neighborhoods, housing formerly commanding a premium for its location near the high-income families no longer elicits that extra value; the income associated with the property declines, placing downward pressure on property values in the immediate area. Although it is true that there is no necessity for property to deteriorate with age, if income falls there will be fewer resources available for normal repairs. Maintenance is reduced because other property costs, such as taxes and mortgage payments, remain fixed. . Declining maintenance inexorably leads to deterioration in the housing quality. 
The end of this cycle is abandoned housing. The boundary is pushed too far, driving the price of housing within the exclusively poor neighborhood so low that it is no longer able to meet the building code standards or such fixed costs as taxes and mortgage payments. The least expensive solution then is abandonment of the property. (Leven et a1., 1976, PP. 39-40)

Little (1976) used a hedonic pricing index to estimate neighborhood filtering against "bundles" of housing characteristics that included structural, neighborhood, and local public sector characteristics in a sample of thirty-two census tracts in the city of St. Louis. Neighborhood characteristics, especially income class, significantly influenced residential preference rankings. The study further revealed that residential changes in the short run were significantly affected by racial change.

Lipton (1977) studied twenty large cities across the country to determine if the core areas of those cities showed any significant increase in high-status neighborhoods. Statistically significant evidence of neighborhood revitalization activity, as measured by the rapid increase in administrative or white-collar jobs, was observed in half the sample.

James (1977) used data derived from the Census Bureau survey of residential alterations and maintenance to estimate inner-city housing market reinvestment. Evidence of increased revitalization activity--based on changes in home values, rents, and home improvement expenditure--was observed in the sample. 
The National Urban Coalition (1978), in a forty-four city survey of realtors, government officials, and local informants knowledgeable on revitalization activity, made the following observation: Nearly $50 \%$ of the neighborhoods in the survey sample that had a significant minority population before the beginning of revitalization began to experience a decline in their minority numbers at the end of the revitalization process. The decline in the minority population in the study area was attributed to gentrification.

Clay (1978) found that $50 \%$ of a total of 105 revitalizing neighborhoods examined in different cities were located within one mile from the central business districts and exhibited one or more of the following neighborhood qualities that enhance revitalization: high elevation, like Seattle's Capitol Hill and Cincinnati's Mount Adams located on hillsides; proximity to coastal, river or lake areas, such as Philadelphia's Queen Village, Boston's North End, and Portland's Front Avenue located on or near waterfronts; and public parks and historic landmarks. He further revealed that $75 \%$ of the neighborhoods studied had buildings that were over 75 years old--a finding consistent with the hypothesis that housing quality, especially its architecture, enhanced revitalization. Areas that have experienced revitalization, the study further revealed, had either single-family detached housing units or town houses. 
Clay (1979) conducted a similar survey of 105 neighborhoods from thirty of the largest cities in the country, and his findings were even much stronger. About forty-eight neighborhoods, representing $46 \%$, experienced neighborhood change as a result of "incumbent upgrading," while the remaining neighborhoods, representing 54\%, experienced gentrification.

Laska and Spain (1979) documented a profile of renovators in New Orleans, a southern city believed to have experienced extensive inner-city revitalization, to test the hypothesis that the renovation of housing in the inner city by both the middle- and upper-income residents may contribute to neighborhood revitalization. The profile included the socioeconomic characteristics of the residents and other neighborhood factors.

The major factor 1 isted by respondents in that study for selecting residence in the inner city was neighborhood attractiveness. The second factor listed by respondents was architectural design. About $9 \%$ of the respondents listed nearness to work (Black, 1975) as a factor, compared to $30 \%$ of the respondents listing neighborhood attractiveness and $24 \%$ of the respondents 1 isting architectural design. Additionally, $38 \%$ of the respondents (including high-income professionals with families) considered suburban neighborhoods to be unattractive. Another $27 \%$ of the sample (including college-educated middle-income residents and 
young couples) considered suburban housing units to be unattractive for their tastes. The expression of dissatisfaction by the respondents with suburban neighborhoods may suggest that the renovators' traditional values negate what Warner (1962) described as "the search for the rural ideal," which earlier led to the flight of the affluent from the inner-city neighborhoods into the suburbs.

The findings by Laska and Spain (1979) seem to further suggest a subtle interest and desire by college-educated middle-class residents to opt for the inner-city areas which were considered unattractive during the urban renewal activity of the 1950s and 1960s. Since homeownership was considered by some residents as a means of providing a hedge against inflation (Schill and Nathan, 1983), the findings also underscore the long-term desire by American households to buy their own homes in the inner-city at fairly affordable prices as opposed to the more expensive suburban homes. Although the proportion of American households owning their own homes increased from $55 \%$ in the 1950 s to $65 \%$ in the early 1970s (HUD, 1979), since the 1980s the homeownership proportion has continued to decline for reasons which may have political and economic underpinnings.

Kern (1979) investigated the incomes and household composition of residents in three areas of New York that included central Manhattan and its inner ring, the suburbanlike outer area of New York, and the actual suburbs of New 
York. It was observed that unrelated individuals living together were more likely to live in central Manhattan. In comparing high-income residents of central Manhattan with high-income residents of its suburbs by census tract, it was also found that different household types lived in the central city. For example, single-person households, households comprised of married couples with no children under eighteen years, and households that included adults with at least some years of college education lived together in the same neighborhoods. Kern (1979) concluded that the two factors accounting for the selection of intra-urban residential location by young, educated, single and married households were nearness to workplace (Black, 1975; Lipton, 1977) and consumer preference.

Sternlieb and Hughes (1979), in a study of demographic trends in a sample of selected metropolitan areas to evaluate the speculation of a rapid resurgence of an urban middle class in revitalized areas, postulated the following: The demand for central city transportation was a function of its resident population--especially its reflection in the demand for housing--of non-resident workers, as well as nonresidents attracted to the inner city for the non-job related facilities it offers. The study revealed that a few urban resettlement activities were observed in some central city neighborhoods with economics catering to young 
white-collar workers who had been lured into such areas by a "unique" housing stock amenable to efforts of renovation. These two elements were influenced by strong transportation modes. The study, however, warned against the contention of American cities experiencing a complete back-to-the-city trend because of a few isolated revitalization efforts in the following statement:

It is difficult not to acknowledge the harsh reality that a new town may be evolving intown-the gentrified neighborhood--but at most it is relatively slender, much too limited to support and bring back with it the aging entities that we call central cities. (Sternlieb and Hughes, 1979, p. 634)

Spain (1980) examined how low-income black households are being gentrified by higher income white households in a study that utilized data on population shifts as a proxy for reinvestment. It was found that between 1973 and 1976 the proportion of the housing units in which gentrification had occurred was twice the proportion of housing units in which a similar process had occurred between 1967 and 1971.

Black (1980), in a mail and telephone study of a sample of cities with a population of 150,000 inhabitants each, observed that revitalization as defined by the private market renovation of housing, had spread to $86 \%$ of the sample.

De Giovanni (1983) documented the magnitude and extent of neighborhood revitalization initiated by private market activity and identified the effects of such activity on the 
housing stock as well as on the neighborhood residents. The sample consisted of one non-revitalizing and two revitalizing neighborhoods selected from the cities of San Francisco, Denver, Atlanta, Cincinnati, Hartford, and Philadelphia. The attributes used to monitor neighborhood changes over time included sales volume, sales prices, speculative sales, the conversion of properties from rental status to owner-occupancy, and the socioeconomic composition of the neighborhood. The findings suggested that the changes in revitalizing areas were found to be discontinuous and abrupt rather than following an orderly pattern or sequence as some of the stage models of revitalization had suggested. Much of the fluctuation in private market activity, as well as the changes observed in the indicators, were found to reflect the effect of the national recession in housing of the mid-1970s.

Lee and Mergenhagen (1984) used block-level as well as tract-leve 1 data to monitor neighborhood changes in a sample of five Nashville neighborhoods after the occurrence of revitalization and the reversals of prior trends. The findings revealed evidence of demographic and housing market changes in the study area. The changes represented "continuations" of the revitalization process of the mid-1970s rather than "turnarounds" or "reversals" of patterns that were reminiscent of the 1960 s. 
Lee et al. (1985) compared revitalizing and nonrevitalizing neighborhoods of Washington, D.C. to determine how the arrival of white-collar households in selected neighborhoods of Washington, D.C. disrupted their racial and socioeconomic composition over time. It was found that between 1970 and 1980 the number of black residents in revitalizing areas in the city core sharply dropped from $69.7 \%$ to $56.6 \%$; the number of owner-occupied housing units in the core area surpassed that in adjacent or peripheral areas of the city; although the level of racial segregation changed very little in the city as a whole, racial residential segregation was found to have declined more rapidly in the city core than in other neighborhoods within the District. The study concluded that between 1970 and 1980 the revitalizing core area of Washington, D.C. showed a proliferation of white-collar residents but less segregation.

Elliott et al. (1985), in a study of St. Louis, used factors associated with neighborhood decline to explain how and why maintenance and investment expenditures across neighborhoods vary and to challenge the arbitrage model (Leven et a1., 1976). First, the problem of neighborhood decline was overstated by the arbitrage model because of the assumption that neighborhood decline was exclusively the outcome of race and income factors. Second, the model also implied that maintenance and other capital project spending was bound to decrease as a result of the race and income 
factors (Leven et a1., 1976). To the contrary, Elliott et a1. (1985) found that diseconomies such as code enforcement and crime accounted for more of the variation in maintenance and investment spending than the race and income factors. London et al. (1986) combined data from a national survey on the presence of gentrification and data from the Permanent Community Sample for forty-eight of fifty-one cities to determine which explanation posited in the literature provided the strongest support for explaining gentrification. The explanations include demographic, ecological, sociocultural, and political-economic factors. The findings were consistent with the postulated hypotheses. On the whole, the political-economic explanation provided the strongest empirical support for explaining why some cities are targeted for gentrification while others are not. Lee (1986) examined 3,303 census tracts in fifty-eight American cities to monitor the decline in the numbers of black residents between 1970 and 1980 as a result of gentrification. It was observed that $30.5 \%$ of the tracts in the sample showed a decline during the decade as a result of gentrification. While the decline in the numbers of blacks in 83 of 86 census tracts in Los Angeles was the result of the increased growth in the Hispanic population, in the rest of the cities in the sample the result was due to whites displacing blacks. 
Goodman (1988) used a national sample of home owners and renters derived from the Annual Housing Survey (AHS) to develop an econometric model to assess the effects of income, price of housing, tenure choice, and housing demand on changes in neighborhoods. The empirical results showed that the demand for housing reflected the interaction of all four attributes. In the tenure choice equations, income and price elasticities exerted major effects. The effects of the sociodemographic variables were found to be both complex and mixed and were discounted.

Bond and Coulson (1989) developed a model to analyze the process of neighborhood change. They postulated that while the value of housing is positively related to the percentage of higher income households, the aging of housing units that eventually filter down to lower income residents becomes an externality. This causes the neighborhood to alter its racial composition in the direction of lower income residents. The study noted two ways in which the externality effect manifests itself. First, it can cause a reduction in the neighborhood incomes and housing values that can drive other higher income neighborhood residents. Second, the presence of low-income residents may result in a postponement of the replacement of older housing units with new housing, thereby resulting in a higher proportion of low-income housing units in the area. 
Dubin and Sung (1990) employed a non-nested test to determine which set of neighborhood characteristics adequately explains the variations in housing prices. The race factor and socioeconomic characteristics were found to be more important determinants of neighborhood quality than the quality of public services.

CHANGING AGE STRUCTURE AND NEIGHBORHOOD REVITALIZATION

Henig (1980) employed a census tract-level analysis in a study identifying factors related to gentrification in the following American cities: Cincinnati, Dayton, Louisville, Memphis, Milwaukee, Minneapolis, Oklahoma, Rochester, and St. Paul. The data for the study were derived from the R.L. Polk and Company's Profiles of Change, and the data provided a longitudinal profile of certain demographic changes taking place at the tract level in each of the cities in the sample.

The study showed that most of these cities were not experiencing significant gentrification as measured by changes in the numbers of professional-headed households, but rather the cities were experiencing an out-migration pattern and decline in professional and retired households. However, a relationship between immigration of professional households and an out-migration of retired people at the tract level was found. The relationship was more significant in tracts located near the central business districts. 
Moreover, the type of neighborhood change that is usually associated with gentrification was observed in only a few of the cities included in the sample. That trend was found to be more prevalent in older neighborhoods in the inner cities which also had a considerable proportion of older housing units targeted for rehabilitation.

Henig (1981), in a follow-up study to assess residential mobility trends in a sample of nine cities in the country, made the following observations. The settlement of younger, wealthier and better educated elite in the innercity neighborhoods represented a threat of displacement of elderly residents; the gentrification-induced displacement process in the study areas occurred because the inmigration of professional households was more likely to occur in census tracts with a relatively high proportion of retired households that were closer to the central business districts.

Hodge (1981) conducted a survey of 1,269 persons to estimate the extent of revitalization and its effects on the residents of Seattle, a rapidly growing city characterized by low vacancy rates, high cost of living, and often referred to as "America's most liveable city." In addition to the survey, the study also employed a census-tract level analysis of residential change by using R.L. Polk data as well as real estate speculations. The following observation was made: Inner-city revitalization was not confined to 
specific neighborhoods, but rather was the outcome of general market conditions. In other words, the neighborhood changes in Seattle can be described as a filtering-up process caused by a depressed housing market that was unable to keep pace with housing demand; the significant demand for housing in the central city was caused by the formation of new households in the city, as well as by the decreased mobility rates to the suburbs rather than to in-migration of residents from the suburbs; and the displacement rates in Seattle were exceptionally high and affected every socioeconomic and geographical group.

Laska et al. (1982) assessed neighborhood changes as measured by the existence of real estate activity (real estate transfer sales), the extent of such activity, and the peak year of the occurrence of such activity. These measures were estimated against sixty-eight inner-city census tracts in New Orleans from nineteen housing and socioeconomic as well as locational factors of the census tracts. Two factors--a higher owner-occupied housing rate and the age of the housing unit--were found to be more predictive of revitalization activity than the remaining factors. Neighborhoods that were not experiencing this process were those located closer to public housing projects. As suggested by Clay (1979), "dire poverty"--as it is symbolically reflected in public housing projects--is avoided by renovators. 
Schill and Nathan (1983) provided a model of neighborhood revitalization that borrowed heavily from the works of Pattison (1977), Goetze et a1. (1977), Gale (1977), the National Urban Coalition (1978) and Clay (1979). The model postulated that revitalizing neighborhoods go through three stages of change. In stage one households comprised of young, single persons or childless couples who are employed in artistic and design fields buy and renovate homes within a few blocks of a neighborhood that is declining. More often than not, the households are trying to seek or estab1 ish a community that is free from social pressures usually encountered in a more homogeneous community. The households are lured into these neighborhoods by the housing they offer and mix well with existing residents.

In the second stage, as the neighborhood is discovered by the news media and realtors, homes are purchased and resold without being renovated, and more confidence is placed in the neighborhood. The households moving into the neighborhood during this stage are comprised of mostly career-oriented persons, like teachers and lawyers. These in-migrants do not mix as easily as their predecessors in stage one. They very often run into conflicts with their neighbors over such issues as noise and crime. The increasing desirability of the neighborhood at this stage causes tensions to rise over increasing rents and property taxes. 
In the third and final stage of the reinvestment process, most of the housing units in the neighborhood are renovated and the number of original tenants is greatly reduced. The migrants moving into this type of neighborhood are described as "risk averse" (Pattison, 1977; Gale, 1977). They usually comprised of older married couples with children moving from the suburbs and are employed as professionals and managers. Unlike the in-migrants in stages one and two the in-migrants in stage three are concerned with value preservation as well as organizing to prevent zoning alterations and subsidized housing projects in their neighborhood.

Gale (1984) employed a tract-level analysis to determine the extent to which there has been consistency in the direction of change occurring in the neighborhoods of the cities of San Francisco, Denver, Cincinnati, Atlanta, and Washington D.C. between 1970 and 1980. The sample included a wide range of demographic, socioeconomic, and locational factors. The findings of the study were found to be mixed in terms of which neighborhood was gaining or losing gentrifiers at the expense of the other. However, an increase in the numbers of gentrifier households in the inner-city neighborhoods of the five cities known to have experienced revitalization was observed. The revitalizing areas were also observed to have attracted quite a sizeable proportion of newcomers, especially young adults in the twenty-five to 
thirty-four age cohort. At the same time the numbers of long-term area residents were noted to be rapidly decreasing.

In summary, neighborhood revitalization, a phenomenon believed to have begun in the mid-1970s, has varied from one community to another due to the different historical, physical, demographic or social composition of each community. It is this variation which has given rise to a body of literature reflecting demographic, ecological, sociocultural and political-economic ramifications to explain the process (London et al., 1986). In most of the metropolitan areas where the process has been documented, for every neighborhood that may be experiencing revitalization another neighborhood inay be experiencing disinvestment. However, the models discussed in this literature review are considered germane to this study, and they provide a sufficient theoretical framework for comparing structural changes in the inner-city neighborhoods of Portland as well as predicting revitalization.

Although the literature tends to reveal a variety of plausible explanations for the gentrification process, the studies reviewed for this research hinge upon two broad tenets--ecological (with emphasis on such parameters as population and neighborhood characteristics, social organization, and technology) and age structure. These studies tend to provide a further insight into the gentrification 
process in order to enhance the predictions of developments in the near future, as well as enhancing policy formulation as it relates to urban housing policy.

But gentrification has been and continues to be a controversial subject due to the fact that it is both a political as well as an economic issue which has led, in some instances, to a conflict of interests in the urban landscape. To conclude that a knowledge of such a controversial subject as provided by the findings of these studies is adequate to enhance the prediction of future policy developments would be an overstatement. At best the studies reviewed in this research have aided in the replication of future studies on gentrification which will help in the understanding of how policies related to effecting neighborhood change have only benefited one group of city residents or neighborhood at the expense of the other.

In the next chapter the conceptual development of the methodology is discussed. 
CHAPTER IV

\section{METHODOLOGY}

Before embarking upon the discussion of the methodology for this research it is worthwhile to provide the reader with a brief review of the positive steps that were undertaken to cumbat the forces of time and change through neighborhood revitalization in the city of Portland.

Visible evidence of neighborhood decline in the early 1950 s manifested itself by the incursion of commercial as well as industrial activities into what were considered as Portland's nice residential neighborhoods.

But an earlier attempt by concerned policy-makers and planners to revitalize the declining Thurman/Vaughn Street neighborhood in Northwest Portland in the early 1950 s failed. That failure was attributed to the lack of a planning agency that would coordinate planning decisions with the input from neighborhood residents (Abbott, 1983).

However, the failure of the Thurman/Vaughn Street project saw the creation in 1958 of the PDC, which was entrusted the task of revitalizing the city's core and its surrounding neighborhoods. 
Since the creation of the PDC several revitalization projects such as the South Auditorium, the Albina Project, Emmanuel Hospital Urban Renewal Project, Lair Hill-CorbettTerwilliger Project, and the new Convention Center were undertaken and completed by the PDC.

The formation of the PDC also witnessed the rise in the 1960 s and 1970 s of several neighborhood associations around the city of Portland that served as advocacy groups that brought pressure to bear upon the PDC in terms of which projects the agency should embark upon.

The creation of the PDC and the creation of various neighborhood associations around the city of Portland underscore two major things. First, the problem of neighborhood decline was no longer just a problem of the larger and older American cities; even a smaller and younger city like Portland was also a victim to the forces of time and change. Second, policy-makers, planners, and private citizens were concerned about this problem in the city of Portland.

The revitalization activity undertaken by the PDC is an ongoing process described by housing market analysts in a variety of terms. Such terms as neighborhood change, gentrification, private market residential rehabilitation, filtering, and "back-to-the-city movement," to mention but a few, have been used to describe such inner-city neighborhood housing renovation activity. 
Despite these research efforts, the literature still remains weak in terms of the urban structural impacts of the revitalization phenomenon (Lee et al., 1985). In light of this, the present study should be seen as yet another contribution in that direction by employing a number of structural characteristics to explain neighborhood change over a period of time.

The following research hypotheses assessing the urban structural characteristics influencing neighborhood change in the city of Portland between 1970 and 1980 are formulated and discussed.

\section{HYPOTHESES}

\section{Hypothesis 1}

Distance from the $C B D$ is negatively related to neighborhood revitalization. Several studies in the literature have used the distance variable in explaining urban spatial residential patterns with reference to neighborhood change. The models include Sjaastad (1962), Gallaway et al. (1967), and Greenwood $(1969,1970)$. The rationale for using the distance variable is that migration or mobility is considered a function of moving cost which has a monetary and non-monetary element (Greenwood and Gormely, 1971). The monetary element is comprised of both the actual transportation costs and the opportunity cost. The non-monetary element, on the other hand, refers to the psychological 
costs resulting from an individual's refusal to relocate to an unfamiliar neighborhood, leaving friends and relatives behind (Greenwood and Gormely, 1971). Therefore, distance in these respects becomes a proxy for economic as well as non-economic factors. In retrospect, because of economic constraints, young, educated, single adults and childless couples especially, employed in middle-class professional jobs will opt for a central city residential location in order to be closer to their places of work and to defray transportation as well as fuel costs. Assuming this is the case, the shorter the travelling distance, the greater the incidence of neighborhood revitalization. Inversely, the greater the distance from $i$ to $j$, the less the incidence of neighborhood revitalization.

Other spatial residential location models often make reference to the economic models or the "bid rent curve" models of Alonso (1969), Mills (1972), and Muth (1972) which assume that, because most employment opportunities are found in the core of central cities, it is incumbent upon those residents who want to be closer to the work place to make trade-offs between living in the suburbs and having easy accessibility to the CBD (Schill and Nathan, 1983).

Hypothesis 2

Education is positively related to neighborhood revitalization. Since no direct measure of the growth of 
service industries in the core of the city was undertaken, it was assumed that given the relatively high proportion of highly educated households in the service industries catering for white collar administrative and managerial jobs, the education variable would be an appropriate proxy. The expectation is that the more highly educated the adult population of the city, the greater its economic viability; that is, the greater the chances in employment opportunities and the greater the investment potential in terms of the highly educated personnel investing in housing in the innercity neighborhoods. In other words, it is assumed that highly educated households have the potential to make an investment contribution in housing, especially the children of the post-war baby boom who want to own their own homes at a time when the production of new housing was low and the price of suburban housing units was very high (James, 1977; Goetze et al., 1977). Therefore, the greater the proportion of high status professional households, the greater the incidence of neighborhood change.

This being the case, a reverse neighborhood change in the inner-city neighborhoods becomes even more probable and thus challenges or prompts the modification of the conventional filtering trend of white-to-black neighborhood change (Burgess, 1925; Leven et a1., 1976). The reverse black-towhite neighborhood change or reverse filtering may, ceteribus paribus, reflect the success or failure of housing 
programs aimed at addressing the problem of neighborhood decline (Lee, 1986). Examples of models of the reverse filtering concept in the literature include Spain et al. (1982), Gale (1984), and Lee et a1. (1985).

Hypothes is 3

Race is negatively related to neighborhood revitalization. Among neighborhood revitalization theorists race has become one of the most extensively used variables in predicting nelghborhood change. For example, neighborhood succession models assume that as blacks move into an adjacent neighborhood the movement signals the change of that neighborhood from high status households to low status black households (Burgess, 1925; Leven et al., 1976; Clay, 1979). Eventually the influx of the black residents will force the "affluent" to move from the inner city to the periphery in order to consume more space than they would normally at the city core. Then, the low-income black residents will move in high densities and occupy the housing units the affluent leave behind (Schill and Nathan, 1983). As a result of the relatively high presence of blacks in the neighborhood, renovators tend to avoid such areas or the neighborhoods may simply become of less interest in the gentrifier's scale of preference (Clay, 1979).

But by the same token the discovery of inner-city neighborhood revitalization during the mid-1970s seems to 
have rendered the traditional models of neighborhood revitalization to criticism by other urban theorists, especially the proponents of the displacement hypothesis (Lee et a1., 1985). The hypothesis states that the proportion of black" residents in a neighborhood will decline with the advent of revitalization (Lee et al., 1985). The economic justification for this hypothesis is contained in the models of Zeitz (1979), Sumka (1979), and Schill and Nathan (1983).

\section{Hypothesis 4}

The unemployment rate which is employed as a proxy for neighborhood crime will be negatively related to neighborhood revitalization. Some revitalization theorists (Elliott et al., 1985; Laska et al., 1982) have employed actual measures of crime or proxies of crime to predict neighborhood revitalization. The economic rationale for the selection of crime as an indicator of neighborhood change is that it tends to increase maintenance expenditure due to increased property abuse as well as neighborhood vandalism, especially in areas with a strict code enforcement policy. Assuming this is the case, property values tend to decline gradually to the point where uncertainty increases with respect to the future of property values in that neighborhood. The feeling of uncertainty leads to a lack of neighborhood commitment, which in turn reduces the desire of 
other residents to even remain and revitalize the area. Therefore, neighborhood unemployment will have negative expectations.

Hypothes is 5

Owner-occupied housing will be positively related to neighborhood revitalization. In the absence of speculative property sales which are sometimes employed as an indicator of neighborhood change (Zeitz, 1979), the use of owneroccupied housing to determine whether neighborhoods that have experienced revitalization are characterized by a significant increase in the proportion of owner-occupied housing has become popular among such revitalization theorists as Zeitz (1979), Laska et a1. (1982), and Elliott et a1. (1985).

Homeowners generally tend to have a vested interest in their own neighborhoods for two reasons. First, the neighborhood is regarded as a place to live, and second, the home or the dwelling unit is regarded as a capital investment. In essence, homeowners have both a monetary stake and a psychological investment in their neighborhood to the point that their commitment and belief in the future of their neighborhood becomes even much greater (Varady, 1986). If this is the case, an increase in the proportion of homeownership is indicative of an improvement in the 
neighborhood. By the same token a decline in the proportion of homeownership may indicate a decline in the neighborhood.

\section{Hypothesis 6}

The percent of elderly residents will be negatively related to neighborhood revitalization. Among revitalization theorists a higher proportion of elderly residents within a given neighborhood may be indicative of neighborhood decline assuming that this element of the city population is of low or moderate income. The image of the elderly in some aspects of the literature has been considerably negative. Many see the elderly as individuals who are socially isolated and living in deteriorating housing units and often subjected to street crime (Varady, 1986). Additionally, many of the elderly subsist on fixed incomes from social security or pensions and that even with costs of living increases from the government they will still find it difficult to cope with inflationary costs of housing. Presumably, the elderly are believed to have a much greater housing cost burden than the non-elderly (Varady, 1986). By and large, elderly homeowners are incapable or less able to provide "sweat equity," thereby causing their units to deteriorate faster than the housing units of younger residents. Moreover, elderly rental residents are also less mobile and thus demand fewer services from their landlords. As a result the landlords tend to provide lower quality 
maintenance or basic maintenance of the rental units and thereby causing such units to deteriorate further. Based on these conditions the homes of the elderly become less desirable among renovators (Varady, 1986).

\section{Hypothes is 7}

The percentage of housing units built in 1939 or earlier will be negatively related to neighborhood revitalization. While some researchers have often stressed demographic indicators affecting neighborhood change, others have stressed the structural characteristics of the housing unit. For example, it is believed that as the age of the housing stock increases, the need for maintenance also increases. Additionally, the probability of the housing stock becoming technologically obsolete increases. The two conditions do suggest neighborhood decline in terms of the housing stock wearing out at a much faster rate and becoming less functional than the new stock in other neighborhoods (Varady, 1986).

However, changes in the housing market characterized by low production levels of new housing units since 1974 and the price of new suburban housing units reaching astronomical proportions have created a renewed interest in the existing housing stock in the inner-city neighborhoods (James, 1977). In retrospect, older housing units which carry low property values at the first stage of the 
revitalization process and can be renovated at cheaper costs (De Giovanni, 1983) have become more desirable among young middle-class professional couples and individuals (Clay, 1979; Laska and Spain, 1979; Gale, 1980). First-time home buyers of the baby-boom age cohort are also attracted to these older housing units (London et a1., 1986). The changes in the housing market as well as the demographic and social changes provide a justification for the quality of the neighborhood housing stock hypothesis and the reverse filtering concept.

Hypothesis 8

The percentage of housing units lacking plumbing facilities is positively related to neighborhood revitalization. This is another aspect of the structural characteristic of the housing unit that has been employed by revitalization theorists to develop a hypothesis based on the quality of the neighborhood housing stock and the reverse of the filtering concept. Demand for housing with an architectural appeal among first-home buyers has increased since the mid-1970s. The demand for this type of housing unit has also led to landlords arbitrarily increasing their rents, evicting tenants, and converting multi-family rental units to single-family homes in the wake of revitalization (Lee et a 1., 1985). 
Hypothesis 9

The median number of rooms per dwelling unit is positively related to neighborhood revitalization. This hypothesis is concerned with the quality of the neighborhood housing stock and the reverse of the invasion-succession or filtering concept (Burgess, 1925). Interest in housing units that can be renovated at cheaper costs and housing with suitable room arrangements (Clay, 1979; De Giovanni, 1983) has increased for reasons already discussed in the seventh and eighth hypotheses. Laska and Spain (1979) used socioeconomic characteristics of the residents and housing quality factors to monitor neighborhood change in a New Orleans sample. Respondents listed the quality of the neighborhood as the major reason for selecting inner-city locations. The second reason listed was housing quality.

The hypotheses discussed in this research were developed from the various approaches posited in the literature. Since the explanations themselves are not mutually exclusive but rather hinge upon a number of factors focused on by some researchers, it is hoped that by incorporating different plausible explanations a reasonable insight into the problem of neighborhood change would be achieved in this research.

DATA AND METHODS

The data for this research were obtained primarily from Census Tracts Reports for the periods 1970 and 1980 on the 
Census of Population and Housing Characteristics provided by the U.S. Census Bureau. Other sources included the Metropolitan Service District Data Source Center Publications on neighborhood information profiles by Census Tracts, 19701980. Another Metropolitan Service District Data Source was the Regianal Fact Book that contained information on demographic, employment and land development trends in the five districts of the city of Portland. From the City the sources were a data summary provided by the City and the urban renewal report of the Portland City Club and the PDC. The sample consists of 117 census tracts located in the city of Portland. A total of 12 variables--3 dependent and 9 independent--were developed from the 1970 and 1980 census data. The three dependent variables were employed as measures reflecting structural changes implied in the research hypotheses.

Since the objective of this research is to determine the structural changes associated with neighborhood revitalization in the city of Portland between 1970 and 1980, the following procedure with respect to transforming the values for the dependent variables was used. For example, the ratio value for every census tract for each measure was obtained by relating the change in income for the census tract to that of the city for each period. The difference in income obtained thus becomes the value for that census tract. The values derived through this method, which was 
first developed by Fisher and Winnick (1951) and later used by Toulan (1960), it should be emphasized, are ratios rather than absolute values.

\section{DEPENDENT VARIABLES}

Three dependent variables--change in the median household income, change in the median home value, and change in the median contract rent for all the census tracts--were selected as measures of neighborhood change in the study area between 1970 and 1980 .

The measures comprised of the ratio differences obtained from the following procedure. For each dependent variable the change in the housing element for the unit (census tract) was related to the change in the same element for the city, for example, the difference between the median household income for the tract relative to the median household income for the city in 1980 and the same income for the tract relative to that of the city in 1970 . The ratios thus obtained through this procedure represent the values for the variables. These ratios may have negative, positive or zero values.

\section{Median Household Income}

This variable was measured as follows:

$$
\mathrm{Ia}^{\prime \prime} / \mathrm{Im}^{\prime \prime}-\mathrm{Ia} a^{\prime} / \mathrm{Im}^{\prime}=i^{\prime \prime}-i^{\prime} . \text {. . }
$$

where 
$\mathrm{Ia}^{\prime}=$ Median household income of the tract, 1970

Ia" = Median household income of the tract, 1980

Im ' = City median household income, 1970

Im" = City median household income, 1980

Household income is a factor that is generally acceptable in empirical studies as being a measure of multidimensional concepts. Some observers believe that neighborhoods with higher income households are likely to reinvest in older housing units close to the CBD. Because of their strong financial standing, they are capable of meeting repair and maintenance costs of older housing units as opposed to residents in low-income areas who are constrained by their low financial status.

Median Home Value

The change in median home value was measured as follows: $\mathrm{Ha}{ }^{\prime \prime} / \mathrm{Hm}^{\prime \prime}-\mathrm{Ha}{ }^{\prime} / \mathrm{Hm}^{\prime}=\mathrm{h}^{\prime \prime}-\mathrm{h}^{\prime} . .$.

where

$$
\begin{aligned}
& \mathrm{Ha}^{\prime}=\text { Median home value of tract, } 1970 \\
& \mathrm{Ha}^{\prime \prime}=\text { Median home value of tract, } 1980 \\
& \mathrm{Hm}^{\prime}=\text { Median city home value, } 1970 \\
& \mathrm{Hm}^{\prime \prime}=\text { Median city home value, } 1980 \\
& \text { This variable was also operationalized as a multi- }
\end{aligned}
$$
dimensional concept. For example, the demand for housing in a neighborhood that has reached some degree of respectability may increase, which in turn may encourage absentee 
landlords or property owners to raise rents or home values (Lee et a1., 1985). Other changes like tenant eviction, as well as the conversion of some rental housing units to single-family occupancy, which are considered to signal neighborhood revitalization, may also occur (Lee et al., 1985).

Median Rent

This index of neighborhood revitalization was measured as follows:

$$
\mathrm{Ra}{ }^{\prime} / \mathrm{Rm}^{\prime}=\mathrm{Ra}{ }^{\prime} / \mathrm{Rm}^{\prime}=\mathrm{r}^{\prime}-\mathrm{r}^{\prime} . .
$$

where

$$
\begin{aligned}
& \mathrm{Ra}^{\prime}=\text { Median rent of tract, } 1970 \\
& \mathrm{Ra}^{\prime}=\text { Median rent of tract, } 1980 \\
& \mathrm{Rm}^{\prime}=\text { Median city rent, } 1970 \\
& \mathrm{Rm}^{\prime \prime}=\text { Median city rent, } 1980
\end{aligned}
$$

For each dependent variable or neighborhood revitalization index, if the ratio differential has a negative value then that particular tract or neighborhood is declinin or filtering down; if the ratio differential has a positive value, then the neighborhood is rising or filtering up; and if the ratio differential has a zero value, then the neighborhood is stable.

The patterns or trends resulting from the ratio methods for each index are discussed in the next chapter. 


\section{INDEPENDENT VARIABLES}

There are nine structural indicators designated as independent variables representing the existing conditions in the study area at the beginning of the 1970 decade. These conditions at the start of the decade were developed from the 1970 census data for the city of Portland. These nine structural indicators of neighborhood revitalization were derived from locational, demographic, and housing characteristics and operationalized as follows.

\section{Locational Factor}

For this study the distance from the mid-point of the CBD measured in feet on the 1970 census tract of the city of Portland was selected for the following reasons. First, renovators are typically young, employed in middle-class professional positions in central city businesses and may prefer inner-city residence in order to be closer to their places of work. Second, renovators are typically childless and thus less concerned about the quality of schools, playgrounds and other recreational facilities for children. Third, renovators may opt for inner-city residence in order to be close to cultural facilities. 


\section{Demographic Factors}

The set of variables selected from this category are education, race, age structure, unemployment, and owneroccupied housing units.

Education. This variable was operationalized as the percent of persons aged 25 years and older with four or more years of college education. It was included in the tractlevel analysis as a measure of social status. Research on neighborhood revitalization has found a consistent pattern in the level of educational achievement among those living in revitalized inner-city neighborhoods (Laska and Spain, 1979).

Race. This variable was operationalized as the percent of blacks living in the study area in 1970 . Other minority groups such as Hispanics, American Indians and Vietnamese were excluded because their numbers may not have been significant during the study period.

The choice of this structural factor is to complement the filtering concept--white-to-black as well as the blackto-white succession in revitalizing neighborhoods.

In housing market analysis relocations are believed to occur in response to changes in the expected utility of given locations (Leven et a1., 1976). For example, the greater the proportion of blacks in an area, the greater the chances of succession occurring. In essence, neighborhoods with a large percent of black residents are avoided by 
renovators because such neighborhoods are considered to be in decline (Clay, 1979).

Age Structure. This factor was operationalized as the percent of persons aged 60 years or older living in the study area. This variable, in retrospect, represents the elderly element of the population in the study area that comprised of retirees subsisting on fixed incomes, and many of whom live in public housing projects considered by renovators as a distraction (Varady, 1986).

Unemployment. This factor was proxied for crime, vandalism, and other diseconomies that may reduce the incidence of neighborhood revitalization.

Owner-Occupied Housing. This factor was operationalized as the percent of owner-occupied housing units in the study area. It was included to capture initial signs of reinvestment in housing that may be justified by the gradual increase in the percentage of housing units shifting to owner-occupancy. For example, the purchase and subsequent repair of homes by "risk-oblivious middle-class persons" (De Giovanni, 1983) in neighborhoods previously considered undesirable encourages other people to invest in that neighborhood to help reshape it. Clay (1979) identified two types of neighborhoods--upgrading and gentrifying. Renovations in neighborhoods that are upgrading are being undertaken by the current residents, while improvements in 
neighborhoods that are gentrifying are being undertaken by in-movers who buy and rehabilitate homes.

\section{Housing Factors}

The parameters proxied for the quality of the residential neighborhood as well as the quality of housing were as follows. First, the age of the dwelling unit was operationalized as the percent of all dwelling units built in 1939 or earlier. Second, the median number of rooms per dwelling unit in a building. Third, the percent of all housing units lacking some or a 11 plumbing facilities. These parameters were included to capture other conceptual dimensions such as the demand for architecturally appealing housing units at the onset of neighborhood revitalization and the notion of sustained maintenance production (E11 iott et a1., 1985).

Although style obsolescence becomes a secondary stimulus in inducing an appreciation of value, it is not uncommon to find older housing units being sought after because of their architectural uniqueness rather than new housing units (Smith, 1979).

The level of maintenance affects the value of a dwelling unit in the housing market (Elliott et al., 1985). Property owners are usually faced with making minor repairs as well as major repairs. Minor repairs like painting doors and window frames and interior decorating, must be done on a regular basis if a house is to retain its value. But major 
repairs like replacing plumbing or electrical systems, replacing floor boards or roof, involve larger capital outlays and are done on a less regular basis (Smith, 1979).

\section{REGRESSION MODELS}

The research hypotheses are tested by the following regression models. Since there are three measures of neighborhood revitalization, comprised of the ratios for household income index, home value, and rent, each measure is regressed against the nine structural indicators comprised of the pre-existing conditions in 117 census tracts, developed from the 1970 census data for the city.

The sample of 117 census tracts represents five commercial districts of the city of Portland. Among the five districts, two districts--Northeast Portland and Southeast Portland--were selected to monitor varying structural impacts implied in the hypotheses in both areas. To enhance this procedure, two samples of 43 and 34 census tracts representing the inner Northeast and the inner Southeast were developed. Each sample contained the same set of three dependent and nine independent variables that were used in testing the hypotheses for the entire study area represented by the sample of 117 census tracts.

For the sample of 43 census tracts in Northeast Portland each dependent variable was regressed against the nine independent variables, resulting in three regression 
equations for the sample. The same procedure was employed for the sample of 34 census tracts representing Southeast Portland and resulted in three equations for this sample. The above regression methods resulted in the following stages of testing the postulated hypotheses. First, a correlation matrix containing means and standard deviations for the original research sample was developed. Second, the concepts implied in the postulated hypotheses were examined by assessing the relationship between each independent variable and dependent variable while holding the effects of the other variables constant. Third, the varying structural impacts of neighborhood revitalization within the two selected inner-city areas during the study period were estimated from the pooled cross-sectional results of the two samples.

The hypothesized relationships for each of the dependent variables or measures of neighborhood revitalization are expressed as follows:

$$
Y=a+b 1 \times 1+b 2 \times 2=\cdot \cdot \cdot b 9 \times 9+e \cdot \cdot(1,2,3)
$$

where

$Y$ represents the measures of change in the median household income, median home value, and median rent in the inner-city neighborhoods of Portland, 1970 and 1980

b1, 2 . - n are the coefficients of $x 1,2$. . $n$ $\mathrm{X} 1$ is the distance from the CBD 
$\mathrm{X} 2$ is the percent of persons aged 25 years and older with 4 or more years of college education

$\mathrm{X} 3$ is the percent of the black population in the study area

X4 is the percent of persons aged 60 years or older living in the study area

$X 5$ is the percent of all owner-occupied housing units in the study area

X6 is the percent of unemployed persons in the study area

$X 7$ is the median number of rooms per housing unit in the study area

$\mathrm{X} 8$ is the percent of housing units lacking some or all plumbing facilities

X9 is the percent of housing units built in 1939 or earlier found in the study area

e is the error term.

The products used for evaluating the variation among the variables in the cross-sectional regression analyses were the coefficient of determination $\left(R^{2}\right)$, the estimated coefficient (unstandardized coefficients), the beta weights (standardized coefficients) and the significance of the tratio scores which are shown in parentheses in the reference tables.

The estimated coefficients measure the level of association between each predictor variable and the criterion 
variable. But it is sensitive to violation of homogeneity of variance in multivariate analysis of this kind. Therefore, the BETA, which is also referred to as the standardized coefficient and which adjusts for heterogeneity, is included to complement the cross-sectional regression analysis.

To be reported in conjunction with the $R^{2}$ is the standard error of the estimate (SEE). The SEE is considered a "summary statistic" that determines the spread of the residuals around the "line of best fit." Its value, in other words, reflects the degree of variance of the observed values from the perfect linear association. 


\section{CHAPTER V}

\section{ANALYSIS AND RESEARCH FINDINGS}

This chapter consists of three sections. The first section presents a descriptive analysis of the results of the ratio method which resulted in patterns or trends of declining neighborhoods (filtering down) for tracts with negative ratio values, rising neighborhoods (filtering up) for tracts with positive ratio values, and stable neighbor-

hoods for tracts with zero values for each measure of neighborhood revitalization.

The second presents an in-depth analys is of the crosssectional regression results developed by regressing the three measures of neighborhood revitalization--change in median household income, change in median home value, and change in median rent--against the nine urban structural indicators to test the postulated hypotheses for the sample of 117 census tracts representing the entire study area.

The third section provides analysis of the six crosssectional regression results--three equations for the sample of 43 census tracts representing the inner Northeast district of Portland and three other equations for the sample of 34 census tracts representing the inner Southeast 
district of Portland--developed by regressing the three dependent variables against the same nine predictor variables for each subsample for the period 1970-1980.

\section{SECTION ONE: RESULTS OF THE RATIO METHOD}

The ratio method discussed in the previous chapter for the 117 census tracts in the city sample produced varying ratio values for each measure of neighborhood change in the city of Portland. For example, the difference between the change in the median household income index for each census tract in the sample relative to the change in the household income for the city in 1970 and 1980 resulted into ratio differentials having either a positive, negative, or a zero value for each census tract. Similar ratio values for the census tracts were obtained for the median home value index as well as the median rent index. Based on these results, the following categorization of the tracts was made.

All census tracts with negative ratio values were considered to be in a state of decline. Census tracts with positive ratio values were considered to be revitalizing, and census tracts with zero ratio values were considered to be stable. This grouping translates into three distribution trends of neighborhood change in the city of Portland for each index of change between 1970 and 1980. The distribution patterns of each neighborhood change index are discussed below. 
Neighborhood Revitalization

Trends of the Income Index

Figure 2 shows the three patterns--declining, revitalizing, and stable--of neighborhood change for the income index between" 1970 and 1980. Approximately $80 \%$ of the census tracts or neighborhoods in this sample index declined between 1970 and 1980. During the same period 16\% of the remaining census tracts had revitalized and another $4 \%$ of the remainder remained stable.

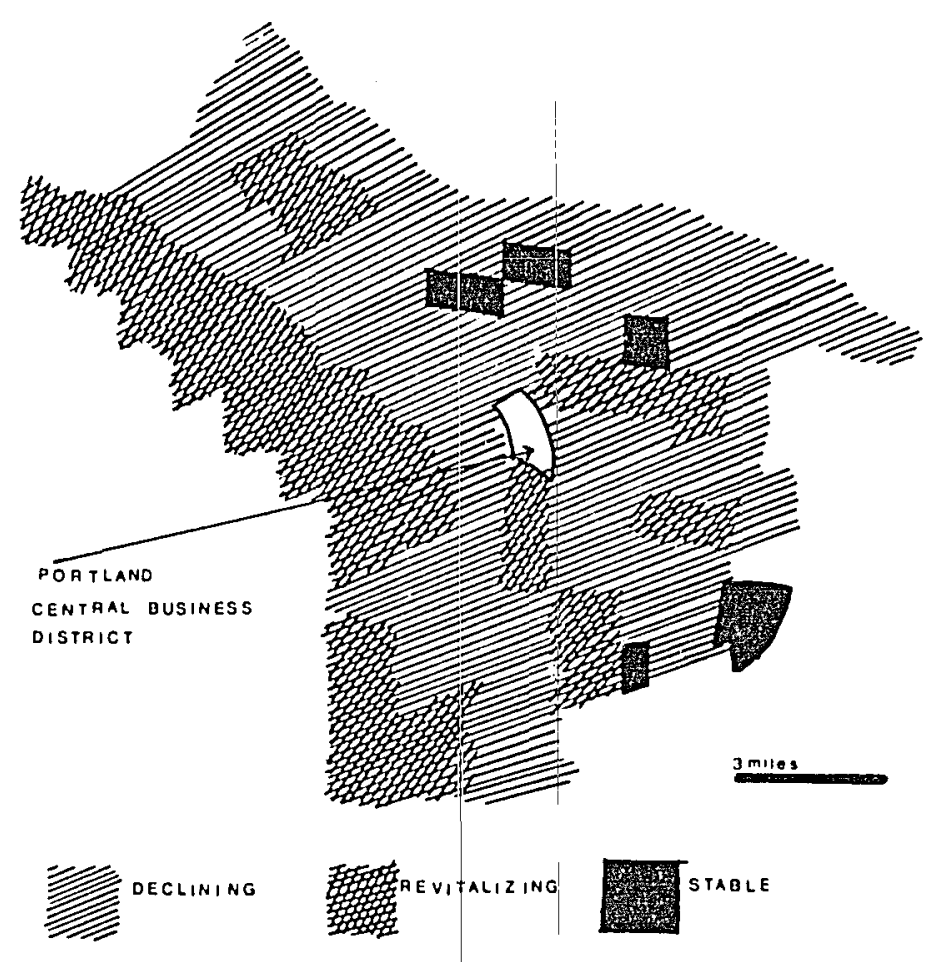

Figure 2. Neighborhood change trends for the income index: 1970-1980. 
Neighborhood Revitalization

Trends of the Home Value

Index

In Figure 3 the three neighborhood change patterns-declining, revitalizing, and stable--are shown. In this index $55 \%$ of the census tracts were at the threshold of decline or filtering down between 1970 and 1980 because of their negative ratio values. During the same period, $39 \%$ of the tracts in the sample index had declined or filtered and $6 \%$ of the remaining census tracts in the sample index remained stable.

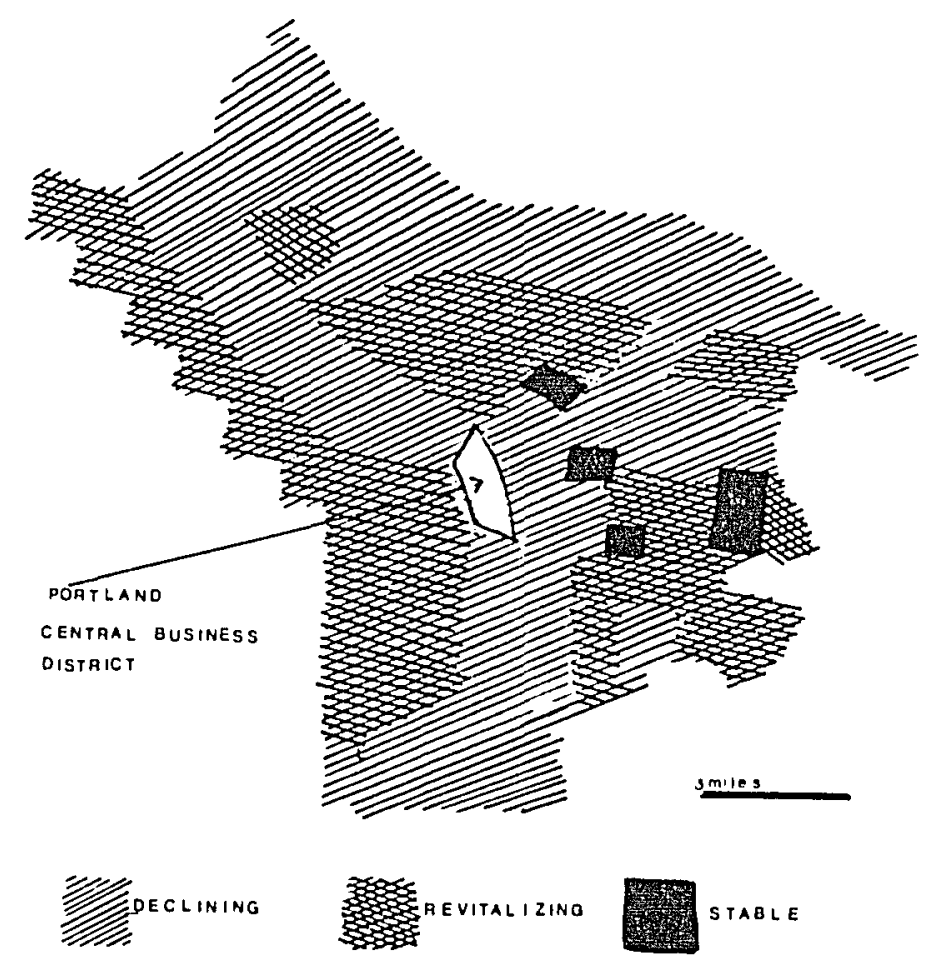

Figure 3. Neighborhood change trends for the home value index: 1970-1980. 
Neighborhood Revitalization Trends of the Rent Index

Figure 4 shows the same neighborhood change trends-declining, revitalizing, and stable--for the rent index. While $57 \%$ of the census tracts in the sample declined or filtered down, another $39 \%$ of the census tracts revitalized or filtered up between 1970 and 1980. During the same period only $4 \%$ of the census tracts in the rent index of the sample remained stable.

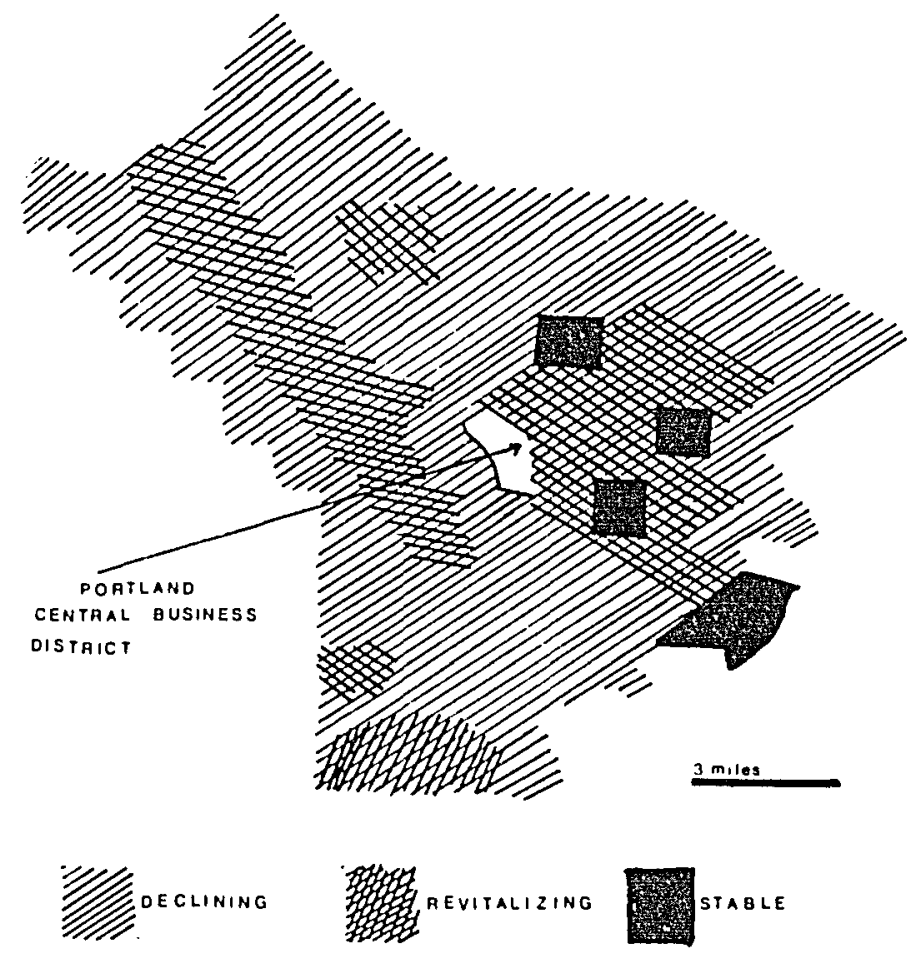

Figure 4. Neighborhood change trends for the rent index: 1970-1980. 
In all three measures of neighborhood revitalization for the sample of 117 census tracts, $64 \%$ of tracts declined between 1970 and 1980. During the same period, while $31 \%$ of the remaining census tracts revitalized, only $5 \%$ of the census tracts remained stable.

The discussion continues with the second stage of the analysis.

\section{SECTION TWO: ANALYSIS OF THE REGRESSION MODELS FOR THE CITY SAMPLE}

Since there are three dependent variables--change in median household income, change in median house value, and change in median rent--three regression equations were developed for testing the hypotheses.

For a brief review, the following postulations were made:

1. Travelling distance from the CBD will be negatively related to neighborhood revitalization. A large proportion of renovators often comprised of single individuals and childless couples are employed in middle-class professional jobs in central-city businesses. For these groups of people residential location preference is centrality to services and employment as well as commercial and cultural activities. In other words, it is assumed that the less the travelling distance, the greater the occurrence of neighborhood revitalization. 
2. Education is expected to be positively related to neighborhood revitalization because of the investment contribution that the highly educated and high status residents are 1 ikely to make in inner-city neighborhoods.

3. The race factor is expected to exert a negative impact upon neighborhood revitalization. It is assumed that the movement of black residents into an inner-city neighborhood may be a reflection of that neighborhood being at the threshold of decline. Consequently, predominantly black neighborhoods are avoided by renovators (Clay, 1979) or simply become of less interest in the gentrifier's scale of preference.

4. By the same token the unemployment rate, used as a proxy for neighborhood crime, vandalism and other diseconomies, is expected to be negatively related to neighborhood revitalization. Since crime tends to preclude leisure activities in a neighborhood, renovators tend to avoid such areas.

5. The number of persons aged 60 years and over proxied for the elderly residents in the study area will be negatively related to neighborhood revitalization. Quite a considerable proportion of elderly residents subsist on fixed incomes and 1 ive in federally assisted public housing units. Neighborhoods with a mix of public housing units not only for the elderly but for other low-income groups are avoided by renovators ( $\mathrm{Clay}, 1979$ ). 
6. The owner-occupied housing factor is expected to exert a positive impact on neighborhood revitalization. It is believed that inner-city areas that have experienced some revitalization activity at any given period of time tend to have a relatively higher proportion of owner-occupied housing units than non-revitalizing areas.

7. It is hypothesized that the age of the housing unit will be positively correlated with neighborhood revitalization. Older housing units tend to have an architectural uniqueness that sometimes appeals to renovators. Several studies on revitalization have empirically supported this speculation (Clay, 1979; Gale, 1980; Laska and Spain, 1980; Laska et al., 1982).

8. Plumbing is another structural factor proxied for neighborhood housing quality and is expected to be positively related to neighborhood revitalization. It is assumed that some housing units, despite the lack of plumbing facilities, are structurally strong and $c$ an be renovated at less expense.

9. The median number of rooms will also be positively correlated with neighborhood revitalization. This variable is proxied for neighborhood housing quality. It is believed that housing structures that are sometimes most valued by renovators are those that have a room arrangement that is suitable for them. 
These variables were proxied for neighborhood as well as housing quality, especially its architectural appeal, to capture the reverse of the invasion-succession process (Burgess, 1925). The increasing demand for older but strong housing units led to an increase in rental prices, the conversion of rental units into single-family units, and an increase in property taxes (Lee et al., 1985).

With this brief review, the analyses now continue with a discussion of the descriptive measures and the multiple regression results obtained from the regression methods used to test the postulated hypotheses.

\section{Descriptive Measures}

Table $I$ is a tabular presentation of a correlation matrix showing all zero-order level relationships among the independent variables.

The last two rows in Table I present means and standard deviations for the variables operationalized in the previous chapter. While the means are a measure of central tendency, the standard deviations provide a measure of dispersion.

For this study the measure of dispersion was considered relevant in determining the degree of skewness or the degree of deviation from symmetry exhibited by the frequency distribution. Besides, it is a more meaningful measure of dispersion because of its intuitive interpretation, being 
TABLE I

CORRELATION MATRIX WITH MEANS AND STANDARD DEVIATIONS FOR STUDY AREA

\begin{tabular}{|c|c|c|c|c|c|c|c|c|c|c|c|c|c|}
\hline & & 1 & 2 & 3 & 4 & 5 & 6 & 7 & 8 & 9 & 10 & 11 & 12 \\
\hline 1. & Distance & 1.00 & -.31 & -.17 & .55 & -.41 & -.04 & .29 & -.42 & -.43 & .07 & -.19 & -.02 \\
\hline 2. & Education & & 1.00 & -.22 & .17 & -.03 & -.54 & .43 & -.11 & -.26 & .05 & -.18 & -.01 \\
\hline 3. & Race & & & 1.00 & -.22 & -.01 & .51 & -.09 & .10 & .27 & -.28 & -.00 & .04 \\
\hline 4. & Owner & & & & 1.00 & -.36 & -.45 & .87 & .72 & .31 & .10 & -.41 & -.12 \\
\hline & Age struc & & & & & 1.00 & .02 & -.39 & .44 & .40 & -.00 & .24 & -.23 \\
\hline 6. & Unemployme & & & & & & 1.00 & .47 & .38 & .27 & -.12 & .18 & .09 \\
\hline & Median no & f rms. & & & & & & 1.00 & -.70 & -.18 & .03 & -.39 & -.05 \\
\hline & Plumbing & & & & & & & & 1.00 & .25 & .01 & .36 & .06 \\
\hline & Age of hot & ng unit & & & & & & & & 1.00 & -.09 & .39 & .11 \\
\hline & Median in & le ratio & & & & & & & & & 1.00 & -.01 & -.02 \\
\hline 11. & Median hon & value $\mathrm{r}$ & atio & & & & & & & & & 1.00 & -.08 \\
\hline & Median rer & ratio & & & & & & & & & & & 1.00 \\
\hline Mea & & 3.61 & 12.96 & 6.42 & 57.82 & 5.37 & 6.57 & 4.91 & 3.87 & 51.68 & -.34 & -.01 & -.24 \\
\hline Sta & idard dev. & 1.81 & 10.73 & 16.65 & 22.89 & 1.18 & 2.97 & .96 & 5.92 & 23.30 & 2.01 & .15 & 2.21 \\
\hline
\end{tabular}


based on the same units as the original variable (Norman et a1., 1975). As a measure of dispersion a low standard deviation indicates that the values of the individual observations are grouped close to the mean. Conversely, when the standard deviation is high, the values of the individual observations are spread over a wide area around the mean (Blalock, 1979).

The intuitive interpretation of the standard deviation as a measure of dispersion becomes meaningful when the proportion of observations falling under the normal curve is to be determined. For example, for one standard deviation we move to the right the area between the mean, and an ordinate drawn to that point is estimated to be .3413 . Therefore, if we move one standard deviation on either side of the mean, the area between the two ordinates will be .6826 , i.e., twice the area $(.3413)$ between the mean and a single ordinate. This implies that $68 \%$ of the observations are within one standard deviation on either side of the mean. Similarly, for two standard deviations the area will be .4773 , i.e., $95 \%$ of the observations are within two standard deviations, and $99 \%$ of the observations within three or more standard deviations.

The last row of Table I shows the standard deviations for all the variables included in the analysis. A close inspection of these variables shows that among the nine independent predictors, education, race, unemployment 
owner-occupied housing units, plumbing, and the age of the housing unit have high standard deviations. Intuitively, $99 \%$ of the observations in the study area as impacted by these factors exhibited a normal distribution. Among the remaining independent predictors, distance and age structure have standard deviations of 1.81 and 1.18 , respectively, and these translate to .4649 and .3810 as the areas between the ordinates on either side of the means for these factors. Intuitively, $92 \%$ of the observations in the study area as impacted by distance exhibited a normal distribution while $72 \%$ of the observations in the study area as impacted by age structure exhibited a normal distribution. But the median number of rooms factor, with $S=.96$, has little meaning. In Table I, the last three columns (10, 11, and 12) provide mixed support in sign at the zero-order level for the postulated research hypotheses. However, it is the regression results of the three measures of neighborhood revitalization (presented later in Tables II, III, and IV) that provide an in-depth assessment of the impact of each structural characteristic in the sample of 117 inner-city census tracts of Portland.

The regression results of each index of neighborhood revitalization in the city of Portland are analyzed and discussed below.

Regression Results of the Income Index. With reference to Table II, the a priori expectations as reflected by the 
TABLE II

REGRESSION RESULTS FOR THE CHANGE IN THE MEDIAN HOUSEHOLD INCOME INDEX FOR THE INNER-CITY NEIGHBORHOODS OF PORTLAND 1970 AND 1980

\begin{tabular}{|c|c|c|c|}
\hline \multirow{2}{*}{\multicolumn{2}{|c|}{ Independent Variables }} & \multicolumn{2}{|c|}{$\begin{array}{l}\text { Dependent Variables } \\
\text { Income } 1970 \text { and } 1980\end{array}$} \\
\hline & & $\mathrm{B}$ & Beta \\
\hline 1. & Distance from the CBD & $\begin{array}{l}-.0065 \\
(-.039)\end{array}$ & -.0059 \\
\hline 2 . & $\begin{array}{l}\text { Percent of persons with four or } \\
\text { more years of college education }\end{array}$ & $\begin{array}{l}.0093 \\
(.287)\end{array}$ & .0495 \\
\hline 3 . & Percent of black population & $\begin{array}{l}-.0322^{a} \\
(-2.283)\end{array}$ & -.2664 \\
\hline 4. & $\begin{array}{l}\text { Percent of owner-occupied } \\
\text { housing units }\end{array}$ & $\begin{array}{l}.0238 \\
(.903)\end{array}$ & .2715 \\
\hline $5 \cdot$ & $\begin{array}{l}\text { Percent of persons aged } \\
60 \text { years and over }\end{array}$ & $\begin{array}{l}-.0519 \\
(-.250)\end{array}$ & -.0304 \\
\hline 6. & $\begin{array}{l}\text { Percent of persons } \\
\text { unemployed }\end{array}$ & $\begin{array}{l}.0247 \\
(.258)\end{array}$ & .0365 \\
\hline 7 . & $\begin{array}{l}\text { Median number of rooms per } \\
\text { housing unit }\end{array}$ & $\begin{array}{l}-.2872 \\
(-.432)\end{array}$ & -.1376 \\
\hline 8. & $\begin{array}{l}\text { Percent of housing units } \\
\text { lacking plumbing }\end{array}$ & $\begin{array}{l}.0482 \\
(.967)\end{array}$ & -.1420 \\
\hline & $\begin{array}{l}\text { Percent of housing units } \\
\text { built before } 1939\end{array}$ & $(.0012)$ & .0138 \\
\hline $\begin{array}{l}\mathrm{R}^{2} \\
\mathrm{~N} \\
\mathrm{SEE}\end{array}$ & & $\begin{array}{r}.09 \\
117 \\
.199\end{array}$ & $\begin{array}{l}-- \\
117 \\
---\end{array}$ \\
\hline
\end{tabular}

NOTE: t-ratio scores in parentheses.

asignificant at the .05 level in a two-tailed test. 
signs of the estimated or unstandardized regression coefficients showed mixed support for the hypotheses. For example, seven factors--distance from the $C B D$, education, race, owner-occupied housing units, age structure, plumbing, and the age of the housing units--have the expected coefficient signs that are consistent with the hypotheses. Among these seven factors, race was the only structural indicator that strongly correlated with neighborhood revival because of its statistical significance at the .05 level.

The significant negative effect of the race factor suggests that the systematic revival trend observed in the city of Portland did not extend into predominantly black areas. The observed neighborhood revival in the city of Portland at the beginning of the 1970 decade was significant. Its functional significance may not be substantial compared to other older and larger cities like St. Louis or New Orleans. In these cities the best evidence of revival were isolated cases of neighborhood revival that captured the attention of the media, policy makers and planners, and other participants in the revitalization process. But the city of Portland was an exception. It may be the only city in the nation wherein a systematic neighborhood revival trend was observed at the start of the 1970 decade.

The outcome of the race factor also implies that the black population in the city of Portland at the start of the 
decade was sma11. The question is, what happened to this population? Were blacks the victims of racism or discriminatory practices in the housing market or victims of involuntary displacement? Since the presence of racism is very difficult to prove scientifically, one can only make indirect inferences about it. In the housing industry, especially in the rental housing market, landlords, all things being equal, may not select rental housing applications from a minority. Similarly, lending institutions may redline against predominantly black neighborhoods. The demographics of the 1970 s in terms of age and household characteristics may have had negative consequences for the housing market in Portland that may have resulted in the involuntary displacement of some blacks.

The other six factors did not have any significant impact on neighborhood revival due to the lack of statistical significance. Similarly the remaining two factors-number of rooms per unit and unemployment--operating in the opposite direction were insignificant.

An inspection of the standardized coefficients for all nine indicators presented in Table II shows a relatively high beta weight of $b=.27$ for the race factor. This is indicative of race being a much better predictor of neighborhood revival between 1970 and 1980 .

The estimated coefficients reveal a great deal more about the structural impacts on neighborhood revitalization 
in the study area between 1970 and 1980. The variation in the neighborhood revitalization index--change in median household income, as explained by all the structural indicators operating jointly--is relatively very low, $R^{2}=.09$.

However, the relatively low standard error estimate of .19 suggests that this first model was successful in relating the criterion variable to the predictor or structural variables.

The analysis continues with the discussion of the regression results of the home value index and the rent index.

Results of the Home Value Index. The regression results presented in Table III show mixed support for the postulated hypotheses. Six of the nine structural indicators included in the regression equation for the home value index have coefficient signs in the predicted direction and consistent with the research hypotheses. The six indicators are education, race, age structure, unemployment, plumbing, and the age of the housing unit. Among these, the age of the housing unit factor is the only indicator whose impact on neighborhood revitalization was found to be significant because of its statistical significance at the .001 level. The other five factors, because of the lack of statistical significance, did not have any impacts. Similarly, the remaining three statistical indicators--distance, owneroccupied housing units, and the median number of rooms per 
TABLE III

REGRESSION RESULTS FOR THE CHANGE IN THE MEDIAN

HOME VALUE INDEX FOR THE INNER-CITY

NEIGHBORHOODS OF PORTLAND

1970 AND 1980

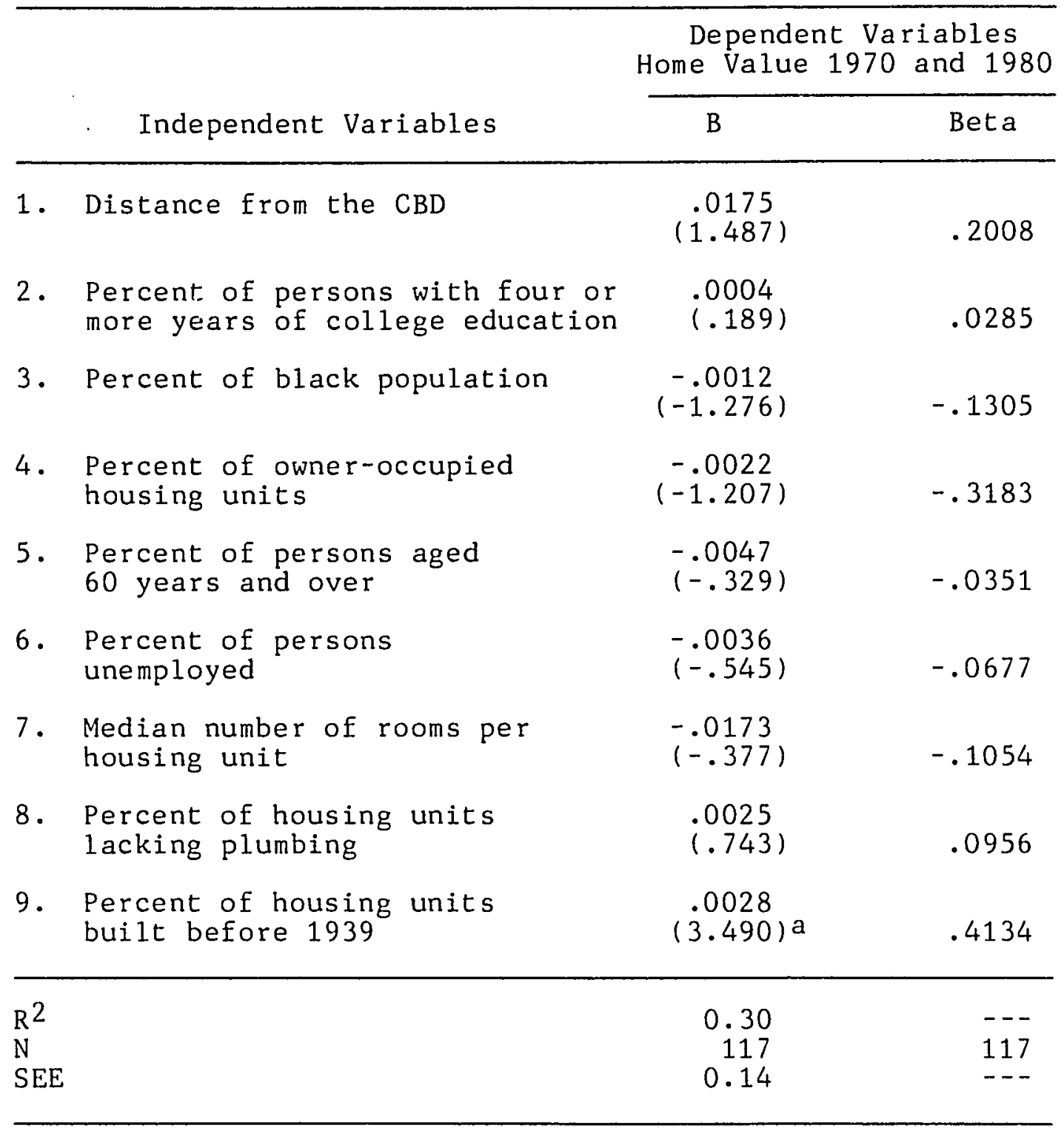

NOTE: t-ratio scores in parentheses.

asignificant at the .001 level in a two-tailed test. 
unit--did not have any significant impacts on neighborhood revitalization and are not consistent with the research hypotheses.

According to the standardized coefficients of the nine statistical indicators presented in Table III, the age of the housing unit factor, with a relatively high beta weight of $\mathrm{b}=.41$, emerged as a much better predictor of neighborhood revitalization between 1970 and 1980 .

The variation in the neighborhood revitalization index --change in median home value, as explained by all the statistical indicators operating jointly--is relatively high, $R^{2}=.30$. In essence, the high value of the $R^{2}$ and the low value (.14) of the standard error estimate for this model confirm the success of this model in relating the criterion variable to the nine statistical indicators.

The strong positive correlation of the age of the housing variable suggests that a significant and systematic reverse filtering trend occurred in the inner-city neighborhoods or stop-over neighborhoods (Abbot, 1983) of Portland at the start of the 1970 decade. This trend was reflected in the interest by renovators, especially first home-buyers, in older but strong housing units, some of which were endowed with unique architectural designs and which were possibly renovated at less cost.

The regression results of the rent index are discussed in the section below. 
Regression Results of the Rent Index. The regression results of this index presented in Table IV also reveal mixed coefficient signs for the research hypotheses. Out of the nine statistical variables included in the regression equation, six variables--education, race, age structure, median number of rooms per unit, plumbing, and the age of the housing unit-have coefficient signs in the predicted direction that are consistent with the hypotheses. Among the six factors mentioned, the age of the housing unit factor with a level of significance at the .10 and the age structure with a level of significance at the .05 level exerted significant impacts on neighborhood revitalization at the start of the 1970 decade. The effects of the other four variables were not significant at the start of the decade. The remaining factors--distance, owner-occupied housing units, and unemployment--in the regression equation refuted the hypotheses and had no significant impacts.

The regression results presented in Table IV further show that the age of housing unit and age structure factors, with beta weights of $b=.21, b=.23$, respectively, were much better predictors of neighborhood revitalization.

The variation in the neighborhood revitalization index --change in median rent, as explained by the nine structural indicators operating jointly--is very low, $R^{2}=.08$. But nonetheless, the low value (.22) of the standard error estimate of the model confirms the success of this model in 
TABLE IV

REGRESSION RESULTS FOR THE CHANGE IN THE RENT INDEX FOR THE INNER-CITY NEIGHBORHOODS OF PORTLAND 1970 AND 1980

\begin{tabular}{|c|c|c|c|}
\hline \multirow{2}{*}{\multicolumn{2}{|c|}{ Independent Variables }} & \multicolumn{2}{|c|}{$\begin{array}{l}\text { Dependent Variables } \\
\text { Rent } 1970 \text { and } 1980\end{array}$} \\
\hline & & B & Beta \\
\hline 1. & Distance from the CBD & $.1772)$ & .1452 \\
\hline 2 & $\begin{array}{l}\text { Percent of persons with four or } \\
\text { more years of college education }\end{array}$ & $\begin{array}{l}.0149 \\
(.414)\end{array}$ & .0721 \\
\hline 3. & Percent of black population & $\begin{array}{l}-.0067 \\
(-.433)\end{array}$ & -.0508 \\
\hline 4 . & $\begin{array}{l}\text { Percent of owner-occupied } \\
\text { housing units }\end{array}$ & $(-.0334)$ & -.3454 \\
\hline 5 & $\begin{array}{l}\text { Percent of persons aged } \\
60 \text { years and over }\end{array}$ & $\begin{array}{l}-.4347 \\
(-1.882) a\end{array}$ & -.2310 \\
\hline 6. & $\begin{array}{l}\text { Percent of persons } \\
\text { unemployed }\end{array}$ & $\begin{array}{l}.0135 \\
(.127)\end{array}$ & .0181 \\
\hline 7. & $\begin{array}{l}\text { Median number of rooms per } \\
\text { housing unit }\end{array}$ & $(.3638)$ & .1582 \\
\hline 8. & $\begin{array}{l}\text { Percent of housing units } \\
\text { lacking plumbing }\end{array}$ & $\begin{array}{l}.0156 \\
(.282)\end{array}$ & .0417 \\
\hline 9. & $\begin{array}{l}\text { Percent of housing units } \\
\text { built before } 1939\end{array}$ & $\begin{array}{l}-.0201 \\
(1.549) b\end{array}$ & .2110 \\
\hline $\begin{array}{l}\mathrm{R}^{2} \\
\mathrm{~N} \\
\mathrm{SEE}\end{array}$ & . & $\begin{array}{r}0.08 \\
117 \\
0.22\end{array}$ & $\begin{array}{l}--- \\
117 \\
---\end{array}$ \\
\hline
\end{tabular}

NOTE: t-ratio scores in parentheses.

asignificant at the .05 level in a two-tailed test. bSignificant at the .10 level in a two-tailed test. 
relating the dependent variable to the nine predictor variables.

As in the discussion of the results of the previous index, the positive correlation of the age of the housing unit variable is indicative of a significant and systematic reverse filtering trend in the inner-city neighborhoods of Portland at the beginning of the 1970 decade.

The statistically significant outcome of the age structure variable may also suggest that the proportion of elderly residents in the study area at the start of the decade was relatively small rather than being an indication of renovators avoiding areas with a relatively high proportion of elderly residents as the literature suggests.

In this second stage of the analysis the regression coefficients in all three models show mixed support for the hypotheses in terms of predicted direction, as well as in magnitude. However, evidence of a reverse filtering trend at the start of the 1970 decade was overwhelming.

The third stage of the analysis continues with the presentation and discussion of the results of the two samples representing the Northeast and Southeast districts of Portland. 


\section{SECTION THREE: ANALYSIS OF THE REGRESSION MODELS FOR THE TWO SAMPLES}

The three measures of neighborhood revitalization estimated from the ratio differences and regressed against the nine structural indicators for the two samples resulted in six regression equations or models. Three equations were developed for the sample of 43 inner-city census tracts representing the inner Northeast area and another three equations for the sample of 34 inner-city census tracts representing the inner Southeast area of Portland.

The six regression results in terms of testing the research hypotheses for both samples, and the relevant cross-sectional tables are presented and discussed in the following sections.

Regression Results of the Income Index in Northeast Portland

The regression results presented in Table $\mathrm{V}$ show mixed support for the research hypotheses in predicted direction and in magnitude. Four factors--owner-occupied housing units, age structure, plumbing, and the age of the housing unit--have coefficient signs that support the hypotheses and at the start of the 1970 decade had significant impacts on neighborhood revitalization. 
TABLE $V$

REGRESSION RESULTS FOR THE CHANGE IN THE

INCOME INDEX FOR N.E. PORTLAND 1970 AND 1980

\begin{tabular}{|c|c|c|c|}
\hline \multirow{2}{*}{\multicolumn{2}{|c|}{ Independent Variables }} & \multicolumn{2}{|c|}{$\begin{array}{l}\text { Dependent Variables } \\
\text { Income } 1970 \text { and } 1980\end{array}$} \\
\hline & & $\mathrm{B}$ & Beta \\
\hline & Distance from the $C B D$ & $\begin{array}{l}.0067 \\
(-.372)\end{array}$ & -.0839 \\
\hline 2. & $\begin{array}{l}\text { Percent of persons with four or } \\
\text { more years of college education }\end{array}$ & $\begin{array}{l}-.0016 \\
(-.480)\end{array}$ & -.0889 \\
\hline 3. & Percent of black population & $(i .9018) a$ & .3162 \\
\hline & $\begin{array}{l}\text { Percent of owner-occupied } \\
\text { housing units }\end{array}$ & $(4.0065) \mathrm{c}$ & 1.1135 \\
\hline & $\begin{array}{l}\text { Percent of persons aged } \\
60 \text { years and over }\end{array}$ & $\begin{array}{l}-.0402 \\
(-2.511) a\end{array}$ & -.3498 \\
\hline $6 \cdot$ & $\begin{array}{l}\text { Percent of persons } \\
\text { unemployed }\end{array}$ & $\begin{array}{l}-.0093 \\
(-1.522)\end{array}$ & -.2286 \\
\hline & $\begin{array}{l}\text { Median number of rooms per } \\
\text { housing unit }\end{array}$ & $\begin{array}{l}-.0279 \\
(-.568)\end{array}$ & -.1841 \\
\hline & $\begin{array}{l}\text { Percent of housing units } \\
\text { lacking plumbing }\end{array}$ & $(4.0228) c$ & .6036 \\
\hline & $\begin{array}{l}\text { Percent of housing units } \\
\text { built before } 1939\end{array}$ & $(i .414) \mathrm{b}$ & .2506 \\
\hline $\begin{array}{l}\mathrm{R}^{2} \\
\mathrm{~N} \\
\text { SEE }\end{array}$ & & $\begin{array}{r}0.72 \\
43 \\
0.06\end{array}$ & $\begin{array}{l}-- \\
43 \\
--\end{array}$ \\
\hline
\end{tabular}

NOTE: t-ratio scores in parentheses.

aSignificant at the .05 level in a two-tailed test. bSignificant at the .10 level in a two-tailed test. cSignificant at the .001 level in a two-tailed test. 
The two housing and neighborhood quality factors-plumbing and the age of the housing unit--are statistically significant at the .001 and .10 levels, respectively. Their strong positive correlation suggests a systematic reverse filtering trend in Northeast Portland at the start of the decade.

The owner-occupied housing units factor has a level of significance of .001 . The strong positive outcome suggests an increased incidence of revitalization activity in Northeast portland at the start of the 1970 decade as reflected in the relatively high proportion of owner-occupied housing units. This phenomenon was not observed in the city sample.

The age structure variable is statistically significant at the .05 level. The negative outcome suggests that the number of elderly residents in Northeast Portland at the start of the 1970 decade was relatively small.

Among the remaining structural indicators in the regression equation, the performance of the race factor refuted the hypothesis, and it is statistically significant at .05 leve1. The strong positive outcome suggests that the causal relationship may be operating in the opposite direction. That is to say renovators, rather than avoiding black residential neighborhoods in Northeast Portland, moved there in tandem at the start of the 1970 decade. The question that needs to be asked is, what happened to these black residents? Two things may have happened. While 
some of them may have been displaced by the renovators themselves, some others may have been subjected to discriminatory practices perpetrated by lending institutions as well as property owners. The other variables (distance, education, unemployment, and median number of rooms) either supported or refuted the hypotheses, but their impact was insignificant due to the lack of statistical significance.

The results presented in Table $V$ show that the variation in the change in median income as explained by the structural indicators operating jointly is high, $\mathrm{R}^{2}=.72$. The standardized coefficients in Table $V$ also reveal that owner-occupied housing unit and plumbing, with beta weights of $b=1.11$ and $b=.60$, emerged as much better predictors of neighborhood revitalization in both direction and in magnitude for the Northeast sample. The high $\mathrm{R}^{2}$ and the low standard error estimate confirm the success of this model in relating the dependent variable to the nine independent variables included in the regression equation.

Regression Results of the Home Value Index in Northeast Portland

In Table VI the distance from the CBD factor has the coefficient sign in the predicted direction and confirms the hypothesis. This variable is also statistically significant at the .10 level. On the other hand, the owner-occupied housing units factor refutes the hypothesis, but it is 
TABLE VI

REGRESSION RESULTS FOR THE CHANGE IN THE HOME VALUE INDEX FOR N.E. PORTLAND 1970 AND 1980

\begin{tabular}{|c|c|c|c|}
\hline \multirow{2}{*}{\multicolumn{2}{|c|}{ Independent Variables }} & \multicolumn{2}{|c|}{$\begin{array}{l}\text { Dependent Variables } \\
\text { Home Value } 1970 \text { and } 1980\end{array}$} \\
\hline & & B & Beta \\
\hline 1 & Distance from the CBD & $(-.0192) b$ & -.3900 \\
\hline 2 & $\begin{array}{l}\text { Percent of persons with four or } \\
\text { more years of college education }\end{array}$ & $\begin{array}{l}-.0004 \\
(-.160)\end{array}$ & -.0356 \\
\hline 3 . & Percent of black population & $\begin{array}{l}-.0004 \\
(1.696)\end{array}$ & -.1342 \\
\hline 4 & $\begin{array}{l}\text { Percent of owner-occupied } \\
\text { housing units }\end{array}$ & $\begin{array}{l}-.0025 \\
(-2.114) a\end{array}$ & -.6940 \\
\hline 5 & $\begin{array}{l}\text { Percent of persons aged } \\
60 \text { years and over }\end{array}$ & $\begin{array}{l}.0117 \\
(-.982)\end{array}$ & -.1665 \\
\hline 6. & $\begin{array}{l}\text { Percent of persons } \\
\text { unemployed }\end{array}$ & $\begin{array}{l}-.0034 \\
(-.757)\end{array}$ & -.1383 \\
\hline 7 . & $\begin{array}{l}\text { Median number of rooms per } \\
\text { housing unit }\end{array}$ & $\begin{array}{l}.0351 \\
(.959)\end{array}$ & .3766 \\
\hline 8 . & $\begin{array}{l}\text { Percent of housing units } \\
\text { lacking plumbing }\end{array}$ & $(-0023)$ & -.1004 \\
\hline 9. & $\begin{array}{l}\text { Percent of housing units } \\
\text { built before } 1939\end{array}$ & $\left(\begin{array}{l}.0010 \\
(1.484)\end{array}\right.$ & .3202 \\
\hline $\begin{array}{l}\mathrm{R}^{2} \\
\mathrm{~N} \\
\mathrm{SEE}\end{array}$ & & $\begin{array}{r}0.59 \\
43 \\
0.05\end{array}$ & $\begin{array}{l}-- \\
43 \\
--\end{array}$ \\
\hline
\end{tabular}

NOTE: $\underline{t}$-ratio scores in parentheses.

aSignificant at the .05 level in a two-tailed test. bSignificant at the .10 level in a two-tailed test. 
statistically significant at the .05 level. The remaining eight variables, including education, race, age structure, unemployment, median number of rooms per unit, plumbing, and the age of the housing unit, have mixed support for the hypotheses, and their impact on neighborhood revitalization in Northeast Portland at the start of the 1970 decade was not significant.

The strong negative outcome of the distance from the CBD factor suggests that a significant revitalization activity by young, educated, single individuals as well as childless couples employed in middle-class professional positions in the downtown businesses in order to be closer to work occurred in areas of Northeast Portland that are closer to the CBD at the start of the 1970 decade. In the city sample the distance factor did not have any impact on neighborhood revitalization.

The strong negative correlation of the owner-occupied housing units suggests a causal relationship operating in the opposite direction. The effect of this variable in the city sample was also not significant either in support of the hypothesis or in opposing it.

A further inspection of Table VI shows that the variation that resulted from the change in the home value index as a result of the nine variables operating together is relatively high, $\mathrm{R}^{2}=.59$. Table VI also shows the 
standardized coefficients for the variables. According to these coefficients, owner-occupied housing units and distance, with beta weights of $b=.69$ and $b=.39$, emerged as much better predictors of neighborhood revitalization. The relatively high $\mathrm{R}^{2}$ and the low standard error estimate confirm the success of this model in terms of relating the dependent variable to the independent variables.

Regression Results of the Rent Index in Northeast Portland

According to the results presented in Table VII two factors--owner-occupied housing units and plumbing--have the expected coefficient signs that support the hypotheses, and both factors are statistically significant at the .001 level. The race factor refutes the hypothesis, but it is statistically significant at the .001 level, indicating a causal relationship in the opposite direction. The remaining factors in the regression equation have mixed support for the hypotheses, but the lack of statistical significance renders very little meaning to their impact on neighborhood revitalization.

The strong positive causal relationship of the plumbing factor indicates a systematic reverse filtering trend in Northeast Portland at the start of the 1970 decade. That is, first home-buyers were attracted to old, strong, and architecturally unique housing units in Northeast Portland. 
TABLE VII

REGRESSION RESULTS FOR THE CHANGE IN THE

RENT INDEX FOR N.E. PORTLAND 1970 AND 1980

\begin{tabular}{|c|c|c|c|}
\hline \multirow{2}{*}{\multicolumn{2}{|c|}{ Independent Variables }} & \multicolumn{2}{|c|}{$\begin{array}{l}\text { Depencient Variables } \\
\text { Rent } 1970 \text { and } 1980\end{array}$} \\
\hline & & B & Beta \\
\hline 1 . & Distance from the CBD & $\begin{array}{l}.0298 \\
(.801)\end{array}$ & .2628 \\
\hline 2. & $\begin{array}{l}\text { Percent of persons with four or } \\
\text { more years of college education }\end{array}$ & $\begin{array}{l}.0035 \\
(.499)\end{array}$ & .1332 \\
\hline 3 . & Percent of black population & $(\dot{00044}) \mathrm{a}$ & .5314 \\
\hline 4 . & $\begin{array}{l}\text { Percent of owner-occupied } \\
\text { housing units }\end{array}$ & $(2.0077) a$ & .9260 \\
\hline 5 & $\begin{array}{l}\text { Percent of persons aged } \\
60 \text { years and over }\end{array}$ & $\begin{array}{l}-.0184 \\
(-.561)\end{array}$ & -.1136 \\
\hline & $\begin{array}{l}\text { Percent of persons } \\
\text { unemployed }\end{array}$ & $(.0047)$ & .0826 \\
\hline 7. & $\begin{array}{l}\text { Median number of rooms per } \\
\text { housing unit }\end{array}$ & $\begin{array}{l}-.0808 \\
(-.807)\end{array}$ & -.3781 \\
\hline 8. & $\begin{array}{l}\text { Percent of housing units } \\
\text { lacking plumbing }\end{array}$ & $\begin{array}{c}.0271 \\
(2.374) \mathrm{a}\end{array}$ & .5081 \\
\hline 9. & $\begin{array}{l}\text { Percent of housing units } \\
\text { built before } 1939\end{array}$ & $\begin{array}{l}.0006 \\
(.337)\end{array}$ & .0868 \\
\hline $\begin{array}{l}\mathrm{R}^{2} \\
\mathrm{~N} \\
\text { SEE }\end{array}$ & & $\begin{array}{r}0.42 \\
43 \\
0.13\end{array}$ & $\begin{array}{l}-- \\
43 \\
--\end{array}$ \\
\hline
\end{tabular}

NOTE: $\underline{t}$-ratio scores in parentheses. asignificant at the .05 level in a two-tailed test. 
This finding is consistent with the reverse filtering trend observed in the city sample.

The strong positive causal relationship of the owneroccupied housing units factor indicates an increased incidence of neighborhood revitalization activity in Northeast Portland at the start of the 1970 decade as reflected in the high proportion of owner-occupied housing units. In the city sample this factor did not have any statistical significance.

The strong positive causal relationship of the race factor underscores the problem of housing affordability faced by black renters in Northeast Portland whose incomes could not keep pace with housing costs. Consequently their demand for rental housing may have grown faster than the supply of rental housing in an already segregated rental market at the start of the decade.

The variation in the change of the rent index with all the nine predictors operating jointly is relatively high, $\mathrm{R}^{2}$ $=.42$. According to the standardized coefficients presented in Table VII, owner-occupied housing units, race, and plumbing factors, with beta weights of $b=.92, b=.53$, and $\mathrm{b}=.50$, emerged as the best predictors of neighborhood revitalization. The relatively high $\mathrm{R}^{2}$ and the low standard error estimate confirm the success of this model in relating the dependent variable to the independent variables. 
In all of the three models used for assessing the effects of the structural indicators on neighborhood revitalization in Northeast Portland, significant evidence of an upward filtering trend at the start of the decade was observed. Such evidence was underscored by the strong positive causal relationship of the age of the housing unit indicator which suggests an increased interest by renovators in old but strong housing units with an architectural appea1. Further evidence of the upward filtering trend in Northeast Portland was manifested by the movement of black residents and renovators in tandem and the high proportion of home ownership at the start of the 1970 decade as reflected by the strong positive causal relationship of the race and home ownership indicators.

In the discussion that follows, the effects of the nine indicators on neighborhood revitalization in Southeast Port1 and are evaluated. This will be followed by an analysis of the pooled models in which a Chow Test (Maddala, 1977) was used to evaluate the stability of the coefficients and the urban structural shifts in the Northeast and Southeast samples relative to the city sample between 1970 and 1980 .

Regression Results of the Income Index in Southeast Portland

The results presented in Table VIII show distance as the only structural indicator with a strong negative causal relationship. The remaining structural indicators in the 
TABLE VIII

REGRESSION RESULTS FOR THE CHANGE IN THE

INCOME INDEX FOR S.E. PORTLAND

1970 AND 1980

\begin{tabular}{|c|c|c|c|}
\hline \multirow{2}{*}{\multicolumn{2}{|c|}{ Independent Variables }} & \multicolumn{2}{|c|}{$\begin{array}{l}\text { Dependent Variables } \\
\text { Income } 1970 \text { and } 1980\end{array}$} \\
\hline & & $\mathrm{B}$ & Beta \\
\hline 1 . & Distance from the CBD & $\begin{array}{l}-.0542 \\
(-2.30 .5) a\end{array}$ & -.8800 \\
\hline 2 . & $\begin{array}{l}\text { Percent of persons with four or } \\
\text { more years of college education }\end{array}$ & $\begin{array}{l}.0033 \\
(.495)\end{array}$ & .1770 \\
\hline 3 . & Percent of black population & $\begin{array}{l}-.0226 \\
(-.490)\end{array}$ & -.1105 \\
\hline 4 & $\begin{array}{l}\text { Percent of owner-occupied } \\
\text { housing units }\end{array}$ & $(.0012$ & .2179 \\
\hline 5 & $\begin{array}{l}\text { Percent of persons aged } \\
60 \text { years and over }\end{array}$ & $\begin{array}{l}-.0234 \\
(-.830)\end{array}$ & -.2396 \\
\hline 6 & $\begin{array}{l}\text { Percent of persons } \\
\text { unemployed }\end{array}$ & $\begin{array}{l}-.0092 \\
(-.747)\end{array}$ & -.1942 \\
\hline 7 & $\begin{array}{l}\text { Median number of rooms per } \\
\text { housing unit }\end{array}$ & $\begin{array}{l}-.1096 \\
(-.835)\end{array}$ & -.7142 \\
\hline 8. & $\begin{array}{l}\text { Percent of housing units } \\
\text { lacking plumbing }\end{array}$ & -.0077 & -.0005 \\
\hline 9 & $\begin{array}{l}\text { Percent of housing units } \\
\text { built before } 1939\end{array}$ & $\begin{array}{l}-.0023 \\
(-1.518)\end{array}$ & -.4861 \\
\hline $\begin{array}{l}\mathrm{R}^{2} \\
\mathrm{~N} \\
\mathrm{SEE}\end{array}$ & & $\begin{array}{r}0.49 \\
34 \\
0.08\end{array}$ & $\begin{array}{l}-- \\
34 \\
--\end{array}$ \\
\hline
\end{tabular}

NOTE: t-ratio scores in parentheses. aSignificant at the .05 level in a two-tailed test. 
regression equation had no statistical significance either in support of or in opposition to the research hypotheses.

The strong negative outcome of the distance factor at the .001 level of significance supports the contention that the shorter the travelling distance, the greater the incidence of neighborhood revitalization. That is, areas in Southeast Portland closer to the CBD experienced a significant incidence or occurrence of revitalization at the beginning of the 1970 decade. In the city sample the outcome of this variable was negative but had no significant impact.

The variation in the change of the household income index with all the nine structural indicators operating jointly is relatively high, $\mathrm{R}^{2}=.49$. The standardized coefficients presented in Table VIII further reveal that the distance factor, with a beta weight of .88 , was the best predictor of neighborhood revitalization. Furthermore, the high $\mathrm{R}^{2}$ and the low standard error estimate of .08 confirm the success of this model in predicting neighborhood revitalization in Southeast Portland.

Regression Results of the Home Value Index in Southest Portland

The results of the home value index in Table IX are mixed in terms of predicted direction as well as in magnitude. One factor--the age of the housing unit--among the nine structural indicators has the expected positive 
TABLE IX

REGRESSION RESULTS FOR THE CHANGE IN THE

HOME VALUE INDEX FOR S.E. PORTLAND

1970 AND 1980

\begin{tabular}{|c|c|c|c|}
\hline \multirow{2}{*}{\multicolumn{2}{|c|}{ Independent Variables }} & \multicolumn{2}{|c|}{$\begin{array}{l}\text { Dependent Variables } \\
\text { Home Value } 1970 \text { and } 1980\end{array}$} \\
\hline & & B & Beta \\
\hline 1 . & Distance from the CBD & $\begin{array}{l}.0040 \\
(.325)\end{array}$ & .0840 \\
\hline 2. & $\begin{array}{l}\text { Percent of persons with four or } \\
\text { more years of college education }\end{array}$ & $\begin{array}{l}.0004 \\
(.232)\end{array}$ & .0560 \\
\hline 3. & Percent of black population & $\begin{array}{l}-.0099 \\
(-.407)\end{array}$ & -.0621 \\
\hline 4 . & $\begin{array}{l}\text { Percent of owner-occupied } \\
\text { housing units }\end{array}$ & $(.0010)$ & .2330 \\
\hline 5. & $\begin{array}{l}\text { Percent of persons aged } \\
60 \text { years and over }\end{array}$ & $\begin{array}{l}.0008 \\
(.056)\end{array}$ & .0110 \\
\hline 6. & $\begin{array}{l}\text { Percent of persons } \\
\text { unemployed }\end{array}$ & .0002 & .0065 \\
\hline 7. & $\begin{array}{l}\text { Median number of rooms per } \\
\text { housing unit }\end{array}$ & $\begin{array}{l}-.0999 \\
(-1.441)\end{array}$ & -.8346 \\
\hline 8. & $\begin{array}{l}\text { Percent of housing units } \\
\text { lacking plumbing }\end{array}$ & $\begin{array}{l}-.0002 \\
(-.005)\end{array}$ & -.0015 \\
\hline 9. & $\begin{array}{l}\text { Percent of housing units } \\
\text { built before } 1939\end{array}$ & $(2.0023) a$ & -.6023 \\
\hline $\begin{array}{l}\mathrm{R}^{2} \\
\mathrm{~N} \\
\mathrm{SEE}\end{array}$ & & $\begin{array}{r}0.76 \\
34 \\
0.04\end{array}$ & $\begin{array}{l}-- \\
34 \\
--\end{array}$ \\
\hline
\end{tabular}

NOTE: t-ratio scores in parentheses.

asignificant at the .05 level in a two-tailed test. 
coefficient sign that is consistent with the hypothesis. This factor is also statistically significant at .05 level. The remaining factors in the regression equation have mixed expectations and their impact was insignificant due to the lack of levels of significance.

The strong positive causal relationship of the age of the housing unit factor suggests that at the beginning of the 1970 decade renovators who were likely first-home buyers showed a vested interest in older housing units in the inner Southeast area of Portland. This finding is consistent with the reverse filtering trend observed in the entire city sample as well as in the Northeast sample of Portland. Table IX further shows that the variation in the home value index caused by all the nine structural factors operating togehter is relatively high, $\mathrm{R}^{2}=.76$. The outcome of the standardized coefficient for the age of housing unit factor, with a beta weight of $b=.60$, further suggests that this factor was the best predictor of neighborhood revitalization in Southeast Portland at the start of the 1970 decade. The high $\mathrm{R}^{2}$, the low standard error estimate notwithstanding, confirms the success of the model in predicting gentrification. 
Regression Results of

the Rent Index in

Southeast Portland

The results of this index shown in Table $X$ have mixed support for the hypotheses. For example, among the nine structural indicators in the regression equation six factors --race, age structure, unemployment, median number of rooms per unit, plumbing, and the age of the housing unit--have the expected coefficient signs consistent with the hypotheses. The remaining three factors--education, distance, and homeownership--have opposing coefficient signs. All together, the effects of the structural indicators in this index were nonsignificant due to the lack of statistica1 significance.

The variation in the rent index with all the factors operating jointly is very sma $11, R^{2}=.13$. The small standard error estimate of .12 may be indicative of the success of the model in predicting gentrification rather weakly. On the whole the statistically significant outcome of the distance factor in the income index on one hand and the statistically significant outcome of the age of the housing unit factor in the home value index on the other may be indicative of a reverse filtering trend of neighborhood revitalization in areas of Southeast Portland that are closer to the CBD at the start of the 1970 decade.

The analysis continues with the results of the pooled models discussed below. 
TABLE $X$

REGRESSION RESULTS FOR THE CHANGE IN THE RENT INDEX IN S.E. PORTLAND 1970 AND 1980

\begin{tabular}{|c|c|c|c|}
\hline \multirow{2}{*}{\multicolumn{2}{|c|}{ Independent Variables }} & \multicolumn{2}{|c|}{$\begin{array}{l}\text { Dependent Variables } \\
\text { Rent } 1970 \text { and } 1980\end{array}$} \\
\hline & & B & Beta \\
\hline 1. & Distance from the CBD & .0121 & .1675 \\
\hline 2. & $\begin{array}{l}\text { Percent of persons with four or } \\
\text { more years of college education }\end{array}$ & $\begin{array}{l}-.0001 \\
(-.011)\end{array}$ & -.0049 \\
\hline 3. & Percent of black population & $\begin{array}{l}-.0351 \\
(-.496)\end{array}$ & -.1462 \\
\hline $4 \cdot$ & $\begin{array}{l}\text { Percent of owner-occupied } \\
\text { housing units }\end{array}$ & $\begin{array}{l}-.0054 \\
(-1.003)\end{array}$ & -.8078 \\
\hline 5. & $\begin{array}{l}\text { Percent of persons aged } \\
60 \text { years and over }\end{array}$ & $\begin{array}{l}-.0471 \\
(-1.084)\end{array}$ & -.4098 \\
\hline 6. & $\begin{array}{l}\text { Percent of persons } \\
\text { unemployed }\end{array}$ & $\begin{array}{l}-.0233 \\
(-1.225)\end{array}$ & -.4172 \\
\hline $7 \cdot$ & $\begin{array}{l}\text { Median number of rooms per } \\
\text { housing unit }\end{array}$ & $.1036)$ & .5749 \\
\hline 8. & $\begin{array}{l}\text { Percent of housing units } \\
\text { lacking plumbing }\end{array}$ & $(.0056)$ & .2771 \\
\hline 9 . & $\begin{array}{l}\text { Percent of housing units } \\
\text { built before } 1939\end{array}$ & $\begin{array}{l}.0006 \\
(.057)\end{array}$ & .1077 \\
\hline $\begin{array}{l}R^{2} \\
N \\
S E E\end{array}$ & & $\begin{array}{r}0.13 \\
34 \\
0.12\end{array}$ & $\begin{array}{l}-- \\
34 \\
--\end{array}$ \\
\hline
\end{tabular}

NOTE: t-ratio scores in parentheses. 


\section{RESULTS OF THE POOLED MODELS}

At this stage of the analysis it is essential to estab$l$ ish whether or not there is a difference in the urban structural changes between the regression models representing the two submodels representing Northeast and Southeast Portland with respect to the null hypothesis. Therefore, the null hypothesis is that there is no difference. Presumably, the differences between one model in terms of the structural changes that occurred at the start of the 1970 decade were actually different from those of the other model. But the significance level at which the null hypothesis can be rejected becomes the question. In order to make this assessment, various forms of the Chow Test (Maddala, 1977) were employed. The test is represented by this formula:

$$
F=\frac{\left(\left(R_{R S S}-\mathrm{URSS}_{1}+\mathrm{URSS}_{2}\right)\right) / \mathrm{K}}{\left(\mathrm{URSS}_{1}+\mathrm{URSS}_{2}\right) /(\mathrm{n} 1+\mathrm{n} 2-2 \mathrm{~K})}
$$

where

$$
\begin{aligned}
\text { RRSS }= & \text { the restricted residual sum of squares } \\
& \text { derived from the regressions of the } \\
& \text { Northeast and Southeast Portland } \\
& \text { models or samples combined. } \\
\text { URSS } 1=_{1} & \text { the unrestricted residual sum of squares } \\
& \text { derived from the Northeast Portland sample }
\end{aligned}
$$




$$
\begin{aligned}
& \text { URSS }_{2}=\text { the unrestricted residual sum of squares } \\
& \text { derived from the Southeast Portland sample } \\
& \mathrm{nl}=\text { number of cases for the Northeast Portland } \\
& \text { sample } \\
& \text { n2 }=\text { number of cases for the Southeast Portland } \\
& \text { sample } \\
& \mathrm{K}=\text { number of regressors }
\end{aligned}
$$

The $\mathrm{F}$ distribution has $\mathrm{K}, \mathrm{nl}+\mathrm{n} 2-2 \mathrm{~K}$ degrees of freedom, respectively.

Al1 together there are three measures of neighborhood revitalization regressed against nine urban structural indicators. This resulted in three regression equations for the entire city of Portland sample. The same three measures (change in median household income, change in median home value, and change in median rent) were regressed against the same nine structural indicators to assess the urban structural changes that occurred in the two submodels representing the Northeast and Southeast areas of Portland between 1970 and 1980. This procedure resulted in six regression equations--three equations for each submodel--that were used in the Chow Tests.

Al1 together three Chow Tests--one test for each measure of neighborhood revitalization--were employed to assess the structural differences between the two submodels. Each test comprised of the difference between the combined restricted residual sum of squares for the two submodels and 
the sum of the unrestricted residual sum of squares of the two submodels. The calculated $F$ ratios for the Chow Tests are presented in Table XI.

According to the $F$ ratios which were compared to the $5 \%$ significance level, the following conclusions with regard to the null hypothesis were made. All the calculated F ratios were found to be significant at the $5 \%$ level. It implies that between 1970 and 1980 there were significant urban structura1. differences in neighborhood revitalization between the two submodels. Therefore, the null hypothesis of no difference between the regression coefficients is i rejected. For example, in the household income index for both submodels the regression coefficients of four factors (home ownership, age structure, plumbing and age of the housing unit had signs in the predicted direction and at the same time exerted a significant impact on the neighborhood revitalization process in Northeast Portland. Compared to the Southeast submodel only one factor (distance) had a । coefficient sign in the predicted direction and at the same time exerting a significant impact on neighborhood revitalization. For the home value index for both submodels two: factors (distance and home ownership) were found to exert a significant impact on neighborhood revitalization in Northeast Portland. But while the effect of distance turned out as predicted, the effect of home ownership was found to be operating in the opposite direction. Compared ta the 
TABLE XI

CHOW TEST RESULTS OF THE DIFFERENCES BETWEEN THE REGRESSION COEFFICIENTS OF THE TWO SUBMODELS

\begin{tabular}{lccccccc}
\hline Dependent Variable & RRSS & $\mathrm{URSS}_{1}$ & $\mathrm{URSS}_{2}$ & $\mathrm{DF}_{1}$ & $\mathrm{DF}_{2}$ & Chow F & $\begin{array}{c}5 \% \\
\text { Significance }\end{array}$ \\
\hline 1. Income & 1.4478 & .1512 & .1585 & 9 & 59 & 24.1 & .05 \\
2. Home value & 1.4478 & .0842 & .0442 & 9 & 59 & 67.6 & .05 \\
3. Rent & 1.4478 & .6347 & .3750 & 9 & 59 & 2.8 & .05 \\
\hline
\end{tabular}


Southeast submodel the effect of the age of housing was not only significant and in the predicted direction but also suggests a reverse filtering trend in Southeast Portland. Similarly, the results of the rent index for both submodels show that three factors (home ownership, plumbing and race) had a significant impact on neighborhood revitalization in Northeast Portland. But while the coefficients of home ownership and plumbing had the expected signs, that of the race factor had an opposing coefficient sign. Compared to Southeast Portland no coefficient was found to have any significant impact.

Since the Chow Tests only revealed the significance of the differences between the coefficients, another pooling technique--a measure of relative variability to obtain coefficients of variation derived by dividing the standard deviation by the mean of each structural variable for the two samples--was used. This technique was employed to determine the effect of each structural characteristic on neighborhood revitalization between the two submodels. The results of this pooling technique are presented in Table XII.

According to these results, the coefficient differentials for the nine structural indicators in both submodels range from -.37 to 1.14 . The computed coefficient of variation for the race factor in the Northeast submodel is 2.01 . The corresponding coefficient of variation for the same 
TABLE XII

COEFFICIENTS OF VARIATION (MEASURES OF RELATIVE VARIABILITY) FOR THE TWO SUBMODELS

\begin{tabular}{|c|c|c|c|c|c|c|c|c|}
\hline \multirow{2}{*}{\multicolumn{2}{|c|}{ Variables }} & \multicolumn{3}{|c|}{$\begin{array}{l}\text { N.E. Portland } \\
\mathrm{N}=43\end{array}$} & \multicolumn{3}{|c|}{$\begin{array}{c}\text { S.E. Portland } \\
\mathrm{N}=34\end{array}$} & \multirow[b]{2}{*}{ Difference } \\
\hline & & Mean & SD & $\begin{array}{l}\text { Coeff. of } \\
\text { Variation }\end{array}$ & Mean & $\mathrm{SD}$ & $\begin{array}{l}\text { Coeff. of } \\
\text { Variation }\end{array}$ & \\
\hline 1. & Distance & 4.151 & 1.415 & .34 & 3.591 & 1.587 & .44 & -.10 \\
\hline 2 . & Education & 9.267 & 5.992 & .64 & 8.162 & 5.152 & .63 & .01 \\
\hline 3. & Race & 9.593 & 19.312 & 2.01 & .544 & .478 & .87 & 1.14 \\
\hline 4. & Owner-occupied housing units & 62.491 & 19.335 & .30 & 58.453 & 16.965 & .29 & .01 \\
\hline 5 . & Age structure & 5.407 & .991 & .18 & 5.138 & .998 & .19 & -.01 \\
\hline 6 . & Unemployment & 6.965 & 2.784 & .39 & 6.429 & 2.053 & .31 & .08 \\
\hline & Number of rooms per unit & 5.012 & .753 & .15 & 4.856 & .637 & .13 & .02 \\
\hline & Plumbing & 2.147 & 3.015 & 1.40 & 3.162 & 5.605 & 1.77 & -.37 \\
\hline & Age of housing unit & 57.249 & 21.492 & .37 & 52.976 & 19.861 & .37 & .00 \\
\hline
\end{tabular}


factor in the Southeast submodel is .87 . The difference in the coefficient of variation between the two submodels is 1.14. Therefore, the impact of the race factor at the start of the 1970 decade was greater in Northeast Portland than in Southeast Portland. The remaining variables in both submodels as reflected by the magnitude of their coefficients had very little effect.

In summary, between 1970 and 1980 there were more census tracts that had reached the threshold of decline than those census tracts that were either rising or considered to be stable. For example, approximately $64 \%$ of all three measures of neighborhood revitalization were in decline, compared to only $37 \%$ of upscaled census tracts and $5 \%$ stable census tracts at the start of the decade.

With regard to the results of the regression model for the city sample, one would conclude that the city of Portland was undoubtedly the only city in the nation wherein a significant and systematic reverse neighborhood revitalization trend was observed at the start of the 1970 decade. The strong causal relationship of the age of housing as well as the home ownership factors were a manifestation of this claim. Unlike evidence of isolated cases of neighborhood revival observed in much older and larger cities such as St. Louis and New Orleans. Such evidence captured a lot of media attention as well as the attention of the major participants in the neighborhood revitalization process even 
though the observed revival process in those cities was not extensive.

But the systematic neighborhood revival trend observed in the city of Portland did not seem to extend into predominantly black neighborhoods as the strong negative outcome of the race factor would seem to suggest. If neighborhood revival fell short of predominantly black areas, this inferentially suggests that this segment of the population of the city of Portland may have been subjected to some kind of discriminatory practices by lending institutions as well as by owners of, particularly, rental housing. The latter (rental property owners in the housing market), if given a choice, would tend not to select applications from minority blacks for rental housing occupancy. By and large, such discriminatory practices in the Portland housing market may have drastically reduced the chances of black households or families for home ownership vis-a-vis housing affordability.

With regard to the results of the regression models for the two subarea samples representing Northeast and Southeast Portland a similar reverse neighborhood revival trend was observed as reflected in the strong causal relationship of the neighborhood housing quality factors. But in both submodels, however, unlike the city model wherein the race factor had a strong negative causality, the race factor had a strong positive causal relationsinip with neighborhood revival. The outcome rather than being an indication of 
renovators avoiding black areas, as conventional wisdom suggests, instead suggests that black residents as well as renovators may have moved into both subareas in tandem, with the latter likely displacing some of the former black residents.

On the whole, structural differences between the two submodels on neighborhood revitalization were found to be significant as manifested by the results of the Chow Tests. Those results show that the structural indicators of neighborhood revival in all three measures have more impact in Northeast Portland than in Southeast Portland as reflected in the significance of their coefficients. But the effect of the race factor was found to be greater in Northeast Portland than in Southeast Portland.

In the next chapter the general summary and conclusions for this research are presented and discussed. 


\section{CHAPTER VI}

\section{SUMMARY AND CONCLUSIONS}

This chapter presents the summary and conclusions of the research. These are divided into two parts. Part one provides the general conclusions based on the research findings for the city model as well as the two submodels representing Northeast and Southeast Portland. Part two provides specifics such as the significance of the research

and its theoretical and policy implications derived from the study, and provides suggestions for future research.

\section{PART ONE: GENERAL CONCLUSIONS}

Based on the ratio method three neighborhood change trends between 1970 and 1980 were identified for the sample of 117 census tracts representing the city of Portland. There were more census tracts that had reached the "threshold" of decline than there were revitalizing and stable census tracts. For example, in all three measures of neighborhood change $64 \%$ of the census tracts in the sample declined between 1970 and 1980. During the same period, while $31 \%$ of the remaining census tracts revitalized, only $5 \%$ of the census tracts in the sample remained unchanged. 
According to the results of the regression models for the sample of 117 census tracts representing the city of Portland the age of the housing unit was observed to have a strong positive causal relationship with neighborhood change as predicted. Therefore, it can be concluded that at the start of the 1970 decade there was a systematic reverse filtering trend in the city of Portland. This trend was reflected in the increased demand for older and renovatable housing units in the inner-city areas of the city.

During the 1970 s when housing prices were rising, when interest rates and energy costs were increasing, and when incomes and economic growth were declining, homeownership was believed to be out of reach for families (Rufolo, 1980). In the face of all these problems, how bleak was the housing affordability issue during the 1970s? In order to answer this question, one has to make a passing reference to the housing affordability issue itself.

For almost over a century the "rule of thumb" concept has been used as a measuring instrument as well as an indicator of housing affordability. That concept states that families should spend $25 \%$ of their incomes for housing. The concept has influenced shelter-costs analyses, federal housing legislation for over half a century, and the practices of mortgage institutions (Schnidman and Silverman, 1983). 
From this perspective the housing affordability issue nationwide would be considered to be bleak, as manifested in the following changes in the housing market. Between 1965 and 1979 the median price of a new home rose $215 \%$, from $\$ 20,000$ to $\$ 62,900$. At the same time the estimated monthly expenses on housing increased by $295 \%$, from $\$ 163$ to $\$ 644$. Mortgage rates increased from $5.8 \%$ to $10.8 \%$. The consumer price index by comparison increased $130 \%$, while the median household income rose 175\%. By 1979 it was estimated that only $24 \%$ of all families had incomes that were sufficient to purchase the median priced new home in the country. By the same token, the proportion of new homes bought by first-time buyers dropped (Anderson, 1983).

Despite this bleak housing situation, sales of new homes actually increased by $65 \%$ between the late 1960 s and the late 1970s. As a result homeownership steadily increased during the 1970s (Rufolo, 1980; Anderson, 1983). What the traditional method of measuring housing affordability did not take into account were such parameters as the benefits of homeownership, property tax gains, variable mortgage rates, inflation, housing as an investment, and changes over time in the size of the house as well as in its quality. When all the above-named housing market conditions are included in assessing housing affordability, homeownership increased in the 1970s (Rufolo, 1980; Anderson, 1983). The cost of owning a new house dropped 30\% between 1969 and 
1979. Housing affordability during that 10-year period increased due to the FHA's Section 235 program. That program subsidized low- and moderate-income buyers (Rufolo, 1980; Anderson, 1983).

On the whole housing played the dual role of a consumption good as well as an investment good, as a tax shelter, and as a hedge for inflation (Rufolo, 1980; Anderson, 1983). The end result of these changes "was an enormously ebullient housing market" (Sternlieb and Hughes, 1987).

Despite the 1970 s being termed the decade of economic shock waves in terms of housing affordability, the decade turned out to be America's housing decade with respect to increased homeownership.

For those who want to own their own home, there was a renewed interest in older inner-city homes relative to those in the suburbs. From a demographic standpoint the 1970s also saw an increase in the number of households, due mainly to the maturing of the baby-boomers. This segment of the population was considered to have put considerable pressure on the nation's housing stock even though only a small proportion of them was, theoretically, capable of buying new homes. As a result, older housing units thus became a major target among these competing households (James, 1977). In general, the demographics of the 1970s in terms of age as well as household characteristics had positive results for the housing market (Sternlieb and Hughes, 1987). 
Other urban structural indicators found to have a strong negative causal relationship with neighborhood change in the face of a systematic reverse filtering trend are race and age structure. It can be concluded that the outcome of the race factor within the framework of this observed reverse neighborhood filtering trend seems to support a number of things. First, at the start of the 1970 decade this systematic neighborhood revitalization trend in the city of Portland did not extend into predominantly black areas. Second, the outcome of the race factor may also imply that the black population in the city of Portland at the start of the 1970 decade was small. What then happened to this black population? Inferentially, they may have been victims of racial discrimination in the housing market, which may have militated against their chances for homeownership or even rental housing. Inferentially, they may have become victims of voluntary displacement caused by the changing demographics as well as housing market conditions of the 1970s, which in turn may have led to a renewed interest in older housing units in the inner-city areas.

The evidence of a reverse neighborhood revival in the city of Portland was found to be statistically significant, but its functional significance may not be substantial when compared to larger and older cities such as St. Louis and New Orleans that received media attention. Despite this, the city of Portland, as the research findings indicate, 
was the only city nationwide that experienced a significantly systematic reverse filtering trend in the 1970 decade.

The outcome of the statistically significant age structure factor implies that at the start of the 1970 decade the reverse neighborhood revival in Portland did not extend to predominantly elderly areas. It also implies that the elderly population at the beginning of the decade may have been small and may also have been victims of displacement in the Portland housing market.

With regard to the results of the regression models of the Northeast Portland sample the neighborhood housing quality factors of plumbing and housing age have a strong positive causal relationship with neighborhood change in that subarea. Therefore, it can be concluded that a significant reverse filtering trend similar to the one observed in the city as a whole occurred in the Northeast Portland subarea. That is, an increased demand by renovators for older and renovatable housing units that can be purchased at cheap costs. Such renovation activity was observed to occur in areas closer to the Portland $C B D$ as reflected in the strong negative causal relationship of the distance factor. Furthermore, race, home ownership and age structure were also observed to have a strong causal relationship with neighborhood change in Northeast Portland. The outcome makes one conclude that a significant revitalization 
activity occurred in Northeast Portland at the start of the 1970 decade as reflected by the relatively high proportion of homeownership. The occurrence of such activity may have been marked by renovators moving into the area in tandem with blacks at the start of the 1970 decade as the strong positive outcome of the race factor seems to suggest. During the same period the number of elderly residents in the area may have been relatively small because of the strong negative performance of the age structure variable. As a result of this the presence of the elderly may not have posed a deterrence to revitalization as suggested by some urban theorists (Varady, 1986).

With regard to the regression results of the Southeast Portland sample two factors--the age of the housing unit and distance--have the expected coefficient signs consistent with the hypotheses. But their effects on neighborhood change in Southeast Portland were found to be discontinuous because of their alternating levels of significance. Therefore, one would conclude that because of the alternating levels of significance exhibited by these two factors a similar reverse filtering trend observed in the city sample as well as in the Northeast Portland sample had either just begun or had started to slow down at the start of the 1970 decade.

In all three samples the results of the Chow Test show that between 1970 and 1980 significant structural 
differences between the models on neighborhood change occurred. But the effect of the race factor was found to be greater in Northeast Portland than in Southeast Portland. This dichotomy may be attributed to the manner in which the population of the city of Portland was distributed at the start of the decade. According to the neighborhood information profiles (Office of Planning and Development, 1970, 1980) Portland's black population in the 1970 s and 1980 s was centered in the Northeast in such neighborhoods as Humboldt, Boise, King-Vernon-Sabin, and Woodlawn with a wide range of socioeconomic levels among the residents.

\section{PART TWO: SPECIFICS FROM THE RESEARCH}

In light of the discussion in the first part of the summary and conclusions and in light of the objective of this research, specifics derived from the present study are presented as responses to the following questions:

1. What is the significance of this research in relation to other studies.

2. What are the theoretical implications of this research?

3. What are its policy implications?

4. What suggestions can be made for future research? 
Significance of the Research

The significance of this research is predicated on two aspects. First, what contribution has this study made toward the field of empirical social research? Second, to what extent are the findings of this study consistent with other studies that pertain to neighborhood change?

With regard to the first question, the major contribution of this research is that it puts into perspective the urban structural indicators that determine neighborhood revival in the city of Portland. Such change in the face of changing demographic as well as housing market conditions can have social and political implications.

As regards the second aspect, the research findings point direction to a systematic reverse filtering trend in the study area due to the strong positive causal relationship of the neighborhood housing quality variables. This outcome provides a contradiction of the conventional theory associated with Burgess (1925) and his associates of the Chicago School. The research findings imply that at the start of the 1970 decade the demand among renovators for older and renovatable housing in the inner-city neighborhoods of the city of Portland was significant. This finding is consistent with the models of Clay (1978; 1979), James (1977), Laska and Spain (1979), Sternlieb and Hughes (1979), Spain (1980), Laska et al. (1982), Lee and Mergenhagen (1984), and Gale (1984) reviewed in the literature in 
which a similar process was attributed to neighborhood housing quality.

The increased desirability of older and renovatable housing units among renovators was precipitated by demographic changes as well as changing housing market conditions (James, 1977; Anderson, 1983; Sternlieb and Hughes, 1987). The demographic changes of the 1970s in terms of age and household characteristics had positive results for housing. First and foremost, the maturing of the babyboomers tended to increase the proportion of potential home buyers in the 1970 s even though, in theory, only a small proportion of them could afford the means of buying new homes (Sternlieb and Hughes, 1987). Changes in housing market conditions that included benefits of homeownership, property tax gains, inflation, variable mortgage rates, and housing as a consumer good and an investment good, all taken into account, tended to increase homeownership in the face of rising prices for housing during the 1970s (Rufolo, 1980; Anderson, 1983).

According to James (1977) the low production of new housing units since 1974 made the prices of new housing units not only more expensive but out of reach for most first-time home buyers. The alternative for these firsthome buyers is to opt for less expensive older housing in inner-city areas relative to those more expensive ones in 
the suburbs. The housing market situation in the country was described as follows:

In recent years new housing has increasingly become a luxury reserved for relatively affluent families. Many housing consumers faced with a choice between modest, basic new homes and older homes available in the existing stock have decided that older housing is the better buy (James, 1977, p. 67).

The research findings seem to be consistent with the economic rationale for the displacement hypothesis (Clay, 1979; Zeitz, 1979; Sumka, 1979; Schil1 and Nathan, 1983). That rationale is hinged on the contention that demand for older and architecturally appealing housing units located in the inner-city tend to increase considerably when a neighborhood has attained an appreciable level of respect among potential renovators during its late cycle of change (Lee et a 1., 1985).

In the city of Portland the results of a displacement study provided tangential or very 1 imited evidence to the city's displacement problem (Lycan, 1978). For example, 10\% of the respondents in the survey sample indicated that they had moved involuntarily. Approximately $3.2 \%$ of these respondents said they had moved because the house was sold or the owner had moved into it. Another $3 \%$ mentioned demolition or poor maintenance as the reason for moving. However, that study estimated that $1.7 \%$ of the households in the city moved involuntarily for various reasons that 
included disinvestment, revitalization, and housing market conditions (Lycan, 1978).

\section{Theoretical Implications}

The research findings have theoretical implications. From a theoretical perspective the invasion-succession concept associated with Burgess (1925) is now open to challenge or modification. This is because the dynamics that concept describes seem to be contradicted by the reverse filtering trend, that is, the increasing popularity of inner-city neighborhoods being the sites of housing revitalization and middle-class homes (Lee and Mergenhagen, 1984).

The strong positive causal relationship of the neighborhood housing quality variables point to a reverse filtering trend in the city of Portland. That is to say, first-time home buyers, especially young educated adults who are employed in professional and managerial positions, are now willing to invest in older and easily renovatable housing units in the inner-city neighborhoods. These areas have invariably been the homes of low-income residents. Therefore, a neighborhood or group of neighborhoods displaying combined demographic as well as housing market changes, characteristically become the type of neighborhood in which reverse filtering causes a neighborhood change that contradicts the conventional ecological or invasion-succession theory (Burgess, 1925). 
The latter has also been referred to as the segregation theory which asserts that the proportion of black residents in a neighborhood can reach a "tipping point" estimated to be $10-30 \%$ of the entire neighborhood population. At this point white residents in the area begin to flee. While other whites in the area begin to move out at the normal rate, those living exclusively outside the neighborhood become even more reluctant to move in. Eventually all the vacant housing units have become completely occupied by the black residents (Lee, 1985).

This theory is not supported by the findings of this research even though the race factor had a strong negative causal relationship with neighborhood change that may imply an avoidance by renovators of areas occupied by blacks. The outcome of the race factor can be explained in terms of the small proportion of black residents in the city of Portland at the start of the decade rather than the race factor being a distraction.

Another theoretical perspective that is not supported by the findings of this research is the arbitrage model (Leven et al., 1976) which asserts that black inmigration signals a change in its housing occupancy. That is to say, lower income residents are succeeding higher income residents in inner-city areas. In other words, household utility has a direct positive relationship on neighborhood 
income and a negative effect on the proportion of the nonwhite population (Leven et a1., 1976).

\section{Policy Implications}

The finding of this research that the city of Portland experienced a reverse filtering trend between 1970 and 1980 has several policy implications that are relevant to policymakers and planners on one hand and to the actors in the housing market on the other. These actors include real estate developers, builders, material producers, mortgage lenders, landlords, and home owners, to name but a few.

From a policy standpoint it is believed that if older and renovatable housing units in the inner-city neighborhoods continue to lure renovators as observed in this research, racial diversity would be achieved in the not too distant future. This implies planning for racially and economically diversified neighborhoods. It is also believed that private inner-city reinvestment provides an opportunity that favors the development of racially and economically integrated neighborhoods (HUD, 1979). Therefore, city governments, all things being equal, tend to encourage neighborhood revitalization because renovators have the capability of increasing the city's tax base and, more importantly, the rate at which they consume public services is comparatively much smaller than that of low-income minority households (Lee et al., 1985). 
The economic rationale for the displacement hypothes is is keyed on the notion of increased demand for older housing units in the inner-city areas. Displacement being a consequence of neighborhood revitalization has intriguing policy implications. If displacement as a concept is voluntary, that is, if low-income minority residents decide to leave the inner-city neighborhoods of their own free volition to occupy good quality housing elsewhere in the city, then the city should adopt the following policies. It should provide more subsidy programs, adopt a mortgage loan disclosure regulation or ordinance, and adopt much stricter fair housing ordinances to ensure that every city resident shares in the American dream. On the other hand, if the displacement is involuntary, that is, if it is caused by gentrification, as is oftentimes the case, then the impacts of any policy on the residents or the neighborhoods become suspect. As a matter of fact, housing policies at all levels of government in the post-World War inner-city era have tended to favor the affluent through direct and indirect assistance, while direct assistance to the low-income residents or households has, at best, been only modest (Adams, 1987). According to Hartman (1983) the improvement in housing in the past by either the local, state or federal government was only undertaken when it reflected the interests of the private sector and when political and economic pressures nave warranted the improvement. 
For those actors 1 ike real estate developers, speculators, mortgage lenders, landlords, and homeowners in the private sector, such housing policies imply a booming business. Once a neighborhood has attained some level of confidence or respect, the arrival of renovators will have a considerable impact on that neighborhood's housing market. For example, the increased demand for older housing creates a sudden increase in homeownership, increase in home values, a reduction in vacancy rates, the eviction rate and rents increase, and multi-family rental units re converted to single-family occupancy. Such housing market changes may result to an increase in property taxes that may be too much of a financial burden for some homeowners, renters, and minority households that are likely to be displaced or evicted.

The demand for older and renovatable housing units in the inner-city has another policy implication. Now that the neighborhood has been revitalized or is undergoing revitalization, such services as the provision of recreational facilities, street lighting, sidewalk improvement, and pubIic safety that declined with the neighborhood should be reactivated.

Also, from a policy standpoint, the demand for older and renovatable housing units in the inner-city implies that a much stricter and workable code enforcement policy deserves credit if proper maintenance and repairs are to be 
sustained in the revitalized neighborhood in the long term. Landlords and homeowners often prompted by the increased demand for older housing units as well as the profit motive, have a tendency to undertake only minor or cosmetic repairs at the expense of major repairs that are far more important. A strict code enforcement ordinance by the city will address this problem.

On the whole a coordinated understanding of what is needed for reinvestment among decision-makers and the other actors in the housing market deserves credit. Otherwise, cities will continue to find ways and means of increasing property tax revenues, lending institutions will try to maximize their economic security and profits for their investment, and the rehabilitated property will continue to elude the vast majority of low- and moderate-income households .

In the opinion of the writer, the political and economic conditions in the city of Portland create a situation in which the housing wants and needs of the highstatus households tend to be given much greater attention and political urgency than the housing needs of the lowincome and minority city residents. Unless a broad-based policy that will cater for all the various interest groups in the housing market is in place, revitalization and its residential consequences will continue in the 1980 s and beyond. 


\section{Suggestions for Future}

\section{$\underline{\text { Research }}$}

The extent to which reverse filtering or gentrification has impacted the racial composition of the residents in the city of Portland--that is, black-to-white racial change--is an empirical question worthy of investigation.

The use of structural indicators such as the ones employed in this research may not be the best way to monitor neighborhood change. For example, the strong negative outcome of the race factor amid a reverse filtering trend in the study sample does not seem to lend support to the conventional racial hypothesis. Since blacks, in most instances, are the ones that are "priced out" in the gentrification process, this research suggests that a benefit-cost analysis deserves credit. This enables the researcher to find out the beneficiaries as well as the losers of various housing programs.

Another empirical challenge is the use of the homeownership variable keyed upon the assumption that an increase in the proportion of homeownership signals an incidence or the start of neighborhood revitalization. According to some housing market analysts the transaction of a property involves multiple sales of the same property within a short period of time. This implies that the initial purchases were not even made by the incumbent property owner (James, 1977). Therefore, an increase in homeownership may not be a 
lead indicator of neighborhood revitalization because homeownership increases can only be determined after the occurrence of a substantial rate of speculation (De Giovanni, 1983). In light of this problem, this research suggests that a much more reliable indicator of neighborhood revitalization is the use of multiple property sales over a certain period of time as a proxy for speculation.

Furthermore, to make the monitoring of the structural impacts of neighborhood revitalization more effective, this research suggests that each structural indicator should be monitored at time intervals. This process can be complemented by frequent spot checks or field observations, such as the various types residents moving into and out of a specific neighborhood. Such a procedure would provide an invaluable insight into the changes that have occurred in that neighborhood in terms of its racial transition. 


\section{REFERENCES}

Abbott, C. (1983), Portland: Planning, Politics and Growth in a Twentieth-Century City, Lincoln: University of Nebraska Press.

Achtenberg, E. P. (1989), "Subsidized Housing at Risk: The Social Costs of Private Ownership," in Sara Rosenberry and Chester Hartman (eds.), Housing Issues of the 1990s, New York: Praeger.

Adams, J. S. (1987), Housing America in the 1980s, New York: Russe1 Sage Foundation.

Alonso, W. (1969), Location and Land Use, Cambridge: Harvard University Press.

Anderson, C. (1983), "Reading the Yardsticks of Affordability," in Frank Schnidman and Jane H. Silverman (eds.), Housing, Supply and Affordability, Washington, D.C.: Urban Land Institute.

Angotti, T. (1986), "Housing Strategies: The Limits of Local Actions," Journal of Housing, 43(5): 197-198.

Appelbaum, R. P. (1990), "A Progressive Program for America" in Sara Rosenberry and Chester Hartman (eds.), Housing Issues of the 1990s, New York: Praeger.

Be11, W. (1968), "The City, the Suburb and a Theory of Social Choice," in Scott Greer (ed.), The New Urbanization, New York: St. Martin's.

Bendick, M. Jr. and D. W. Rasmussen (1986), "Enterprise Zones and Inner-City Economic Revitalization," in G. E. Peterson and C. W. Lewis (eds.), Reagan and the Cities, Washington, D.C.: Urban Institute Press.

Birch, D. L. (1971), "Toward a Theory of Urban Growth," Journal of the American Institute of Planners, 37 : 78-87.

Black, J. T. (1975), "Private Market Housing Renovation in Central Cities," Urban Land, 34:6-10. 
Black, J. T. (1980), "Private Market Housing in Central Cities," in S. B. Laska and D. Spain (eds.), Back to the City, New York: Pergamon.

Blalock, H. M. (1979), Black-White Relations in the 1980s: Toward a Long-term Policy, New York: Praeger.

Bond, E. W. and N. E. Coulson (1989), "Externalities, Filtering and Neighborhood Change," Journal of Urban Economics, 26:231-249.

Bureau of National Affairs (1989), Housing, Community and Economic Development Real Estate, Taxation and Finance. Washington, D.C.: Warren, Gorham and Lamont. Vol. 17, No. 2, pp. 202-220.

Burgess, E. W. (1925), "The Growth of the City," in R. E. Park, E. W. Burgess, and R. D. Mckenzie (eds.), The City, Chicago: The University of Chicago Press.

Clay, P. L. (1978), Neighborhood Revitalization: The Recent Experience in Large American Cities, Cambridge, MA: MIT Press.

Clay, P. L. (1979), Neighborhood Renewal: Middle Class Resettlement and Incumbent Upgrading in American Neighborhoods, Lexington, MA: Lexington Books .

Columbia Region Association of Governments (1978a), "The Inner Southeast Subarea: Reference Guide to Travel Factors," Technical Memo, No. 13.

Columbia Region Association of Governments (1978b), "The Inner Southwest Subarea: Reference Guide to Travel Factors," Tecinnical Memo, No. 14.

Columbia Region Association of Governments (1978c), "The Inner West Subarea: Reference Guide to Travel Factors," Technical Memo, No. 15 .

Columbia Region Association of Governments (1978d), "The Inner Northwest Subarea: Reference Guide to Travel Factors," Technical Memo, No. 16.

Columbia Region Association of Governments (1978e), "The Inner Northeast Subarea: Reference Guide to Travel Factors," Technical Memo, No. 17.

Columbia Region Association of Governments (1978f), "The Outer East Subarea: Reference Guide to Travel Factors," Technical Memo, No. 19. 
Corbett-Terwilliger-Lair Hill Planning Committee (1974), A Plan for Corbett-Terwilliger-Lair Hill.

Corbett-Terwilliger-Lair Hill Planning Committee (1977), A Plan for Corbett-Terwilliger-Lair Hill.

De Giovanni, F. F. (1983), "Patterns of Change in Housing Market Activity in Revitalizing Neighborhoods, "Journal of the American Planning Association, 49:22- $\overline{36}$.

Dubin, R. A. and C. H. Sung (1990), "Specification of Hedonic Regressions: Non-Nested Tests on Measures of Neighborhood Quality," Journal of Urban Economics, $27: 97-110$.

Ehrmann, M. M. and D. Ford (1981), "Community Development Rehabilitation: Analys is Reveals Dramatic Growth, Successful Local Programs," Journal of Housing, $38(6): 330-339$.

E11iott, D. S. Jr., M. A. Quinn, and R. E. Mendelson (1985), "Maintenance Behavior of Large-scale Landlords and Theories of Neighborhood Succession, " Journal of American Real Estate and Urban Economics Association, $13(4): 421-444$.

Fisher, E. and L. Winnick (1951), "Reformulation of the Filtering Concept," Journal of Social Issues, 7:47-58.

Gale, D. E. (1977), The Back-to-the-City Movement Revisited: A Survey of Recent Homebuyers in the Capitol Hill Neighborhood of Washington D.C., Washington, D.C.: George Washington University, Department of Urban and Regional Planning.

Gale, D. E. (1980), "Neighborhood Resettlement: Washington, D.C.," in S. B. Laska and D. Spain (eds.), Back to the City: Issues in Neighborhood Renovation, New York: Pergamon Press.

Gale, D. E. (1984), Neighborhood Revitalization and the Postindustrial City: A Multi-National Perspective, Lexington, MA: Lexington Books.

Gallaway, L. E., R. F. Gilbert, and P. E. Smith (1967), "The. Economics of Labor Mobility: An Empirical Analys is," Western Economic Journal, 5:211-223. 
Goetze, R., W. C. Kent, and F. O. Vincent (1977), Stabilizing Neighborhoods: A Fresh Approach to Housing Dynamics and Perceptions, prepared for HUD, Office of Policy Development and Research, Boston Redevelopment Authority and Public Systems Evaluation Inc.

Goodman, A. C. (1988), "An Econometric Mode1 of Housing Price, Permanent Income, Tenure Choice, and Housing Demand," Journal of Urban Economics, 23:327-353.

Greenwood, M. J. (1969), "An Analys is of the Determinants of Geographic Lalbor Mobility in the U.S.," Review of Economics and Statistics, $51: 189-194$.

Greenwood, M. J. (1970), "Lagged Response in the Decision to Migrate," Journal of Regional Science, 10:375-384.

Greenwood, M. J a and P. J. Gormely (1971), "A Comparison of the Determinants of White and Nonwhite Interstate Migration," Demography, 8(1):142-154.

Guskind, R. (1990), "Enterprise Zones: Do They Work?" Journal of Housing, 47(1):47-50.

Hartman, C. (1983), America's Housing Crisis. What Is to Be Done? Boston Institute for Policy Studies: Routledge and Kegan Paul.

Hays, R. A. (1985), The Federal Government and Urban Housing: Ideology and Change in Public Housing, Albany: State University of New York Press.

Henig, J. R. (1980), "Gentrification and Displacement Within Cities: A Comparative Analysis," Social Science Quarterly, 61:638-652.

Henig, J. R. (1981), "Gentrification and Displacement of the Elderly: An Empirical Analys is," Gerontologist, 21:6774 .

Hodge, D. C. (1981), "Inner City Revitalization and Residential Displacement in a Growth Region," Geographical Review, 71:189-200.

Hoover, E. M. and R. Vernon (1959), Anatomy of a Metropolis, Cambridge: Harvard University Press.

Housing Authority of Portland (1984), Looking Ahead: A Strategic Plan of Action, Portland, OR: Cogvin Associates. 
Jacobs, B. G., K. R. Harney, C. L. Edson, and B. S. Lane (1986), Guide to Federal Housing Programs, Washington, D. C.: Bureau of National Affairs.

James, F. (1977), Back to the City: An Appraisal of Housing Reinvestment and Population Change in Urban Amer ica, Washington, D.C.: Urban Institute.

Kern, C. R. (1979), Upper Income Renaissance in the City: Its Sources and Implications for the City's Future, Binghamton: State University of New York, Department of Economics.

Laska, S. B., J. M. Seaman, and D. R. Mc Seveney (1982), "Inner-City Reinvestment: Neighborhood Characteristics and Spatial Patterns Over Time," Urban Studies Journal, $19: 155-165$.

Laska, S. B. and D. Spain (1979), "Urban Policy and Planning in the Wake of Gentrification: Anticipating Renovators' Demands," American Planning Association Journal, $45: 523-531$.

Laska, S. B. and D. Spain (1980), Back to the City: Issues in Neighborhood Renovation, New York: Pergamon.

Lee, B. A. (1985), "Racially Mixed Neighborhoods During the 1970s: Change or Stability?" Social Science Quarterly, $66: 346-364$.

Lee, B. A. (1986), "From Black to White. Reverse Racial Change in Neighborhoods of Large American Cities, 19701980," Journal of American Planning Association, $52: 338-\overline{344}$.

Lee, B. A. and P. M. Mergenhagen (1984), "Is Revitalization Detectable? Evidence from Five Nashville Neighborhoods," Urban Affairs Quarterly, 19:511-538.

Lee, B. A., D. Spain, and D. J. Umberson (1985), "Neighborhood Revitalization and Racial Change: The Case of Washington D.C.," Demography, 22(4):581-599.

Leven, C. L., J. T. Little, N. O. Nourse, and R. B. Read (1976), Neighborhood Change: Lessons in the Dynamics of Urban Decay, New York: Praeger.

Lipton, S. G. (1977), "Evidence of Central City Revival," Journal of the American Institute of Planners, 43:136- 
Little, J. (1976), "Residential Preferences, Neighborhood Filtering and Neighborhood Change," Journal of Urban Economics, 3:68-81.

London, B. (1980), "Gentrificatrion as Urban Reinvasion: Some Preliminary Definitional and Theoretical Considerations," in S. B. Laska and D. Spain (eds.), Back-tothe-City, New York: Pergamon.

London, B . (1984), Gentrification, Displacement, and Neighborhood Revitalization, Albany: State University of New York Press.

London, B., B. A. Lee, and S. G. Lipton (1986), "The Determinants of Gentrification in the United States: A CityLevel Analysis," Urban Affairs Quarterly, $21(3): 369-387$.

Lycan, R. (1978), "Displacement of Residents of Portland Due to Urban Reinvestment," A Report Prepared for the Office of Planning and Development, Portland, Oregon, Center for Population Research and Census: Portland State University.

Maddala, G. S. (1977), Econometrics, New York: McGraw-Hill.

Mandelker, D. R. (1973), Housing Subsidies in the United States, Indianapolis: Bobbs-Merrill.

Mba, H. C. (1983), Development of an Operational System for Monitoring Changes in Urban Subarea Residential Housing Status. A Spatial Analytic Application of the Formulations of Neighborhood Filtering, unpublished doctoral dissertation, Portland, Oregon, Portland State University.

Mercuse, P. (1981), Housing Abandonment: Does Rent Control Make a Difference? Conference on Alternative State and Local Policies, Washington, D.C.: Government Printing office.

Mills, E. S. (1972), Urban Economics, Glenview, IL: Scott Foresman.

Muth, R: (1972), Cities and Housing, Chicago: University of Chicago Press.

National Urban Coalition (1978), Displacement: City Neighborhoods in Transition, Washington, D.C.: National Urban Coalition. 
Norman, B. M., S. Seymour, and L. G. Galen (1975), Racial Integration in American Neighborhoods: A Comparative Survey, Chicago: National Opinion Survey.

Office of Planning and Development (1970), Neighborhood Information Profiles of the City of Portland, Policy Development and Research Section, Portland, Oregon.

Office of Planning and Development (1980), Neighborhood Information Profiles of the City of Portland, Policy Development and Research Section, Portland, Oregon.

Office of Planning and Development (1981), Neighborhood Information Profiles of the City of Portland, Policy Development and Research Section, Portland, Oregon.

Pattison, T. (1977), The Process of Neighborhood Upgrading and Gentrification, master's thesis, Cambridge, MIT.

Peterson, G. E. and C. W. Lewis (1986), Reagan and the Cities, Washington, D.C.: Urban Institute Press.

Portland Bureau of Planning (1977), Economic Development in Portland, Constraints, and Policy Issues, $A$ Report to the Portland City Planning Commission.

Portland City Planning Commission (1965), Portland's Residential Areas: An Appraisal of B1ight and Related Factors, Portland, Oregon.

Portland City Planning Commission (1969), Portland's Commeercial Areas: An Appraisal of Blight and Related Factors, A Report to the Portland City Planning Commission.

Portland Development Commission (1975), Thurman-Vaughn Corridor Feasibility Study, Portland, Oregon.

Portland Development Commission (1978), Second Decade Report, Portland, Oregon.

Portland Development Commission (1981), Portland's Home Rehabilitation Program: Economic Impact Analysis: Portland, Oregon.

Portland Development Commission (1989), Moving into the Fourth Decade Report, Portland, Oregon.

Portland Development Commission (1990), Quarterly Status Report, Portland, Oregon. 
Rohse, M. (1987), Land Use Planning in Oregon, Corvallis, OR: Oregon State University Press.

Rufolo, A. M. (1980), "What's Ahead for Housing?" Business Week, Federal Reserve Bank of Philadelphia, July/August : 9-15.

Schil1, M. H. and R. P. Nathan (1983), Revitalizing America's Cities: Neighborhood Reinvestment and Displacement, Albany, NY: State University of New York.

Schnidman, F. and J. A. Silverman (1983), Housing, Supply and Affordability, Washington, D.C.: Urban Land Institute.

Sjaastad, L. A. (1962), "The Costs and Returns of Human Migration," Journal of Political Economy, 70:80-93.

Smith, N. (1979), "Toward a Theory of Gentrification," Journal of the American Planning Association, 45:538-

Spain, D. (1980), "Black-to-White Successions in Central City Housing: Limited Evidence of Urban Revitalization," Urban Affairs Quarterly, 5:381-396.

Sternlieb, G. and J. Hughes (1979), "Back to the Central City: Myths and Realities," Traffic Quarterly, $33(4): 617-636$.

Sternlieb, G. and J. Hughes (1980), "Some Economic Effects of Recent Migration Patterns on Central Cities," in G. Sternlieb, J. W. Hughes, R. W. Burchell, S. C. Casey, R. W. Lake, and D. Listoken (eds.), America's Housing: Frospects and Problems, New Brunswick, NJ: Rutgers University, Center for Urban Policy Research.

Sternlieb, G. and J. Hughes (1987), The Dynamics of America's Housing, New Brunswick, NJ: Rutgers, the State University of New Jersey, Center for Urban Policy Research.

Sumka, H. J. (1979), "Neighborhood Revitalization and Displacement: A Review of the Evidence," American Planning Association Journal, 45:48-486.

Sumka, H. J. (1990), "Community-Based Housing in Massachusetts: Comment," in Sara Rosenberry and Chester Hartman (eds.), Housing Issues of the 1990s, New York: Praeger. 
Toulan, N. A. (1960), The Filtering Process: A Conceptual Appraisal," Research paper.

Tri-County Metropolitan Transportation District (1975), Trimet Biennial Report, presented to the 1975 Oregon Legislature, Portland, Oregon.

Turpe1, M. and G. Uba (1990), "Housing Issues," Metro Report, Portland, OR: Metro Publications.

U.S. Bureau of the Census (1980), Current Population Reports, Characteristics of the Population Below the Poverty Level: 1978, Series P-60, No. 124, Washington, D.C.: U.S. Government Printing office.

U.S. Bureau of the Census (1981), Current Population Reports, Money Income of Families and Persons in the United States: 1979, Series P-60, No. 129, Washington, D.C.: U.S. Government Printing office.

U.S. Bureau of the Census (1982), Current Population Reports, Money Income of Households and Persons in the United States: 1980, Series P-60, No. 132, Washington, D.C.: U.S. Government Printing Office.

U.S. Department of Housing and Urban Development (1974), Housing in the Seventies: A Report of the National Housing Policy Review, Washington, D.C.: U.S. Government Printing Office.

U.S. Department of Housing and Urban Development (1977), U.S. Department of Housing and Urban Development Annual Report, Washington, D.C.: U.S. Government Printing office.

U.S. Department of Housing and Urban Development (1979), U.S. Department of Housing and Urban Development Annual Report, Washington, D.C.: U.S. Government Printing office.

U.S. Department of Transportacion (1980), Federal Highway Administration, Bureau of Public Roads, Washington, D.C.: U.S. Government Printing Office.

U.S. Office of Research and Development (1988), U.S. Congressional Budget, Washington, D.C.: U.S. Government Printing Office.

Varady, D. P. (1986), Neighborhood Upgrading, Albany: State University of New York Press. 
Warner, S. B. Jr. (1962), Streetcar, Suburbs: The Process of Growth in Boston, 1870-1900, Cambridge, MA: MIT Press.

Weicher, J. C. (1980), Housing: Federal Policies and Programs, Washington, D.C.: American Enterprise Institute for Public Policy Research.

Wexler, H. J., R. Peck, and R. Hamill (1975), Housing and Local Government: A Research Guide for Policy-makers and Planners, Lexington, MA: Lexington Books.

Wilson, J. Q. (1963), "Planning and Politics: Citizen Participation in Urban Renewal," Journal of the American Institute of Planners, $29(4): 259-269$.

Zeitz, E. (1979), Private Urban Renewal: A Different Residential Trend, Lexington, MA: Lexington Books. 